MENTORING IN MISSOURI SCHOOLS: HOW MENTORING FOSTERS PROFESSIONAL AND PERSONAL GROWTH

\begin{tabular}{c} 
A Dissertation \\
presented to \\
the Faculty of the Graduate School \\
at the University of Missouri \\
In Partial Fulfillment \\
of the Requirements for the Degree \\
Doctor of Education \\
\hline July, 2021 \\
Dandy Hutchinson, Dissertation Supervisor \\
DER WARD
\end{tabular}


(C) Copyright by Derek Ward, 2021

All Rights Reserved 
The Undersigned, appointed by the dean of the Graduate School, have examined the dissertation entitled

\section{MENTORING IN MISSOURI SCHOOLS: HOW MENTORING FOSTERS PROFESSIONAL AND PERSONAL GROWTH}

presented by Derek Ward, a candidate for the degree of Doctorate of Education, and hereby certify that, in their opinion, it is worthy of acceptance.

Dr. Sandy Hutchinson

Dr. Lisa Bertrand

Dr. Melissa Odegard-Koester

Dr. Simin Cwick 


\section{DEDICATION}

I want to dedicate this work to several people in my life. My mother and father, Bill and Shirley Ward, always supported me with the love and support only parents can give and watch down from above. Thank you to my siblings who always kept me in their prayers and supported me in this journey-Billy, Greg, and Shelly. Though Billy is not with us, I felt his support through it all. I also want to thank my wife, Bethanie, for her patience and support through it all. She has been a rock and guiding light that helped me balance work, school, and personal loss. Thank you to my in-laws, Matt and Mignon Ernst, for your continued support and encouragement. Lastly, I want to dedicate this to all of my teachers who have inspired me to keep learning. Each one has touched my life in some way. This is for you all! 


\section{ACKNOWLEDGMENTS}

Pursuing a doctoral degree is a community journey. The candidate passes the required coursework, completes various studies, and writes the final dissertation; however, they are supported by their peers, professors, and family. Though there are more who can be mentioned in one page, there are a few that need to be mentioned.

First, I would like to thank Dr. Hutchinson and Dr. Watkins for accepting, guiding, and providing mentorship throughout this program. Dr. Watkins inspired me to pursue my doctorate and has been a mentor throughout it all. Dr. Hutchinson has been a guiding light to help bring clarity to not only the coursework as a professor, but to the study as an advisor. Thank you both for being amazing educators!

Second, thank you to my fellow classmates in not only the S.E.M.O. cohort, but the state-wide cohort as a whole. In this journey you grow to be a family. We started families together, started new jobs together, lost loved ones together, and survived a pandemic together. We have an online community that is truly supportive, and I could not ask to have been on the road with more awesome people than this group.

Third, a huge thank you goes to my family for unwavering support. I lost both my brother and my mother during this program. Without the rest of my family pushing me to continue, I would never have made it to the end. Thank you to my in-laws, who gave my wife and me a place to stay when we were switching jobs, and have helped us in so many unspeakable ways. 


\section{Table of Contents}

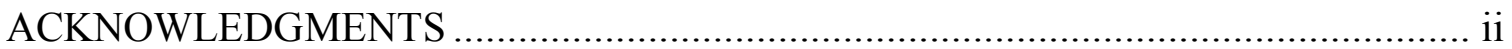

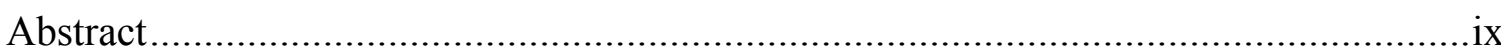

SECTION ONE:

INTRODUCTION TO THE DISSERTATION IN PRACTICE .................................

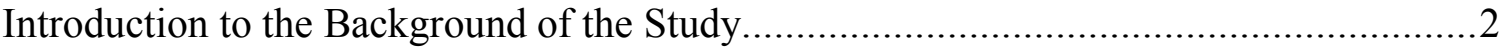

Statement of the Problem............................................................................... 4

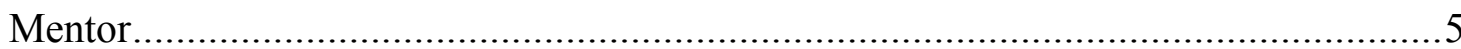

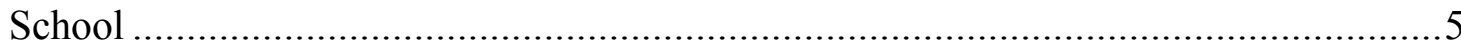

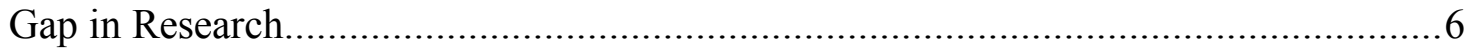

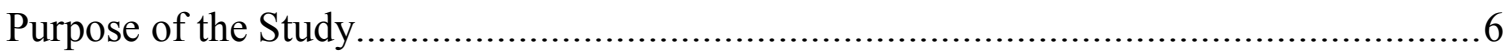

Research Questions ...................................................................................

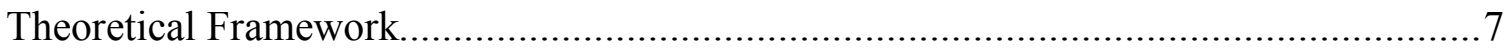

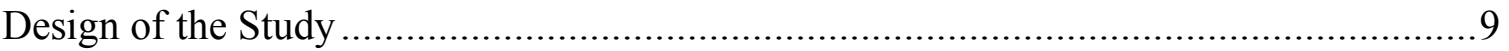

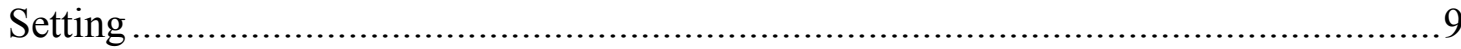

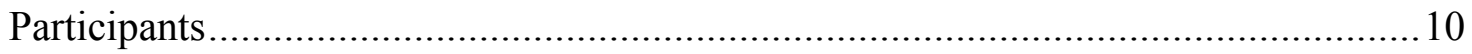

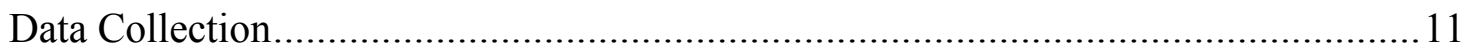

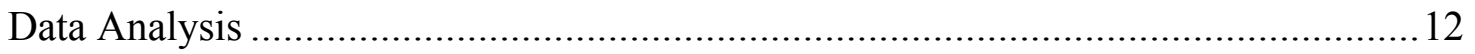

Limitations, Assumptions, and Future Research .................................................. 12

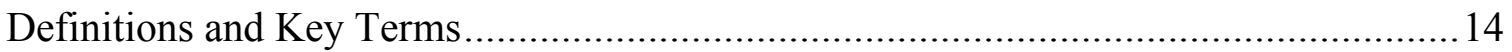




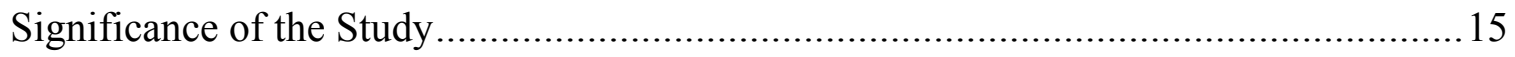

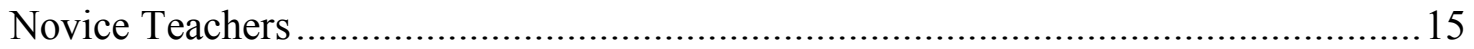

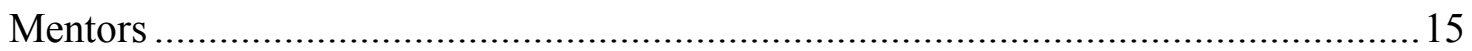

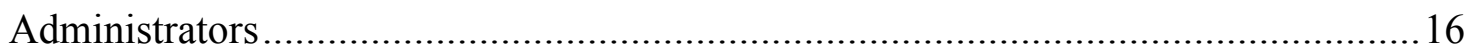

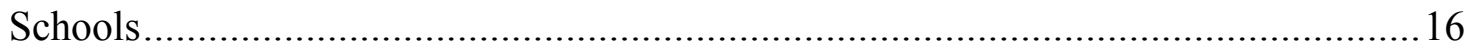

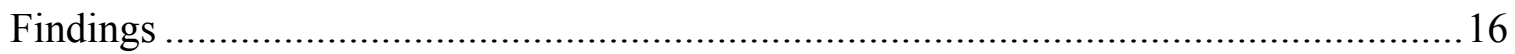

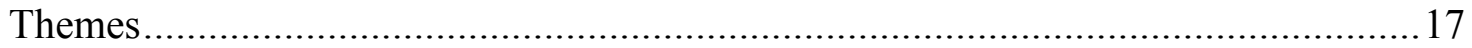

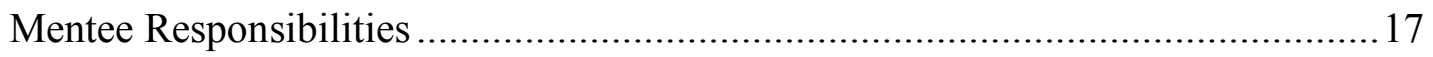

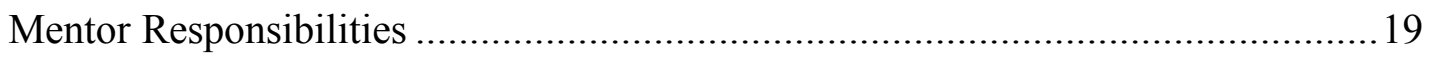

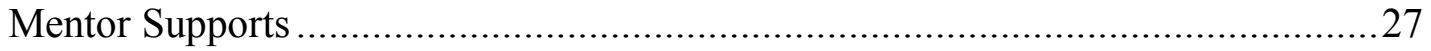

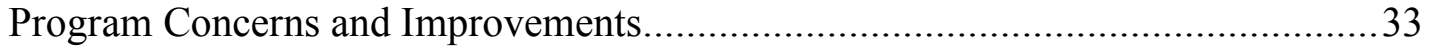

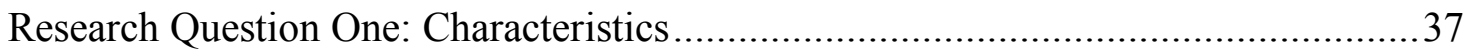

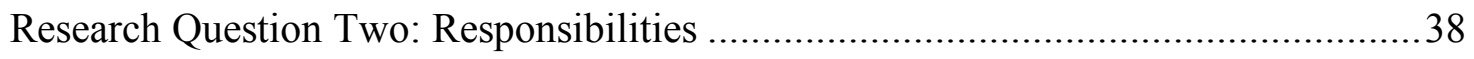

Research Question Three: Professional and Personal Growth...................................39

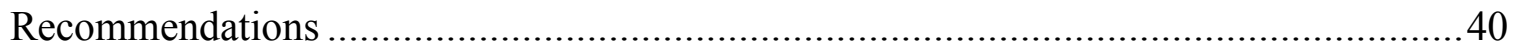

Add Emotional Support ......................................................................... 40

Ensure the Mentor is Willing ................................................................... 41

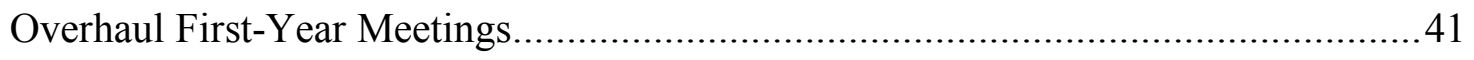

Partner with Other Schools for Observation ...................................................... 42

Make Mentors Accountable ..................................................................................4 43 
Summary

SECTION TWO:

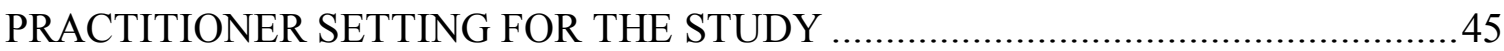

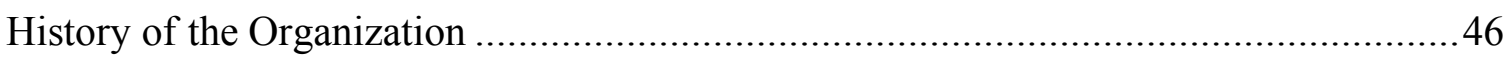

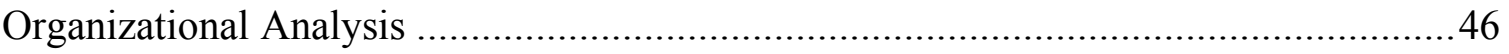

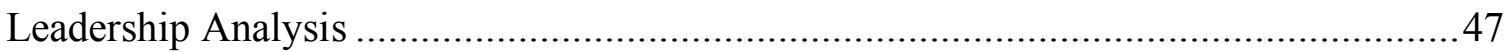

Implications for Research in the Practitioner Setting .................................................48

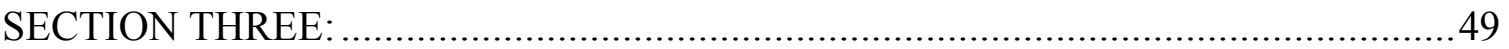

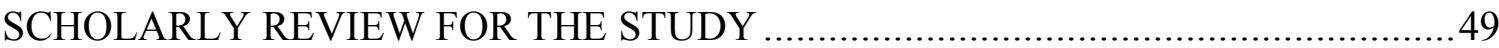

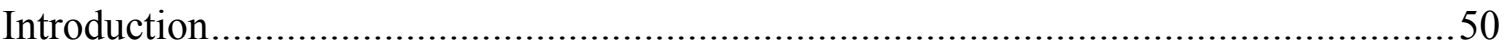

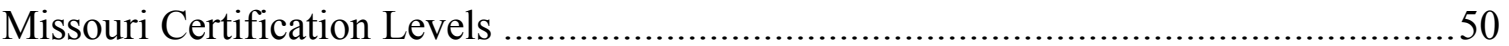

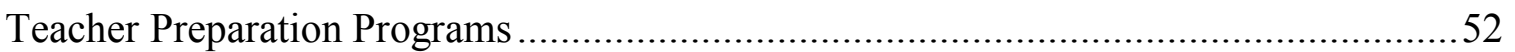

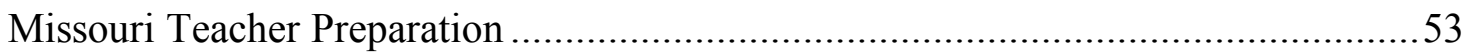

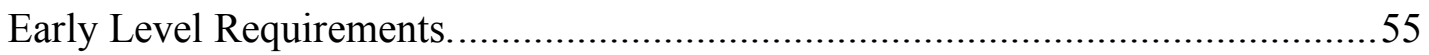

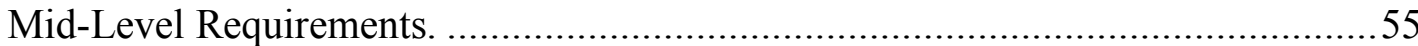

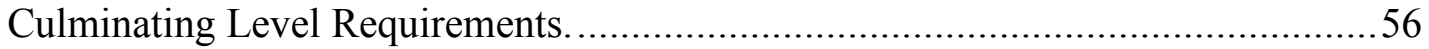

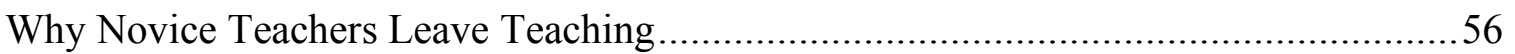

Why Novice Teachers Leave …………….............................................................58

Novice Teachers and Mentoring ............................................................................6

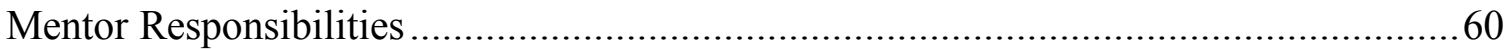


Conclusion

SECTION FOUR:

CONTRIBUTION TO PRACTICE

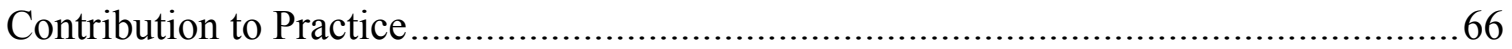

SECTION FIVE:

CONTRIBUTION TO SCHOLARSHIP ........................................................... 91

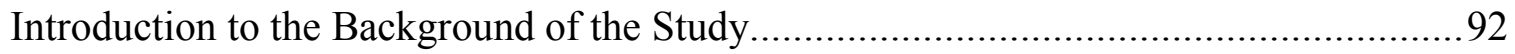

Statement of the Problem.................................................................................... 94

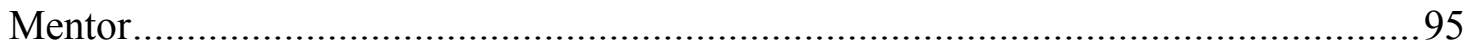

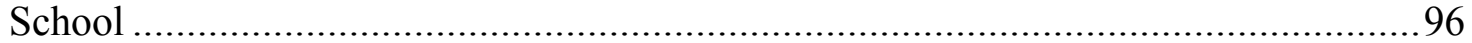

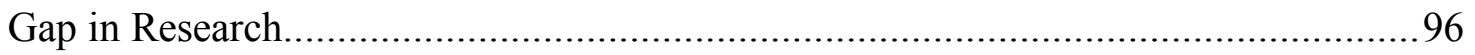

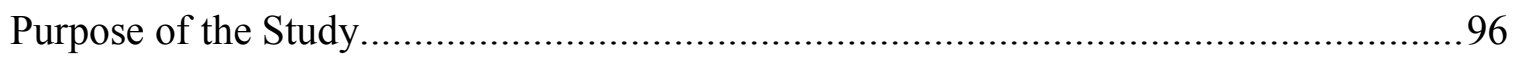

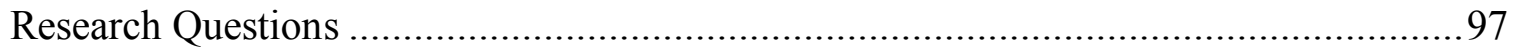

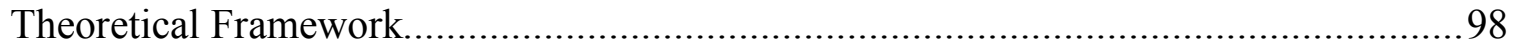

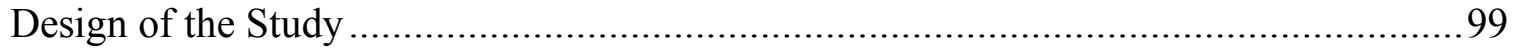

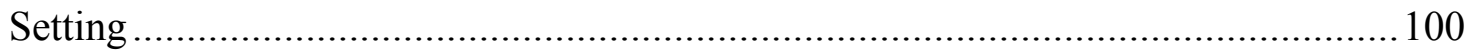

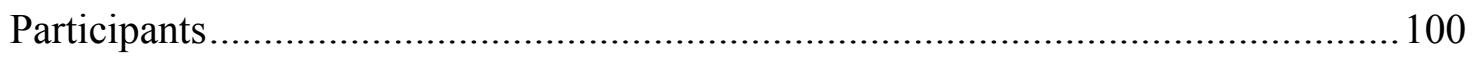

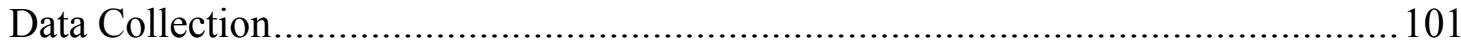

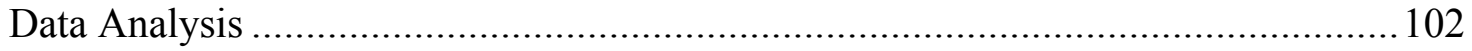


Results 103

Research Question One: Characteristics................................................................. 103

Research Question Two: Responsibilities ........................................................... 104

Research Question Three: Professional and Personal Growth..................................105

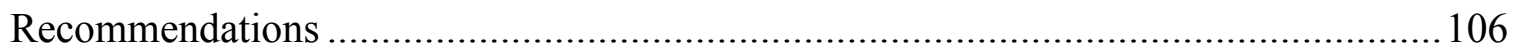

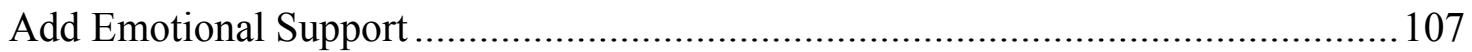

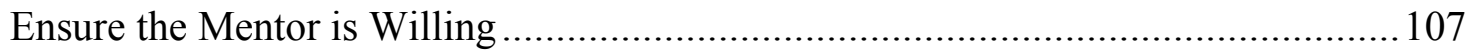

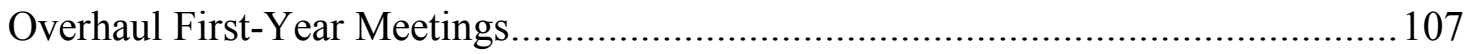

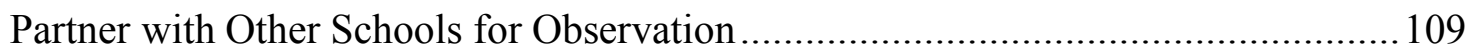

Make Mentors Accountable ................................................................................... 109

Limitations, Assumptions, and Future Research ………........................................110

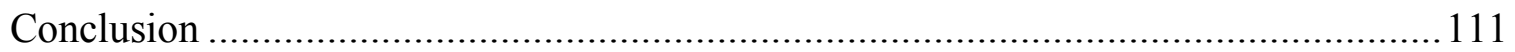

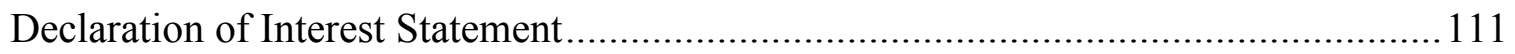

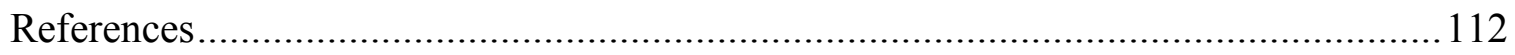

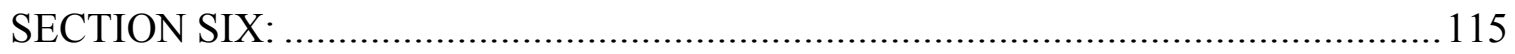

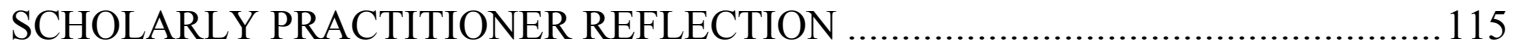

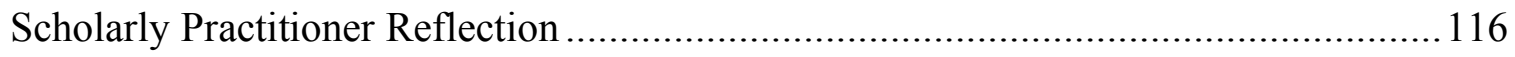

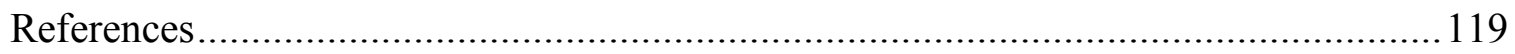

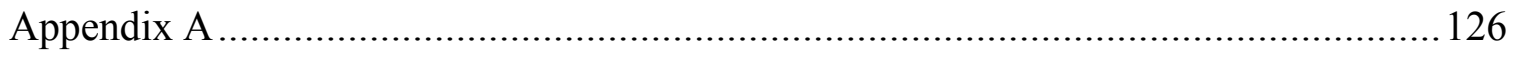

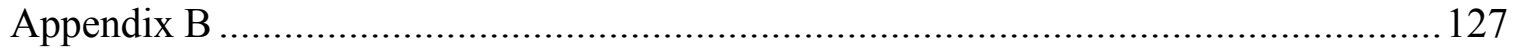


Appendix C

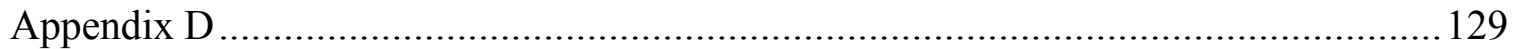

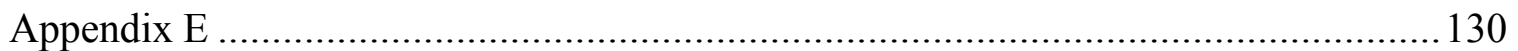

VITA 


\begin{abstract}
The first five years of an educator's career are the most important time in determining if they will stay in the education profession. With the stress of starting a new career, novice teachers are often asked to do the most work. To help them navigate through the first few years of teaching and to increase retention, Missouri has adopted a mentoring policy. This narrative study describes mentee and mentor perception of the mentoring program and how they feel it affects their professional and personal lives. This study opens the doors to show what mentees and mentors feel is beneficial about the mentoring program and what is needed to make it better.
\end{abstract}


SECTION ONE:

INTRODUCTION TO THE DISSERTATION IN PRACTICE 


\section{Introduction to the Background of the Study}

Historically, the role of teaching holds high esteem in American society (Muhammet \& Sarigöz, 2018). Teachers are an important factor in using the insights they have developed with students. Teachers also guide students to reach their goals. Muhammet and Sarigöz (2018) notes that teachers support students' individual and economic growth due to the influence they have on the students' life and career path. Preparing students to meet the challenges of a dynamic twenty-first century requires competent educators from the beginning to the end of their career. The mentor is a key player in developing competent educators that endure the hardships of the first five years of teaching.

The first few years of a teacher's career is defining (Kozikoğlu, 2018). Many novice teachers enter the profession full of energy, ideas, and a willingness to make a difference. They are proud to have the opportunity to teach others in a positive and meaningful way. Further, they have high expectations of the teaching experience (Muhammet \& Sarigöz, 2018). Kozikoğlu (2018) states that the experiences of a firstyear teacher will be a key influence on whether or not they will continue in the field of education. If their first-year is seen as a success, then first-year teachers will persist and continue to grow in their profession. However, if a novice teacher fails, then they are more likely to be either a leaver or a mover. Leavers are educators who leave the profession completely, and movers are those who move from one district to another (Carver-Thomas \& Darling-Hammond, 2017).

Teachers may choose to leave the education profession for many reasons. Low salary and the deterioration of teacher status in the labor market contributes to a novice 
teacher's decision to stay in the teaching profession or leave it (Harris, Davies, Cristensen, Hanks, Bowles, 2019). Furthermore, teacher salaries are 20\% lower than those with a comparable degree. The National Center for Educational Statistics (n.d.) indicated the average national teacher's salary was 1\% lower in 2016 than it was in 1991, when adjusted for inflation. Educators have also seen a government policy shift which has taken the ability to have control and autonomy in the classroom out of their hands. Finally, teachers are leaving the profession because they lack support and training, which costs districts money for the recruitment and hiring of new teachers (Harris et al., 2019).

Because mentoring has shown to be a key factor in teacher retention, many districts have mentoring programs (Nasser-Abu Alhija \& Fresko, 2014). Mentoring is also used to acclimate novice teachers to the policies and procedures needed to be successful in their new position. Mentors work to develop novice teachers' essential skills through careful observations and effective feedback (Callahan, 2016). Mentors seek to increase a mentee's skills in classroom management, relationship development with both students and teachers, and increase the level of pedagogy by offering a high level of support. By developing the skills and competency needed for success in the classroom, mentors provide the key support that novice teachers need in their first few years of teaching. Mentoring experiences for novice teachers have shown promise for retaining competent and skilled teachers. Unfortunately, mentoring programs offer a narrow path for improving the first-year teaching experience. While mentoring has been effective in many schools, some may not be meeting the needs of their novice teachers. 


\section{Statement of the Problem}

While research has been done on mentoring programs and their effectiveness, schools have not implemented a mentoring program that fully addresses all of the new educator's and school's needs (Nasser-Abu Alhija \& Fresko, 2014). This means that current mentoring programs are basic in scope, but fail to support the new teacher, nor do mentoring programs include the school's culture into their mentoring goals (Farmer, 2020). Due to this, between $20 \%$ and $50 \%$ of novice teachers leave the teaching profession within the first five years of teaching, most leaving within their first two years (Farmer, 2020).

New teachers need to feel that they are supported adequately by both administration and other teachers in the acclamation to the teaching profession and their community (Farmer, 2020). According to Dias-Lacy and Guirguis (2017), even though teachers receive mentoring, often the personalities between the mentor and novice teacher do not match, leading to unsuccessful growth. Farmer (2020) tells us that novice teachers are leaving due to difficult assignments, vague expectations, lack of resources, isolation, and the realities of teaching versus what they expected from the profession. Novice teachers are also expected to be proficient and as skilled as their veteran counterparts (Kozikoğlu, 2018). Not only is proficiency an issue, but the teaching assignments could be demanding. Kozikoğlu (2018) reported that novice teachers usually perform the responsibilities that other veteran teachers do not want to perform. With all of the responsibilities that novice teachers have placed on them, many new teachers are losing the initial drive that drove them to the teaching profession (Callahan, 2016). With the establishment of a mentoring program, schools can provide the professional and 
emotional supports novice teachers need to navigate the barriers they may face in the first five years in the field of education.

\section{Mentor}

Current mentoring programs place extra responsibility on the mentor, as they have to plan mentoring sessions outside of contracted time, often with little to no compensation (DeCesare, Workman, \& McClelland, 2016). Mentors are also lacking leadership training that is key to giving feedback that new teachers need to grow both personally and professionally (Callahan, 2016). A study by Nasser-Abu Alhija and Fresko (2014) describe a lack of structured professional development for the mentor. The lack of professional development, training in leadership, and developing interpersonal and networking skills leave mentors ill-prepared to perform the job (Callahan 2016; Israel, Kamman, McCray, \& Sindelar, 2014).

\section{School}

Though research has shown the effectiveness of mentoring, schools may not have the resources necessary to have an effective mentoring program (Hall, Hughes, \& Thelk, 2017). Schools often ask the principal to assign a mentor, forgetting about the issues of mentor/mentee compatibility and lack of mentor training (Hall et al., 2017). In some school districts, mentors are assigned based on their willingness to do the job (Marker, Mitchall, \& Lassiter, 2013). With few people willing to be a mentor, novice teachers may not be paired with a mentor that teaches the same subject or grade level. The average cost of replacing a teacher in 2007 was $\$ 8,000$ (Callahan, 2016). Without mentors that can provide the supports that novice teachers need, school districts will continue to spend thousands of dollars to recruit and train replacement educators. 


\section{Gap in Research}

Most studies of new teacher mentoring have only studied the effectiveness of teacher mentoring or the effects of mentoring versus no mentoring. These limitations have left a gap in research that links the characteristics and responsibilities of a mentoring program to professional and personal growth.

\section{Purpose of the Study}

The purpose of this study is to study mentor and mentee perceptions of the mentoring program in Missouri. Mentors are often not prepared with the right skills and tools to give a novice teacher the support they need (Russell \& Russell, 2011). If the mentor does not receive the training they need to guide a novice teacher, the amount of guidance the novice teacher receives is inconsistent and will have to rely on the school to provide additional support. Mentors are also not given the professional development they need in leading conversations about performance, developing intrapersonal skills, and how to network with other mentors in the district/area (Israel et al., 2014). While some states require schools to have a teacher induction program, others have pulled funding from their mentorship programs and reduced the number of mentored years from three to two years (Marker, Mitchall, \& Lassiter, 2013). Due to decreased funding, schools are not able to invest in proper mentorship for novice teachers, which leaves novice teachers feeling lost and ill-prepared. Therefore, this study will focus on the relationship needed between a mentor and mentee that allows for professional and personal growth, as perceived by both mentors and mentees. 


\section{Research Questions}

The research questions guiding this study are:

1. What characteristics of a mentor are prevalent in a mentoring program, as perceived by the:
(a) Mentor
(b) Mentee

2. What are the responsibilities to each other in a mentor/mentee relationship, as perceived by the:
(a) Mentor
(b) Mentee

3. How does the current mentoring model assist in a mentor and mentee's professional and personal growth according to the:
(a) Mentor
(b) Mentee

\section{Theoretical Framework}

The theoretical framework of this study borrowed from Day and Allen (2004) and Kram's (1983) mentoring theory. This theory states that through psychosocial support, a mentor can increase a mentee's sense of competence, confidence, and self-esteem (Kram, 1983). By increasing a mentee's self-worth, confidence, and job knowledge, a mentee will have a greater sense of career self-efficacy. Using Day and Allen's (2004) mentoring theory, a connection can be made from mentoring to teacher retention. The effects that a mentor has on a novice teacher is substantial. Mentors can increase career commitment, which then leads to goal setting and an increase in the novice teacher's pedagogical 
knowledge. Due to this support, the novice teacher develops a positive outlook and will continue in the education profession.

However, teaching is more than knowing what to teach. A novice teacher must develop supportive relationships with the administrators and teachers with whom they work. Mentoring should also encompass relationship development and how to balance professional and work balance. By developing relationships within the school, a teacher gets introduced to the school climate and culture. Day and Allen (2004) say that new employees also have a hard time separating work and home life, which can lead to burnout. By having a mentor who can help navigate these two aspects of relationship development, a teacher will hopefully develop a positive support system and feel comfortable staying in the teaching profession. The researcher developed Figure 1 to show the path from mentoring to teacher retention.

Figure 1. Path of mentor responsibilities.

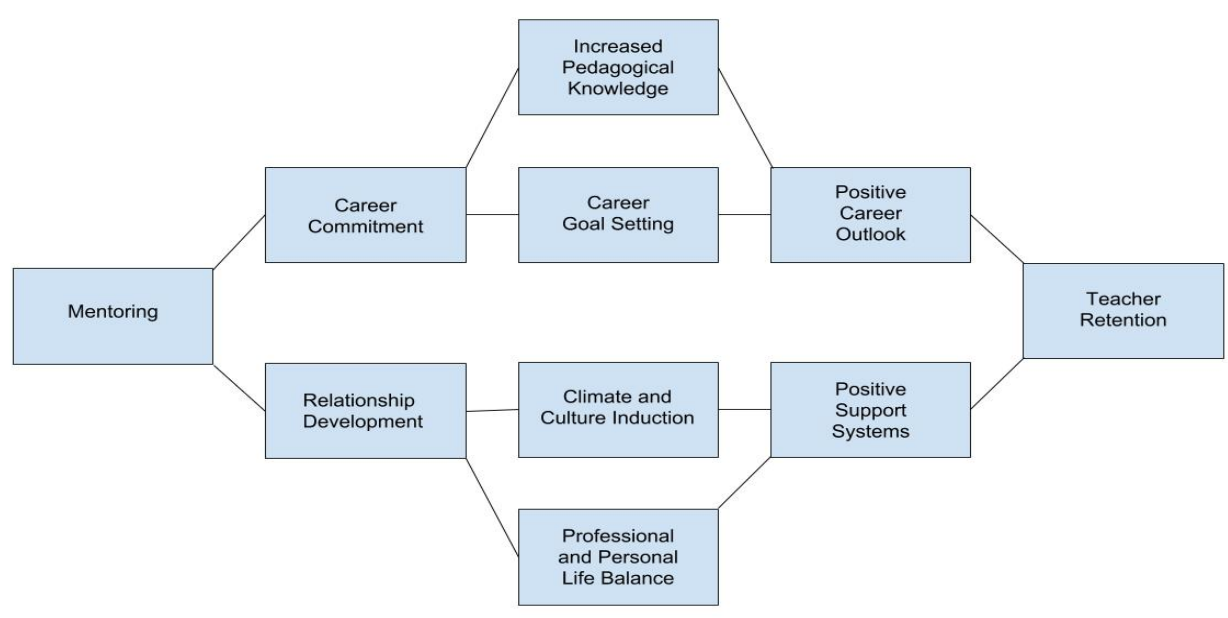

Mentoring is an important part of the networking process for a mentee. Jyoti and Sharma (2017) state that employees who are properly mentored will speak freely and openly about their problems. Mentored employees will have the confidence needed to seek help from others in the organization. By being open and honest, mentees will grow 
confidence, be able to learn new skills, and build a diverse system of networks within the organization. Experienced mentors have a knowledge base that young, inexperienced educators can tap into and learn from (Dias-Lacy \& Guirguis, 2017). To do this, mentors must be willing to take on the task and time commitment necessary for proper mentoring to occur (Nasser-Abu Alhija \& Fresko, 2014).

\section{Design of the Study}

This qualitative narrative study sought to understand how the participants experience the mentoring program. Abkhezr, McMahon, Campbell, and Glasheen (2020) describe narrative research as a way to give people a voice who otherwise would never be heard. Creswell (2014) says that narrative research seeks to study the lives of individuals through the stories they tell about their life. Therefore, this qualitative study sought to answer the research questions by letting the participants tell their "story" of the mentoring program. Since the narrative study sought to understand the experiences of the participants, this study was viewed through the interpretive epistemological perspective (Merriam \& Tisdell, 2016).

\section{Setting}

Public K-12 schools in Missouri represented the setting for this study. The study consisted of six schools in the state: two large schools, two midsized schools, and two small schools. The schools were classified as a small, midsized, or large school district based on population. Schools with a student population larger than 3000 students were classified as a large school, schools with a population of 1000-2999 students were considered midsized schools, and schools with a population of 148-999 students were 
classified as a small school. Interviews took place online using zoom due to the COVID pandemic. Figure 2 gives an overview of the schools selected for the study.

Figure 2. Schools participating in the study.

\begin{tabular}{|l|c|c|}
\hline \multicolumn{3}{|c|}{ Schools Interviewed } \\
\hline \multicolumn{1}{|c|}{ School } & Approximat Enrollment & Average Teacher Experience \\
\hline Adams School District & 400 & 10 \\
\hline Anderson School District & 4000 & 10 \\
\hline Chilton School District & 2800 & 12 \\
\hline Everest School District & 1300 & 13 \\
\hline Sundale School District & 400 & 8 \\
\hline Welton School District & 4000 & 12 \\
\hline
\end{tabular}

\section{Participants}

The participants of this study consisted of mentors and their second-year mentees.

School superintendents and principals were contacted by email to obtain the names of the mentors and mentees (Appendix A) and to ascertain their willingness to provide the names and contact information for the mentors and mentees in their school who might be willing to participate in the study (See Appendix B). Two mentors and two of their mentees were then selected from each of the six school districts selected, for a total of four participants per school and 24 participants total. Mentors and mentees were then personally contacted and invited to participate. Once both the school and the teachers had consented to be part of the study, Zoom invitations were sent to each of the participants to be interviewed. Figure 3 shows the participants interviewed. 
Figure 3. Participants interviewed.

\begin{tabular}{|l|c|c|c|}
\hline \multicolumn{4}{|c|}{ Participants } \\
\hline Name & Role & Years of Experience & School \\
\hline Angelica & Mentee & 1 & Welton School District \\
\hline Eliza & Mentor & 23 & Welton School District \\
\hline Erin & Mentor & 23 & Chilton School District \\
\hline Holly & Mentor & 6 & Raymore School District \\
\hline Jan & Mentee & 2 & Chilton School District \\
\hline Jessica & Mentee & 1 & Sundale School District \\
\hline Jim & Mentee & 2 & Raymore School District \\
\hline Karen & Mentee & 1 & Raymore School District \\
\hline Kelly & Mentee & 2 & Chilton School District \\
\hline Kevin & Mentee & 1 & Sundale School District \\
\hline Linda & Mentee & 1 & Adams School District \\
\hline Lisa & Mentor & 9 & Adams School District \\
\hline Louise & Mentor & 13 & Adams School District \\
\hline Maria & Mentee & 3 & Anderson School District \\
\hline Meredith & Mentee & 2 & Anderson School District \\
\hline Michael & Mentee & 2 & Welton School District \\
\hline Nellie & Mentor & 14 & Chilton School District \\
\hline Pam & Mentor & 30 & Anderson School District \\
\hline Peggy & Mentor & 11 & Welton School District \\
\hline Phyllis & Mentor & 10 & Anderson School District \\
\hline Shelly & Mentor & 5 & Sundale School District \\
\hline Tammy & Mentee & 1 & Rayms School District \\
\hline Tina & Mentor & 26 & \\
\hline Tori & Mentor & 12 & School District \\
\hline & & & \\
\hline
\end{tabular}

\section{Data Collection}

Data collection began by identifying the schools and the participants to be studied. Semistructured interviews consisting of 12 questions (Appendix B) allowed for follow-up questions to be asked during the interview to explore additional views of the interviewee. The interviews took approximately 40-50 minutes to complete.

Interviews with mentors and mentees were completed to collect data on how they perceived the mentoring process and how it has allowed them to grow professionally and 
personally. Interviews were also held with mentors and their mentees to determine their perceived responsibilities to each other in a mentor/mentee relationship. In other words, what do they believe their responsibilities are to each other? During all stages of data collection, artifacts were used to assist in obtaining a clearer picture of how schools prepare teacher mentors and determine the success of the program. Examples of such artifacts were state mandated policies and school board policies, if available. These artifacts were used to determine if the school's policy aligns with the mentor and mentee's expectations of the mentoring program.

\section{Data Analysis}

Interviews were transcribed verbatim and themes were developed. These themes remained fluid as data were collected and compared to each other (Merriam \& Tisdell, 2016). The phenomenon used were repeated words or phrases and contrasting data (Techniques to Identify Themes in Qualitative Data, n.d.). Creswell (2014) recommends sorting data into five to seven themes that can be interconnected. After sorting data into four themes, a word wall was created with each set of key words placed into a theme. Five outside review colleagues then checked the boards and moved words into the categories they thought the data belonged with. Once the outside review members finished, the themes were finalized.

\section{Limitations, Assumptions, and Future Research}

As the researcher is the primary instrument for data collection and analysis, it is important that the researcher recognizes the biases and assumptions that are brought into the study so they can be monitored (Merriam \& Tisdell, 2016). This study had several limitations that were taken into consideration during the course of the study. First was 
that as a teacher, the researcher has experience with Missouri's mentoring program. Care was taken to eliminate any bias from the research questions by having a member of the dissertation committee review and check the questions for errors. Also, schools where the researcher had had been employed were removed from the pool of possible schools to study.

One serious limitation to this study was that it was conducted during the COVID19 pandemic. Due to this, all interviews were conducted via Zoom. This meant that faceto-face interviews could not be conducted to observe the participant in their natural setting. Initially, the study was only to be conducted in the southeast region of the state. However, due to a low response rate, the study was expanded to encompasses the entire state. Once this change was made, there were enough participants to reach saturation.

The researcher is teacher who had a negative experience with a mentoring program and believes there are flaws in it. Assumptions about the program hinged on the belief that schools do not take mentoring seriously and fail teachers as a result. Understanding these assumptions about Missouri's mentoring program were present, steps were taken to ensure an ethical approach to the study by having a research participant review and check the findings reported for accuracy.

This study focused on teachers that are either in their first year or second year of teaching, which excludes data from those that left the profession altogether. Future research on this topic should include teachers that left the profession within their first two years of teaching. Future research could also include how teacher's mental health impacts student mental health. 


\section{Definitions and Key Terms}

For the purpose of this study, the following definitions were used:

Characteristics: A feature or quality belonging to a mentor or mentee that can either be positive or negative.

Department of Elementary and Secondary Education (DESE): The governing body in the state of Missouri that governs and oversees each school district and administers the state's educational laws.

Mentee: A teacher who is within the first two years of their teaching career and is assigned a mentor to assist in the transition process from college student to classroom teacher.

Mentor: A veteran teacher who has either been asked to be a mentor or assigned a mentee to assist in the transition process from college student to classroom teacher. The responsibilities vary from district to district.

Mentoring Program: A mandated state program in which a new teacher is assigned a veteran teacher as a mentor to prepare and guide them through the first two years of teaching.

Novice Teacher: A teacher who has less than 5 years of teaching experience.

Personal Growth: Growth, or maturation, that occurs in a mentor or mentee's personal life.

Principal: Person responsible for the wellbeing and accountability of the students, teachers, and staff in their building, managing faculty and staff, overseeing school performance, managing the buildings budget, and hiring staff. 
Professional Growth: Growth, or broadening, of the mentor or mentee's professional practice.

Responsibilities: The moral, legal, and emotional accountability between a mentor and mentee.

Retention: Refers to when a teacher stays in education profession from one year to the next.

Veteran Teacher: A teacher who has taught for five years or more.

\section{Significance of the Study}

This study adds to current mentoring literature to fill the gap on the relationship needed between a mentor and mentee that allows for professional and personal growth. By filling this gap, a more efficient mentoring system can be developed that could serve the needs of the novice teacher, mentor, administrator, and school district.

\section{Novice Teachers}

This study will benefit novice teachers by enabling a mentoring program to be developed that would address their need for support, resources, and the work/personal life balance they need to be successful in the classroom. By having their needs met, they will have a greater chance of success in the education field.

\section{Mentors}

Teacher mentors will be able to reflect on what the role of the mentor is and how they can be more successful at developing novice teachers' careers. Mentors will also benefit from self-reflection of their teaching practices (Roff, 2012). This will allow them to grow not only as mentors, but as teachers as well. 


\section{Administrators}

This study will also inform administrators on how to improve their current mentoring program to be in line with the best mentoring practices. It will also inform them of the benefits of tracking the mentoring progress for success and failure. By tracking the data, administrators can determine contributors to the success or failure of a novice teacher and seek actions to prevent failures in the future.

\section{Schools}

In the United States, teacher turnover costs school districts over two billion dollars annually (DeCesare, McClelland, \& Randel, 2017). This study will inform school districts on successful and unsuccessful mentoring practices to better develop a mentoring program that is more successful. By having better-trained mentors and novice teachers, the school district will see a positive impact on student achievement.

With the completion of this study, state officials in Missouri can collaborate with schools, teachers, and parents to develop a standardized mentoring system for the state that is accountable, informed, community-based, and geared to give novice teachers the skills and resources they need to succeed in the classroom.

\section{Findings}

After the analysis of the interview transcripts, the researcher gained a better understanding of mentors and mentee perceptions of Missouri's mentoring program and how it allows for them to grow professionally and personally. Each participant gave the researcher a unique perspective to what they felt was important for a new teacher to succeed and the supports that should be present to allow for growth. 


\section{Themes}

As data were analyzed, several themes emerged. Those themes were: mentee responsibilities, mentor responsibilities, mentor supports, and program concerns and improvements. Although not every single participant had the exact same experience with the program, their responses were related. Mentees and mentors shared their perceptions of what the mentor and mentees responsibilities were and also outlined several mentor supports that were beneficial to the mentoring program. They also shared some perceptions of the program and areas that need improvement.

\section{Mentee Responsibilities}

Throughout the interview, not only were a mentor's responsibilities outlined, but those of the mentee as well. The mentee is not only a participant of the program, but an actor of it as well. The mentee must take actions as well in order to be successful.

Michael thought a mentee had a responsibility to, "take the advice and take the feedback and be a sponge. And don't take it personally that they're doing that. They're giving you feedback, giving you advice, to better you and help you, you know, develop as a teacher." Louise also added, "They have to really want to get the advice and the experience, maybe the wisdom of that person that's mentoring them." Tori also said that mentees need to take the advice and try, "to use and implement it in their classroom."

Mentors and mentees thought the mentee should be vocal and communicate with their mentor to reach out and ask questions. Angelica said, "At the beginning, I think it was kind of like hard for us to communicate. But now that we've kind of gotten to know each other, and we've had different meetings together and things like that. It has really helped our relationship." Eliza added, "So, the mentee has to communicate. Has to ask 
questions, because the mentors not going to remember to cover everything, you know, though they will try, but there's going to be things that are going to be left out." Jan had this to say about reaching out, “... it was my responsibility to reach out to her. Because I can't leave it all on her either because she's a teacher too and she's got a lot going on.” She also said, "If I don't reach out and ask for help, then that's totally on me." Kelly had this to say about asking questions, "If you have questions, don't sit back and guess and do what you think you should do." She also added, "The mentee should be encouraged to ask those questions that they need to ask, so, they are on the right track and doing the right things." Holly said, "Sometimes I think, not with her, but in the past, I have thought that they might know something just in general. And they didn't, was curious about it, but never asked, you know?" Holly added, "And then it was like, 'Well, nobody told me'. kind of thing." Pam added, "When they need help, you know, don't, don't let it simmer. Ask questions!" Louise had this to say, "They definitely have to make the effort to come to the classroom of the mentor. They have to be willing to text us or email us if they run into a problem." She added, "They are responsible to be able to ask for help." Shelly said, "They should be responsible. If they're struggling, or if they're having trouble with something, they definitely need to talk to their mentor, and just say, 'I don't know what to do.'" Jim explained, "I think it's also like a two-way road. So, I need to make sure that I'm communicating with them every day. I think that should be a responsibility that it's not just them always checking in..." Without a clear line of communication and expressing what they need as a mentee, a mentor is left blind and unable to help. Jan puts it best when she says, "I don't know what I need to know until I need to know it." This 
means that mentees are not going to know events or procedures until either it is too late or they have asked the question themselves.

Mentors and mentees alike also felt that it was both of their responsibilities to take advice from the mentor as valued help and try to implement it into their own classroom. They should also be vocal about the outcomes and express if the advice did not work for them. When it came to guidelines and expectations, only the mentors brought up that they should know the building/curriculum expectations and guidelines.

Following school guidelines and expectations of a classroom teacher is also another responsibility that was mentioned as being the mentees' responsibility. Peggy stated, "You know, just kind of following the expectations, you know, that our principal has set for us as far as being, you know, a classroom teacher." She added that mentees need to, "follow what the expectations are, you know, just for being an educator in our building." Pam had this to say about a mentee's responsibility to the curriculum, "I help her see the big picture, and then it's her job to help make sure she's following the curriculum, you know, doing what we're expected to."

\section{Mentor Responsibilities}

Mentors are the biggest key to a novice teacher's success. They play a guiding role in their career. If the mentee is a supporting player, the mentor is the lead role. Both

the school and the mentee hinge on this teacher. But, what is it that mentees and mentors perceive the mentor should be responsible for?

Mentor as a Building Leader. Interestingly, there are mixed feelings about the mentor being a leader within the school. Angelica explains: 
I don't think they have to be in a leadership position. I think that a lot of times they are just because there are some of those people that go and take the lead on things. But I think that there are great teachers who aren't leaders in our school just because they stick to their set of what they know.

Eliza has similar views to this. She said, "You don't have to be the one that is even a leader in the building." She adds, "I think those things aren't necessary because it ultimately just boils down to being able to help someone through their curriculum through classroom management and all those aren't necessarily the leaders of the building..." However, Eliza did go on to say that even though she does not think you have to be a leader in the building, the mentor is seen as one. Some teachers, however, believe that mentors are the teachers who are good leaders within the district. Tori said, "I feel like you need to be a leader." Pam says, "I think most of the people that step up to be a mentor or are asked by their administrator to be a mentor are really good leaders..." Jim had this to say about mentors being leaders:

I think a good mentor is naturally a good leader. I think it's necessary because they are leading someone who really doesn't know what's going on like you know what's going on. I think they have to just naturally be a good leader because they're trying to lead us through something that they teach you about in school, but it's totally different going to the real workforce.

Beginning of the Year Responsibilities. Getting started as a first-year teacher can be challenging. That is why it is imperative that the mentor guide them through the initial steps. Tori said, "I feel it's our job to make sure they know all those expectations to kind of guide them in their classroom and answer questions that they have." Peggy also 
said that it was the mentor's job to, “just making sure as best as she can, you know, to kind of follow what the expectations are." Eliza commented, "They have a checklist of these are the things that you need to cover, they have, you know, expectations for the mentee and the mentor." She also added, "I like the fact that the mentors know what is expected of them and helping those mentees." One of the expectations that a mentor can have is to make sure the mentee knows their expectations. Peggy said, “...to be honest, you know, with your mentee about certain expectations and areas for improvement." Jan adds:

And the fact that when I came into this district, it's not a district that I've ever worked with before, and the people I'm working with I didn't know any of them. Along with that comes with different facets of "this school expects this" or "this program expects this", and sometimes that's really intimidating to ask your coteacher.

Holly said, "But I think it's my role to make sure that she gets things done that are expected and that she might not know about." Tori also felt that it was her job to make sure the mentee knows the "extra expectations" of the district.

Knowing the formal and informal policies of a district are also important. Each school has its own culture and a novice teacher will need to learn how to navigate this. Nellie said this about mentors, "I'd like to think that a decent mentor is what colleagues would refer to as the veteran teacher. The teacher who has experienced numerous changes and growth within the school district and numerous policy changes." Holly explained, "So, I would take the traditions, different policies, those policy-type things 
that aren't written down anywhere, you know, that are just known. I think traditions are a big deal to know and that you're not caught off guard."

Another mentor responsibility that the participants said a good mentor should be responsible for is helping the mentee get everything ready for the first day of school. As Angelica said, "I think that kind of getting things started is kind of the mentor's role, just because the new teacher doesn't know what is even going on yet so, like the first week of school or the first module."

Others also said mentors should introduce mentees to the other staff and help them build relationships in the building. Phyllis stated, "So, I think it's ultimately the mentors responsibility to introduce them to people in the department." Jan replied, "I think that it is great. Being able to introduce you to other people kind of gets you comfortable with the environment that you're in." Michael said, "So, she knew a lot of the people and introduced me to all the different people, people that I definitely needed to know and just kind of got me involved in the culture and what the district is all about, and what the high school is all about, and things like that." Jan stated, "I think that it is great being able to introduce you to other people, kind of get you comfortable with the environment that you're in." Nelly said, "Show them the ropes, teach them the folks. Show them who's really in charge, which we know are the secretaries, custodians, and the cafeteria ladies." By building a stronger community, the building can function harmoniously.

Classroom setup was another area that the mentor and mentees felt was an area of the mentor's responsibilities. Peggy stated: 
So, we, you know, took her on the tour of the building, introduced her to as many teachers as we could, just making sure she was set up in her classroom with any materials that she needed or resources or anything like that.

Maria said, "So, I would say definitely her first role to me, I guess, was to make sure I was ready for day one, with all the little practical things that need to be set up." Eliza adds:

They have to at the beginning of the school year, they have to help them get acquainted and adjusted to the building. I mean, whether it's bathrooms, copier, you know, I mean just the little details that being a teacher in the building, you need to know.

A school's curriculum dictates what is being taught in the school and at times, how it will be taught. The participants felt that introducing the mentees to the school's curriculum was an important aspect of the job. Eliza said, “...it ultimately just boils down to being able to help someone through their curriculum..." Pam replied, “...we do have a responsibility to our curriculum and I can't just do what I want all the time. I have to make sure I cover what I have to cover. So, a lot of times I help her see the big picture..." She also added:

I have some things as mentor that I have to make sure happen due to DESE requirements. So, it's important to make sure they're keeping track of their professional development hours, that they've done their beginning Teacher Assistance Program workshop, that we're talking through the Missouri learning standards and helping her understand those, and how she is applying those in her classroom. 
Participants also thought it was important for mentors to answer all of the mentee's questions and bounce ideas off of each other. Tori said it was important to answer questions they may have because that is a way to show support and guide them. Jessica stated:

Even if it's something, you know, that I feel like, is a stupid question. She's gonna answer my question. And, like, I'm not scared to ask her anything. Because if you're scared to go ask someone for help, you're never going to ask them anything. And you're going to wonder or you're just going to guess.

Kelly said, “...they are to be there for you and answer questions and be helpful and kind of go and guide you through those first couple years." Michael stated, "I mean, she, she had, she checked all the boxes, as far as when I needed or when I had questions. She was always there to answer it." As far as bouncing ideas off each other, Jan stated, "Having somebody has been a good thing for me in this district as I've been able to have somebody to kind of bounce stuff off.." She added, "I think that's what eliminates that burnout is that you have somebody to bounce it off of." Tammy added, "Even though I'm not a student-teacher anymore, like we've developed that relationship, and it's bounce ideas off of each other. And she's really the only other science teacher in our building. So, it's kind of nice." Erin said, "I am there if she needs to bounce off ideas or to work out problems. I am not going to give her the solution but help guide her to finding the solution that is best." Michael stated, "Um, it's just, it's given me somebody to talk to, and kind of bounce ideas off of, and get feedback from." Angelica replied, "She gave me some really good ideas as far as like discipline and how to set up a seating chart kind of thing. So, just being able to bounce ideas off of has been really good." 
Participants also thought it was important to accept each other as peers. Pam stated, "I think we have a responsibility to accept the mentee as a professional on the same level. I'm not above her. We're in the same level. And so, it's a give and take relationship.” Maria said, “...she was willing to hear my ideas which made me feel very accepted into this new role." Tammy had this to say:

I heard of some student teachers, open-minded co-teacher, who their host teacher wasn't open to any of their ideas, wasn't treating them like an equal, you know, looking down on them. And that was really discouraging for them because it didn't give them the opportunity that they needed to grow and it didn't make them feel respected.

Maria stated, "You don't want to be treated like you don't have anything to offer. You might be fresh out of college. You may not have that experience, but surely there's something you've learned in those four years of college."

Guidance and Feedback Responsibilities. Guiding a new mentor through their first year is a crucial job which requires providing support and feedback. One of the ways a mentor can support a mentee is by providing guidance and give feedback. Michael stated, "I think responsibility for the mentor is just provide guidance. Be someone to give advice and give feedback to them." Michael adds, "she kind of let me let me do my own thing and kind of find my groove. But when I needed help, she was always there to provide any kind of feedback or advice." Kelly said, "I think the mentor should provide that guidance and ask you those questions, just to make sure you're on the right track and you're doing the things that you need to be doing." Louise felt like the lack of feedback the first year did not help her. She said, "The mentor that I had coming in when I started 
teaching fourth grade was a very quiet lady and she was a great teacher, but she was so quiet. I really didn't get the feedback that I needed to start that first-year teaching." Jan explained, "She gives me those positive feedbacks. Because on my first day in the whole building I felt like I was walking out of a burning building."

Another important part of guidance is collaboration with the mentee and helping them with classroom management. Pam explained that new teachers have some trouble with classroom management and parent issues. She explained:

There's another person that teaches eighth grade and we just work really well together. But I think at the beginning, the whole the classroom management, you know, and then there were the first year some parent issues that we had to talk through together. So, I would say classroom management at the beginning classroom management, let's say like lesson planning and parent communication and solving parent issues.

When Kelly talked about collaboration and working together in the same department, she explained that it made her feel more comfortable. She said, "And we kind of feed off each other in that sense. So, just that willingness to work together and be there for each other." Another aspect of guidance is providing strategies for the mentee to take back to the classroom. Maria explained, "Her other responsibility, I would say, then, is just being available for me to come and observe and learn the strategies that she's using in the classroom. Kevin added:

I'd probably say the mentor's responsibility would be to ensure that the mentee is feeling comfortable in their role and that if they are having any troubles with students, whether it's creating lesson plans or classroom management, helping 
provide those strategies or resources to look up those strategies and checking in with them to make sure that they are making that progress so that they are growing as a teacher.

Mentor Administrative Responsibilities. Mentor administrative responsibilities are the tasks that the participants felt were required and tracked. One of those was to know the procedures of the building. Tori said, "I feel like our job is to help make sure they know, number one, safety features, where all that's at the school, to kind of help them know procedures, extra expectations..." Phyllis believed mentors should make sure their mentees are, “...learning the procedures and learning the IEP process and learning the building.”

Along with making sure the mentee is following procedures, the participants also believed that mentors also need to take care of paperwork and checklists. Nellie stated, "I need to make sure that she can do her paperwork, and that data is collected correctly, I need to make sure that procedures are followed appropriately." Jim stated, "So, like keeping up with all the paperwork, and just helping with that is good." Shelly said: I'm scheduling meetings with them on a regular basis, doing the paperwork. And then, of course, have like a checklist of things. So, making sure that those checklists of things are gone through so that our mentee knows what we're supposed to do and when we're supposed to do it.

\section{Mentor Supports}

Participants mentioned several supports mentors should provide, including supportive traits and supportive actions. Supportive traits encompass what character traits 
a mentor should have. Supportive actions entail what a mentor should do, along with having positive character traits, to support the mentee.

Supportive Traits. No one can be a mentor who makes a positive impact on a new teacher unless they exhibit positive character. Caring, compassionate, and understanding are just some of the traits the participants listed. Jan said, "I feel like for the mentor program and having a mentor in a school system, you have to be caring, compassionate, and understanding." Tammy explained, "She is just a really caring woman in general. Like, she's caring to all of our students and all of her colleagues." She added, "And that was really good for me, because I knew that it was like a safe space to fail, and a really safe place to succeed." Kelly said, “And I know I think it helps that I am close to my mentor and that we do work in the same area because it makes me more comfortable and she's very caring and considerate of my needs..." Tori stated, "And even when you happen to go in, and maybe the lesson flopped that you're observing, show compassion with them and be ready to listen and give advice and be honest." Phyllis said, "And then as far as personal growth, it's teaching me to be more compassionate. Yeah, and more understanding of coming from different educational backgrounds." Linda added:

You're taking somebody that's easy to talk to and is understanding as well. And is also up for giving you advice or ideas that you might not think of, or letting you bounce ideas off of them. So, just someone who can listen. Try to understand what you're saying to them and genuinely care to see you succeed. 
Supportive was next on the list. Karen said, "You need to have that support system. So, open and supportive." She added, "But she's been very nurturing throughout this experience. It's like having someone there the whole time. It's like, 'I got you'.”

Jessica added comfort to the list. She explained, "I would say, just checking in to make sure that they feel comfortable..." Tina said, "for him to feel comfortable with that and having anything and everything that he has a question about feeling comfortable asking." Jan added, "So, personally it's helped me out because it's getting me in and getting comfortable with a large group of people."

Honesty and being trustworthy were other characteristic that mentors and mentees felt were necessary. Eliza said, “...you need someone, like I said, that can be understanding and honest." Karen explained, "I guess honesty is another thing. Not acting like you know everything, but being there. I mean, like, 'I'll figure this out with you'." Jessica said, "Being honest if they're doing something that's wrong. It's nice to know, because sometimes you don't realize you're doing something wrong." Maria spoke about a mentor being trustworthy. She explained, "I would definitely say somebody I can trust, I guess. Tell my ideas to, you know. Like I've worked in situations where I didn't feel comfortable telling my colleagues."

Participants listed several more supportive traits. Meredith said, "A mentor needs to be very friendly and honest when it comes to being a mentor for a first-year teacher. Someone who is easy to work with and get along with.” Linda explained, “...being approachable, essentially. It's hard to talk to somebody as a new teacher when they're not approachable and you don't know how they're going to take things." Jessica added, "I would also say she's very approachable, you know, I can go and tell her anything, or ask 
her anything, and she's going to answer my questions." Kelly said a mentor should have patience as well. She said:

So, she's sharing, patient, helpful she's just all of those things. I think it just fosters that relationship. It just makes it grow even more just because she is so patient and kind and helpful that, you know, it makes it... she's very easy to get along with.

Angelica said, "I think they need to be patient also and just offering help." Jessica explained mentors also need to be sharing. She said, "I would say sharing even of ideas, you know, all of that is very necessary." Erin explained, "Openness/sharing... I think some teachers want to keep all the information and lessons to themselves in fear of the mentee surpassing the mentor." Others said a mentor has to be positive. Jim noted, "She's a very positive person as well, naturally. And I do well with that, because I am, too. So, I think that helps a lot." He added, "Being able to have that communication and being upfront about things in a positive way. Not negative, but, yeah, just being able to work with someone is helpful."

Supportive Actions. Traits alone are not all the support that the mentee needs. There were several actions the mentors took to make the mentees feel comfortable and accepted. One of those actions is to simply welcome them into the school. Peggy stateed, “...first off, like just welcoming her into our building, you know, with those first couple of days. You know, just so, that she doesn't come into the school walking into a meeting, you know, totally overwhelmed." Phyllis added, "I think it's ultimately the mentor's responsibility to introduce them to people in the department. But then I think it's a group effort, like we need to surround each other." Jan said, "I think that it is great being able 
to introduce you to other people, kind of get you comfortable with the environment that you're in." She added, "Because, like again, you're in the middle of an ocean and you've got a life preserver and that's it. Like when you have a tugboat that will help take you to the mainland."

Other supportive actions involved being available to help the mentee. Kelly said, "So, someone that's just close by willing to help and just be there for you, because I do have a lot of questions." Erin stated, "If what is best for the students is helping your mentee to be the best, then by default, you should care about every aspect of the mentee." Tina said:

Somebody who's willing to be helpful. And give guidance, I mean, even their name. You know, like, last year, I'm helping somebody who is language arts, even though I teach math, I can still give ideas. I wasn't her mentor. But her mentor wasn't really helping her. So, I was trying to help her out as well.

Shelly said, "You're just trying to help them to be better, I guess." Eliza explained, “...it ultimately just boils down to being able to help someone through their curriculum, through classroom management and all that...". Part of helping a mentee out is being available. Louise said, "They need to have time to be available." She later added: So, they have to know that they're safe, they have to know you're available. And she has done that she's coming here freely. And if she can tell if I got too much going on, she may just stay a few minutes. Other times I'll be like shut the door. Hang out for a while.

Maria said, "Her other responsibility, I would say, then, is just being available for me to come and observe and learn the strategies that she's using in the classroom." Part of 
being available means having an open door. Maris stated, "I truly appreciated the fact that she was always an open door for me..." Karen explained:

Like open doors, you can always turn to them with anything. Because there are so, many moments where you just feel so, annoying, kind of and you're just like, I need to turn to someone and I need them to be there and not be like, "Not now. You're annoying." You know what I mean? You need to have that support system. Mentees also need emotional supports. Karen stated, "I feel like having a mentor that's emotionally supportive is so important. People underestimate the power of emotionally supporting someone and not just like being there on paper, if that makes sense." Karen told this story:

I feel like people underestimate how important it is for a mentor to be emotionally supportive. Because I feel like people think that it's all school stuff. How can I mentor you in teaching and stuff. But, for me, the best thing that I've had, so far, is my mentor sit there and be like, 'it's gonna get easier'. I've cried to her. There have been moments where I've gone into her room crying. And, just because I had such a long day, and I couldn't stop just because I was at that point of exhausted, COVID, everything. But I was supposed to teach a class in a moment. And so, she was like, "Yep. Okay, you stay in here. You sit in my room and cry, and I'm gonna go teach your class."

Part of the emotional support is also to listen to their mentee. Tammy said, “....sometimes I have a really stressful class, and she listens." Linda explains:

So, she is, of course, a good listener. As I, like, I've kind of already kind of mentioned that a couple of times. But she's been able to help me process through 
a lot of issues or situations that I just needed to talk to somebody about and figure out the best path to take.

Pam stated, "We need to listen and then help. It's like a problem-solving skill. Helps problem solve. So, I think listening is really important.”

\section{Program Concerns and Improvements}

Even the most perfect plan will have flaws that need to be worked out in order to make it more successful. The same is true with mentoring programs. As Kelly said about improvement, "I feel like maybe it could be implemented a little bit better." She added, "I almost feel like it's kind of pushed to the wayside, a little bit. It's just a list of things. It's just a checklist you know it's just not very thorough.” Eliza explained that, “...the districts just have to be aware that we have to provide as much support as we can." She added, "Remember to respect the fact that they are only a first-year teacher."

There were some confusions about the program that the participants noted. When talking about school incorporation of responsibilities, Lisa had this to say, "We haven't really been given any structure. This is what a mentor should do. I haven't really had any guidance. I'm just mentoring from the heart, I guess.” Another participant, Tammy, said, "I don't think this school really has a mentoring program. Like it was just by chance that me and her became mentors. Like there's nothing structured. I think they all assume she will be my mentor." Linda added, "We didn't really have like a guide thing. It just kind of was like, 'Oh, you're my mentor? Okay!' So, it was just, it wasn't like a set program, I guess." Another mentee, Karen, said, "I don't even know what the mentor is, like, technically supposed to be there for. I'm gonna be honest." She added, "I don't even know technically what their responsibilities are." 
Participants also expressed other difficulties. Shelly said, "I feel that our school does a really good job of it at the elementary and high school is a little bit more difficult, because you don't have everybody in the same places." Angelica explained, "So, we don't have the same plan period so, that also makes it difficult." When talking about mentoring a new teacher that teaches a specials class, Shelly noted, “...sometimes that's difficult too because you don't know the scheduling or the timing of different events or contests."

Participants also discussed a lack of time with each other. Holly explained about needing time together:

I wish we had set times where they would give us time to work together. Instead of on our own, you know, our own time. I'm here an hour before school and here two hours after. But I use that time. I need time, maybe during the day, if we could get head time once a month or something. I wish we had more.

Peggy said, "I do wish that I had more opportunities during the day to be able to be in contact with my mentee." Phyllis talked about time with her mentee, "Sometimes there's not enough time, and not allowing time, and not delegating it." Louise stated, "The bad, to me... it's just been not enough time, really, to talk."

Participants also noted that there is a lack of emotional care in the program. Louise explained, "It's a very rewarding job. But we have got to have that support. And we've got to have that empathy." Peggy also mentioned empathy, saying, "We need to be very, you know, empathetic because it's super hard to be a first-year teacher or, you know, first year and a new district." Tammy, a mentee, shared: 
The first thing that comes to my head is empathy. Like, I think, I think they have to be able to recognize what the person they're mentoring is feeling and like, help guide them. I think just because going into education is really overwhelming. Eliza said, "I do think that mentors need to be empathetic to first-year, second-year teachers and their needs. And their experiences going through the first and second year, you know, the hardest times of your life as a teacher." Nellie spoke about the program failing to provide emotionally nurturing support, saying:

It is very by the book. It's very non-emotionally nurturing. I worry that we don't have enough time to do the emotional nurturing that needs to happen and I think that's probably why there is burnout. It is very dry. We check our emotions at the door every day. I think that's the norm here, and I don't appreciate that.

Shelly said, "I think it would be good to teach, like, 'Hey, don't forget to take time for yourself! Don't burn out!"”

Good mentors are the cornerstone to the mentoring program. This can often be challenging because the success of the program is not just about the mentor being knowledgeable, it is also about the relationship with the mentee. Participants brought up several aspects of mentor selection and had some valuable reflections. Kevin said, "I would say, for the most part, they're finding good mentors. They're finding the ones who do want to help the kids and help teach you to help new teachers be able to help the kids."

Selection of the mentor is also important to the success of the program. When it comes to schools selecting mentors, there was no universal selection process. Lisa said, "My experience so far, it's just assigned. In this situation I'm in this year it was assumed that I would be a natural fit since she taught with me." She went on to say, "There were 
mentors assigned that didn't want to be a mentor." When you have mentors who want to be there, they can develop bonds with their mentee. Jan said:

That's the cool thing about, I think, of any kind of mentorship program that you have is that you have that availability to bond with another person and build a relationship, a professional relationship, with somebody that can also help you build the relationships around you in your cohort or whoever you're with.

Karen had a similar viewpoint and said, “...it feels like we have this good bond where we can just help each other out anytime we're in a difficult situation."

Sometimes mentors and mentees are paired together that are not the right fit. Participants felt that schools needed to make it a point to have a path and encourage mentees to seek another mentor if they feel it is not a good fit. Tina expressed:

I mean, if I feel like if it's not working, then there needs to be something set up for that. Because I know what our paperwork it says, if it's not working, you just submit something in writing to the principal. Well, that's kind of awkward to like, you know, just if it's not working, I would think the principal would be able to tell that and try and switch things up or talk with both of them and figure it out. So, I'm kind of disappointed. Last year, that didn't really happen, because it was obvious that the other person wasn't getting the help. But I think that would be an improvement, trying to figure out when it's not working, what do you do?

Louise explained that the school would be benefited, “...if they would make sure that they [mentor/mentee pair] make a good match. And if it doesn't work, they're aware of, that they can get a different mentor for that person." 


\section{Research Question One: Characteristics}

The first research question asked the participants what characteristics of a mentor they thought were prevalent in the mentoring program. There were five traits that both the mentors and mentees believed were the most important. Eighteen of the 24 participants noted good mentors should be supportive. Support also encompassed being helpful and providing emotional support. Participants believe that the first few years are hard on a mentee both mentally and physically. Having someone they trust and will be supported by was important for their success. Participants also said that a mentor needed to be knowledgeable. They noted that the mentor needed to know the inner and outer workings of the school. This involves showing them how to navigate curriculum, introduce them to other teachers and help them build relationships with others. This also involved letting them know the key people in the building. They also believed that mentors needed to be willing to share their knowledge with the mentee. This goes along with their belief that the mentor needs to be experienced. This experience took the shape of a teacher having seen changes in the school over time, having worked through what worked and did not work in the classroom, and their perspective on ideas based on their lived experience.

Several traits were deemed to be negative in a mentor and mentee relationship. Not being open to the new teachers' suggestions and input was one of the less desirable traits. Participants explained that by not being open to others ideas that it shut down the new teacher and caused them to not feel like part of the team. Mentors not being willing to help the mentee is also detrimental for the mentee. Participants noted that mentors should be willing to share their knowledge and help the mentor when they need it. Lastly, 
participants explained that a mentor that is too set in their ways can have a negative impact. This is because they are either not wanting to be a mentor, or unwilling to try new things.

One characteristic that participants had differing viewpoints on was if a mentor should be a leader within the school. One mentor said that a mentor did not need to be a leader in the building, but helpful and knowledgeable about the curriculum and classroom management. Others had a differing view. Two participants thought that the mentor needed to be a leader. One explained they thought the mentor needs to be a naturally good leader to lead them through the initial first few years of being a teacher.

\section{Research Question Two: Responsibilities}

The second research question asked what participants believed their responsibilities were to each other. Mentees should listen and take advice that the mentors give them. One mentor noted that it is concerning when they give advice to the mentee that they should follow and they do not listen to it. Another responsibility the mentee should be responsible for is following the guidelines and school expectations. Keeping an open line of communication was the main responsibility that most of the participants said was important for the mentor and mentee relationship. They said the mentee needs to take the initiative to speak out when they need help or something is not working.

Participants thought mentors should help the mentee get ready to start the school year. This entailed getting acquainted with the building, setting their classroom up, getting familiar with the gradebook system, and anything that helps them get the year stated. They should also be available to answer questions and collaborate with the 
mentee. Mentees said they want to be viewed as peers and want to be able to collaborate with their mentor. As new teachers, they expressed the need to be able to freely ask questions and receive feedback on what they are doing. Both the mentors and mentees believed that it was the mentor's responsibility to take care of the administrative aspects of the mentor and mentee program. Those administrative duties include making sure the mentor/mentee checklist is being completed and the supporting documents are being collected. Other administrative duties also entailed scheduling observations and keeping up with professional development logs.

\section{Research Question Three: Professional and Personal Growth}

The third research question asked the participants how the current mentoring model assists in their professional and personal growth. The participants said the mentoring program has helped them professionally by giving them someone to collaborate with and share ideas and strategies. Mentees in the program noted that it has given them support and helped to boost their confidence. One mentee said it inspired him to find his own professional development. Some did say it was not the school's program that helped them, but having a person that they could talk to and get ideas from. Mentors expressed it makes them want to be a better teacher, keeps them motivated to do new things, and learn new tricks from the younger teachers.

The mentors and mentees expressed growth in their personal life from the process. Mentees expressed it has made them grow from just being a student into a working adult. It also forced some of the mentors to come out of their shell and build relationships they otherwise would not have formed. Mentees also expressed that having a mentor has helped their confidence grow as a person. One of the ways that both the 
mentee and mentor believe they have been personally impacted is becoming more patient.

Mentors said they feel they are seen as a leader in the building. They also reported they feel more supportive since they became a mentor. Mentors also said that being a mentor has taught them to be more compassionate and realize they do not have all of the answers. Some of the mentors also stated they have developed personal friendships with their mentees.

\section{Recommendations}

Based on interviews with both the mentees and their mentors, the mentoring program is not being implemented in a unified manner that benefits novice teachers the same throughout Missouri. While some schools received praise for their program from all of its participants, some had no indication of what the mentoring program was. However, all programs did express that there were some key components they felt were missing. This informed the researcher to suggest the following design changes to the mentoring program.

\section{Add Emotional Support}

Schools need to add a level of emotional support for mentees in their program. As participants have noted, education is a stressful time for new teachers. They are overwhelmed with expectations, extra-curricular responsibilities, and often living on their own for the first time in their life. This adds to the stress of uncertainty and making sure the curriculum is correct. New teachers need to have a safe person to vent to who will keep their conversation confidential. They also need to be encouraged to take time off for their own mental health and decompress. 


\section{Ensure the Mentor is Willing}

While the mentors who were interviewed were all willing mentors, there were several participants who told stories of mentors who did not want the job, but were assigned it. Both mentors and mentees had heard of a mismatch between the mentor and mentee that ultimately left the mentee feeling discouraged and not feeling like an equal in the building. This leads to the recommendation that administrators need to find willing mentors for their new teachers. Being paired with someone in their own department is not as beneficial to having a willing mentor who can work well with the mentee. If the mentoring pair is not a good fit, the school needs to allow the mentee to switch mentors. This can either be to a teacher they have developed a rapport with or to someone in the building who is helpful and personable.

\section{Overhaul First-Year Meetings}

New teachers are not only bombarded with learning the ropes of being the classroom teacher, but in some cases they are given the hardest positions, unwanted extra duties, and some will be coaching a sport. The mentees enjoyed the monthly meeting when they were thoughtful and meaningful to their needs. While learning teaching strategies is an important component to continuing professional development, many new teachers have just finished a program where those are taught. Tina noted, "...we do have meetings. So, they do talk about some stuff. But I mean, honestly, it's, to me, I think it's more of a waste of time than anything." Meredith also explained, "I went to school for 4 years for this degree but every school operates differently and the program has guided me in a more independent direction." It is recommended the first year of orientation should focus on the emotional and professional wellbeing of the mentee. It is also recommended 
for the administrator to ask, "Is this meeting beneficial?" If the answer is yes, then every first-year teacher needs to be in attendance. If it is ok for the coach or sponsor to not be there, then why do the others need to be there as well? Mentoring program meetings need to take priority.

Mentors and mentees in the study have mentioned the use of a mentor/mentee handbook was beneficial. However, the handbook needs to be utilized as a tool for the program, not a substitute for it, as the study found was the case with some schools. The handbook should include a checklist so the mentor and mentee pair fully understand what they need to get done together and individually and the timeline for completion, lay out the measurable responsibilities of each person, list procedures for switching mentors when the relationship is not working, and provide resources for professional development. Handbooks should also list any dates for meetings and make sure the mentor and mentee understand that these are mandatory and they should plan around them.

\section{Partner with Other Schools for Observation}

Being a first-year teacher is daunting. Being a first-year teacher in a small district where they are the only teacher of a particular subject can be even harder. Having a mentor in the school is important, but a new teacher needs to be able to talk to another teacher of the same subject to get their perspective as well. Mentees in this study did not know if they could go to another school outside the district to observe other similar subjects. As Kevin stated when talking about his mentor not having all the answers, "[I am] recognizing that not all the answers are at my school. It's kind of pushed me into these other ways of learning." Schools can benefit from cross-district learning. This will 
enable a new teacher to see multiple perspectives and give new teachers greater resource to work with, which will in turn benefit the student.

\section{Make Mentors Accountable}

During interviews, some mentors mentioned they were paid, and some mentioned that they were not. When the mentor is paid, the amount paid to the time needed to execute the job properly seemed inadequate. The most the participants were paid was \$200 for the year. Furthermore, mentoring is not a contracted position and a teacher cannot be held accountable for their responsibilities as a mentor. It is the researcher's recommendation that schools hold mentors accountable for the responsibilities the district places on them and compensate them as they would a minor sport coaching position. By paying mentors a reasonable salary and having set expectations, the school can more easily ensure each mentee is getting the support they need and the district will hopefully increase teacher retention.

\section{Summary}

While there have been many studies on effects of mentoring versus no mentoring, there have been limited studies on the perceptions and professional/personal growth of mentors and mentees. The study concluded that the overall program was perceived to be successful for the participants studied. However, results indicated that each school had a different approach to mentoring. Some had a structured and immersive program, while

others were basic is scope. None of the programs made a focus on the mentees emotional and mental wellbeing. 
The mentoring program is crucial to keeping new teachers in the profession.

Providing new teachers with the support they need is key to keeping them invested in the teaching profession. 
SECTION TWO:

PRACTITIONER SETTING FOR THE STUDY 


\section{History of the Organization}

Schools in Missouri first opened by legal enactment in 1808 while it was still part of the Louisiana Territory (Phillips, 1911). Schools during this period were private and required funds to attend. Funds were not set aside for public education until 1853.

Currently, Missouri schools are governed by the state's Department of Elementary and Secondary Education, which is charged with setting and monitoring the criteria schools must meet to be accredited and receive state funding.

\section{Organizational Analysis}

Missouri schools follow the Mintzberg Model of organizational structure. Small schools in the state are structured as a "Simple Structure" model of organization. Midsized and large schools have multiple campuses and follow the "Divisionalized" model of organization. Regardless of the model of the school, both types have support staff and a technostructure that assist in day-to-day operations (Bolman \& Deal, 2013).

Bolman and Deal (2013) describe Mintzberg's simple structures as small organizations with few employees. These organizations take their values from their local community, have very few people in the strategic apex. In small schools, you have the superintendent, elementary principal, and the secondary principal in the strategic apex. Due to the size of the school, there is no need for a midline position, an assistant principal or department head, so each person in the apex position has greater power over their employees. Schools that fall into this category generally have a close relationship with the community and can be influenced more easily by it, as well.

In the divisionalized model of organization, there are several "divisions", or campuses, that operate independently and report to a corporate office (Bolman \& Deal, 
2013). The divisionalized model is representative of the midsized and large schools in the state in that they have multiple campuses and one central office. Each campus has its own principal that runs the building. Many buildings also have an assistant principal which helps oversee everyday operations. Each subject is divided into departments that have department heads to coordinate teaching strategies and assure the approved curriculum is being taught. Lastly, the teachers make up the operating core of the building. In these schools, the central office stays out of the day-to-day operations of each school, only having the head principal report on the progress of its goals. Schools in this category tend to have more resources and willingness to try new teaching strategies.

\section{Leadership Analysis}

School leaders in the involved with this study often fall into the situational leadership style, as how they lead is determined by the situation they are in (Northouse, 2016). As the administration of a school wears many hats, situational leadership is the basis of what is necessary to manage a school district and the components that support it. School leaders use varying degrees of supportive and directive behaviors to accomplish their goals. Administrators generally work with a fixed budget and, therefore, must make the necessary budget realignments to maintain school operations.

Due to having many responsibilities, school leaders often develop committees to help make decisions. By forming committees, administrators encourage their employees to give input. The administrator must choose to accept committee's recommendations or formulate a new plan. This is an example of high directive and high supportive leadership behavior. Though the administrator gave the staff a voice and guidance, it is still the 
administrator's responsibility to determine how the goal will be accomplished (Northouse, 2016).

Curriculum is always changing. As new techniques and standards are developed, leaders must give teachers the support they need to incorporate them into the classroom. This means administrators are often in classrooms observing teachers and providing feedback on what they observed. School leaders often are the person that students and staff come to when they have concerns. When all of this occurs, a school leader must be a high supportive and low directive leader.

Although school leadership ultimately has control over the whole building, they do not have the time to direct every classroom. Administrators often exhibit low supportive and low directive behaviors when it comes to how teachers will teach in the classroom. Though standards must be covered, administrators generally give very little direction on how to teach the information. Teachers are given great academic freedom. As such, the administrator will only step in when it becomes necessary (Northouse, 2016).

\section{Implications for Research in the Practitioner Setting}

This study adds to current mentoring research and gives administrators and state officials a current picture of the views and assumptions teachers have about the perceived impact of the mentoring program. With a clearer picture of what is happening in mentoring programs, administrators can assess how to improve them, which will have an impact on how the district can identify and meet the needs of their novice teachers. This study may also help mentors reflect on their current practices as mentors and teachers. 
SECTION THREE:

SCHOLARLY REVIEW FOR THE STUDY 


\section{Introduction}

Teacher attrition is a major issue for school districts. Nationwide, $50 \%$ of teachers will leave the profession within the first five years of teaching (Farmer, 2020). Farmer noted that by forming relationships with other adults, novice teachers experience job satisfaction. For the purpose of this literature review, culture will be defined as the way the people within the school work together and their shared set of beliefs, values, and assumptions ("School Culture and Climate," n.d.). By examining the literature on the novice teacher, mentor, and how the mentoring program includes aspects of culture, a clear picture can be constructed of the mentoring process and how the role the mentor plays in it.

\section{Missouri Certification Levels}

According to the Missouri Department of Elementary and Secondary Education (2020), there are six routes to certification. The traditional route is accomplished by an individual which has graduated with a bachelor's degree in education and has passed a certification assessment. The alternative route allows someone with a bachelor's degree to start teaching in a content area while attending college to take the required education courses to become certified. The Temporary Authorization route is similar to the alternative route, but the college courses are self-directed. The Out-of-State Certified route allows an individual who has a teaching certification from another state to transfer their certificate to Missouri. The American Board of Certification for Teacher Excellence (ABCTE) route allows an individual with a bachelor's degree who has passed the ABCTE program to obtain teacher certification. The areas Missouri will allow certification via this route are mathematics, U.S./world history, English/language arts, 
biology, chemistry, general science, physics, and elementary education. The final route to teacher certification is the Doctoral route. The Doctoral route allows individuals who hold a Ph.D. in a content area and pass the Professional Knowledge: Secondary exam.

Once a novice teacher has completed a certification path, they will be issued an Initial Professional Certificate (IPC) which is valid for four years (Missouri Department of Elementary and Secondary Education, 2020). During this time, a novice teacher will complete four years of teaching, participate in a mentoring program, complete 30 hours of professional development, participate in a beginning teacher assistance program offered by a college, participate in the school district's Performance-Based Teacher Evaluation program, and develop and implement a professional development plan. Upon completion of these requirements, teachers will be granted a Career Continuous Professional Certificate (CCPC), which is valid for 99 years. State Mentoring Laws Missouri requires all school districts to provide every novice teacher with professional development during their first two years of teaching (Missouri Department of Elementary and Secondary Education, 2020). Missouri has started the Missouri Teacher Development System to assist novice teachers in their first two years in the profession (Missouri Department of Elementary and Secondary Education, 2020). This program is broken down into two phases. Phase one covers building relationships and culture, creating and managing learning environments, developing instruction, and engaging students in content. The second phase starts the teachers second year of teaching and includes lesson differentiation, monitoring student progress, and working in a community of practice. State law suggests that a mentoring program should be teacherdriven, administrator supported, and given to all new teachers (Missouri Senate - 
Missouri General Assembly, n.d.). Mentoring programs are also supposed to facilitate open and confidential communication between the mentor and mentee to help establish trust between colleagues. State law also dictates that all teachers in the building are to provide informal support for novice teachers (Missouri Senate - Missouri General Assembly, n.d.). According to the Missouri Senate - Missouri General Assembly (n.d.), mentoring programs should include:

- An introduction to the cultural environment of the community and the school district;

- $\quad$ A systemic and ongoing evaluation by all stakeholders;

- An individualized plan for beginning teachers that aligns with the district's goals and needs;

- $\quad$ Appropriate criteria for selecting mentors;

- $\quad$ Comprehensive mentor training;

- A complete list of responsibilities for the mentor, beginning teacher, and administrators; and

- $\quad$ Sufficient time for mentors to observe beginning teachers and for the beginning teachers to observe master teachers, structured to provide multiple opportunities over time and to minimize the need to require substitute teachers to facilitate observation. (Missouri Secretary of State, n.d.)

\section{Teacher Preparation Programs}

Teacher mentoring starts well before a novice teacher assumes the role and accepts their own classroom (Curcio \& Adams, 2019). Eck and Ramsey (2019) go as far 
as to describe the relationship between the student teacher and the cooperating teacher to a child and a parent. The cooperating teacher will "raise" the student to become a fully functioning classroom teacher (Eck \& Ramsey, 2019). Curcio and Adams (2019) explain that the mentoring that occurs during the teacher preparation program will influence the effectiveness of the novice teacher as they start teaching. This influence can either be positive or negative and is determined by the mentor and mentee relationship.

Eck and Ramsey (2019) say that teacher preparation programs need to prepare novice teachers for more than just the teaching of a subject, but also the other activities that need leaders to run them. Extracurricular activities, such as FFA and Student Council, are often areas that are not accounted for in a teacher preparation program (Eck \& Ramsey, 2019). Even when a student teacher volunteers to participate in an extracurricular activity, cooperating teachers rarely give feedback on the student teachers performance. Even when feedback is given, it is not provided in a structured manner that promots professional and personal growth (Eck \& Ramsey, 2019).

With an increase in the diversity of student populations, teachers need to be equipped with the necessary tools to educate them (Richardson \& Dinkins, 2014). In order to do this, teacher preparation programs must include programs in cultural responsiveness and be placed in more diverse field experiences. In placing student teachers in cross-cultural settings, student teachers can gain knowledge of injustice and recognize it (Richardson \& Dinkins, 2014). By learning about people's cultures and the true situation in which they live, student teachers learn their role as a creator of change (Richardson \& Dinkins, 2014).

\section{Missouri Teacher Preparation}


In Missouri, there are 51 colleges that provide teacher education programs (Missouri Department of Elementary and Secondary Education, 2020). According to Missouri's Department of Elementary and Secondary Education's (2020) “Standards for the Preparation of Educators" (MoSPE), a school must develop a teacher education program using the following standards:

- $\quad$ Standard 1 - Academics: Candidates demonstrate knowledge and application of general education, content knowledge, and pedagogy.

- $\quad$ Standard 2 - Design and Assessment: The data from fair, valid, and reliable assessments will be used to measure the performance of candidates and educator preparation programs by program and certification areas.

- $\quad$ Standard 3 - Field \& Clinical Experiences: Field and clinical experiences, offered in collaboration with PK-12 schools, support the development of educators.

- $\quad$ Standard 4-Candidates: A diverse pool of candidates, who demonstrate potential for effectiveness as educators are recruited, admitted, developed and retained by educator preparation programs.

- $\quad$ Standard 5 - Faculty: Educator preparation faculty are qualified for their assignments, recruited from diverse populations, and model effective professional practices in teaching, learning, scholarship, and service. 
- $\quad$ Standard 6-Operations and resources: Operations and resources are necessary to govern, develop, support, and maintain the educator preparation program.

MoSPE specifies that students will undergo three levels of field experiences before obtaining their teaching certificate, which is: Early Level, Mid-Level, and Culminating Level (Missouri Department of Elementary and Secondary Education, 2020). Each level has its own set of requirements of duration, cooperating teacher requirements, and Field/Clinical Supervisor requirements.

\section{Early Level Requirements.}

Students who are in the first phase of their field experience will spend 30 hours in a classroom, in which they will mostly observe and have limited experiences interacting with the students (Missouri Department of Elementary and Secondary Education, 2020). Cooperating teachers are general practitioners who have at a minimum a bachelor's degree, are certified in their field, and have a minimum of three years of teaching experience in the PK-12 setting. Field/Clinical supervisors must have at least 3 years of teaching experience in the PK-12 setting and have a master's degree.

\section{Mid-Level Requirements.}

Students who are in the second phase of their field experience will spend 45 hours in a classroom, in which they will mostly observe and have structured experiences interacting with the students (Missouri Department of Elementary and Secondary Education, 2020). Cooperating teachers must have a bachelor's degree, be certified in their field, and have a minimum of three years of teaching experience in the PK-12 
setting. Field/Clinical supervisors must have at least 5 years of teaching experience in the PK-12 setting and have a degree higher than a master's degree.

\section{Culminating Level Requirements.}

Students who are in the last phase of their field experience will spend 12 weeks in a classroom, where they will be student teaching under the supervision of a cooperating teacher (Missouri Department of Elementary and Secondary Education, 2020).

Cooperating teachers must have a bachelor's degree, be certified in their field, and have a minimum of three years of teaching experience in the PK-12 setting. Field/Clinical supervisors must have at least 5 or more years of teaching experience in the PK-12 setting and have a degree higher than master's degree. Field/Clinical supervisors must also have weekly contact with both the student-teacher and cooperating teacher, and also perform one observation on the student teacher every two weeks.

\section{Why Novice Teachers Leave Teaching}

It is estimated that 54,200 teachers will exit the teaching profession to work in a different occupation during the 2016-2026 decade (Torpey, n.d.). There are many reasons teachers leave the profession. Sciuchetti \& Yssel (2019) have documented that novice teachers leave the field due to difficulties with classroom and/or behavior management. Teachers also said that student behavior was a factor in their reason for leaving the field (McCarthy et al., 2016). Teacher burnout happens faster when the supports the novice teachers need from parents, administrators, and other teachers are not there (McCarthy et al., 2016).

Teachers also left due to not making enough money for the job that they were performing (Harris et al., 2019). Though warned that the compensation for being a 
teacher is low, novice teachers are not hit with that reality until they actually start teaching. Teachers also leave due to family commitments, such as having children (Harris et al., 2019). This changes the career priorities of predominantly female teachers from education to the home.

Teachers left schools if they did not have a positive perception of the school they taught in. This can be affected by how much administrative support they have and how much autonomy over the work that they do (Wronowski \& Urick, 2019). Teachers cited a loss of control over their work, no influence or input on their curriculum, and not having enough time to teach as reasons for forming a negative perception of the school (Wronowski \& Urick, 2019). Teachers also consider leaving the profession due to increased job responsibilities (Harris et al., 2019). Often, teachers are spending 3-4 hours outside of contracted time preparing lessons for the next day. Standardized testing is another contributing factor in teachers leaving the profession (García-Arroyo et al., 2019). Educators are constantly scrutinized for the results of their tests, yet given no supports to help achieve the goals set by the state. Educators are also frustrated due to the lack of adult interaction (Walters, 2004). This leads to teachers not working as a team, and can cause feelings of favoritism between certain staff members. Isolation leaves novice teachers feeling like there is no support from other teachers and administration (Reitman \& Karge, 2019).

Administrator's attitudes are key to teacher retention (Wronowski \& Urick, 2019). Having administrator support helped the teachers cope with external pressures and job burdens that they may face, which increased teacher satisfaction (Wronowski \& Urick, 
2019). Schools that did not provide this experienced a higher level of turnover than schools that provided these supports (Wronowski \& Urick, 2019).

A lack of a mentor can leave a novice teacher feeling isolated and cut off from their peers (Ingersoll, 2012). Ingersoll noted that by having a mentor, a novice teacher will feel more supported and less isolated. Mentoring relationships are important for the novice teacher. These relationships help the novice teacher form connections with other staff and build networks throughout the school (Hersman, 2018). Mentoring relationships are formed when an experienced teacher supports a novice teacher and provides them with guidance. Mentors need to be trained, invested, and diverse (Hersman, 2018). This includes being able to try different approaches at how they mentor others.

\section{Why Novice Teachers Leave}

Farmer (2020) explains that novice teachers will leave the teaching profession due to difficult working assignments, unclear expectations, inadequate resources, isolation, role conflict, and reality shock. Isolation refers to not being comfortable seeking help from other teachers and administrators, as they do not want them to know they do not know something. Novice teachers want to work in an inclusive environment where they feel they have the structure and support they need. They want to feel they are able to take risks and learn from the outcomes. Novice teachers also need to feel they are a part of the school's community, and want help learning the school's culture. Dias-Lacy and Guirguis (2017) also had similar findings in that when novice teachers form personal relationships with their mentor and other teachers, they share emotions and experiences with each other. 
A novice teacher is truly working two jobs: that of teaching and that of learning Clark (2012). The first two years of a new teacher's career are known as the sink or swim years. During these years, teachers will either be exposed to positive or negative school experiences. Clark (2012) reported that $39 \%$ of all novice teachers will choose to leave their teaching careers for other employment. She also explained that attrition is higher in low-income schools than affluent ones due to the working conditions of the school (Kimball, 2018). School leadership plays an influential role in creating environments in which novice teachers can thrive due to their ability to create school structures that can help new teachers succeed (Clark, 2012). School leaders also should portray a positive school environment, as how they act often becomes the school's reality (Kimball, 2018). However, a novice teacher's perception of support from school leaders and administration is inadequate (Dias-Lacy \& Guirguis, 2017). Being paired with one mentor is often not enough support for a teacher.

Many novice teachers have expressed that the current model of mentoring added feelings of frustration and exhaustion, which kept them from performing to the best of their ability (Lozinak, 2016). Despite the outcry of novice teachers asking for the current model to change, administration and current mentors believe it is adequate in its current state. Novice teachers also need help in balancing their work and personal lives (Jyoti \& Sharma, 2017). Mentors also provide the psycho-social supports necessary to solve liferelated issues. Jyoti and Sharma (2017) found that the outspoken novice teachers are able to create these networks quickly, while others struggle to cope with work and personal issues alone. 


\section{Novice Teachers and Mentoring}

Farmer (2020) concluded to navigate the struggles of the first few years of teaching, novice teachers needed support from both teachers and administrators that were sympathetic to novice teacher issues. Novice teachers need collaborative groups to learn from, discuss ideas with, and talk about frustrations they may be having. The more support a novice teacher receives, the better teacher retention will be (Clark, 2012). Mentoring, orientation, ongoing induction programs, and real-life teacher preparation programs are essential to creating the level of support novice teachers need to succeed and stay in the teaching profession (Farmer, 2020). Ingersoll (2012) noted mentees who had regular communication with their mentor and administrator were more likely to stay in the school district than those who did not have those supports. New teachers also need to be understood, taken seriously, and listened to. Teachers who have these needs met will be less likely to leave, and teacher attrition could potentially be cut by two-thirds.

\section{Mentor Responsibilities}

Mentors are key to the induction of a novice teacher. However, some veteran teachers may not have the experience needed to take on the role of a mentor. Other veteran teachers may not want to take on the role of a mentor (Nasser-Abu Alhija \& Fresko, 2014). Veteran teachers are often assigned to novice teachers with inadequate

training for their responsibilities as a mentor. When this happens, novice teachers are not receiving the best collaborative environment that allows them to develop the reflective and intrapersonal skills needed to be an effective teacher (Nasser-Abu Alhija \& Fresko, 2014). 
Mentors need to have the skills necessary to perform their job well. In order for mentoring programs to be truly effective, mentors need to have ongoing professional development in educational leadership (Whalen, Majocha, Van Nuland, 2019). By providing ongoing professional development for the mentors, schools can increase student scores and behaviors, as well as positive teacher efficacy (Whalen et al., 2019). Mentors need to have professional development in their interpersonal skills in order to have effective, analytical, and nonjudgmental communication when the novice teacher has an issue (Hall et al., 2017). Mentors need to have both personal and program supports to be successful (Doering, 2018). The personal supports entail what types of supports the mentoring system and administrators had for the mentor. The program supports are the program designs and structures within the program that assist in the success of the mentor. This support involves mentor-mentee relationships and networking between fellow mentors (Doering, 2018).

In a study by Isreal et. al. (2014), five highly skilled special education teachers were selected to mentor novice teachers within their own grade levels. The mentors received 10 hours of professional development in teacher evaluation, providing highquality feedback, and how to meet collaboratively to solve mentoring challenges. Isreal et. al. (2014) found that the mentors started giving feedback and support that targeted the needs of the novice teachers. As a result of receiving support, the novice teachers' emotional needs were also met, leading to greater teacher efficacy.

The relationship between the mentor and novice teacher is important. Hall et. al. (2017) describes the ideal mentor as a good communicator, trustworthy, non-judgmental, empathetic, and respectful. These characteristics will have an impact on the mentor and 
novice teacher's relationship. If the novice teachers' beliefs and conceptual knowledge are being understood and appreciated by the mentor, then a productive relationship will form between the two (Hall et. al., 2017). Along with this, mentors will also need to learn to incorporate a novice teacher's contextual factors into the relationship. Those contextual factors consist of the novice teacher's differing needs, as well as their gender and cultural needs (Hall et. al., 2017). This means that there are several steps that need to be taken before a novice teacher is placed with a mentor. One area that needs to be considered is the novice teachers' personality and needs. Novice teachers and mentors want to be paired with people that possess similar content areas, learning styles, and personalities as themselves (Nasser-Abu Alhija \& Fresko, 2014). This is not often done in the current mentoring culture and has had damaging results for teacher attrition. By forming a relationship with each other, the mentor and novice teacher will feel more comfortable talking about their feelings and will feel that they have the support they need to stay (Farmer, 2020).

\section{Effects of Mentoring on School Culture}

A school's culture consists of organizational structures, formal and informal beliefs and assumptions, and espoused beliefs and values (Bruno \& Taylor-Dunlop, 2013). Mentors must be well rounded in these areas in order to effectively navigate a novice teacher through the complex system that is school culture. Bruno and TaylorDunlop (2013) noted that the school's culture can be positively changed if the school becomes a collaborative, reflective, and constructive working environment. School leaders which invest in their novice teacher's future and create positive experiences for 
them will be more likely to turn a negative school culture into a positive one (Muhammad, 2018). The person at the center of the school's culture is the mentor.

Geeraerts et al. (2015) listed the three supports that a novice teacher needs as professional, personal, and social supports. The professional supports that a novice teacher needs encompasses how well they perform their job, and how it affects their motivation and self-confidence. Geeraerts et al. (2015) concluded that there is a directly proportional relationship between novice teachers' professional performance and their self-efficacy. A teacher must also have personal supports, such as identity development, reaffirming of competency, and safe and nonjudgmental working environments. Teacher networking is one of the most beneficial ways for this to occur (Geeraerts et al., 2015). Novice teachers need socialization to feel like they are part of the school's community. Geeraerts et al. (2015) explained that socialization helps novice teachers to form collaborative groups that promote cooperation, and involvement in and from the school's community. Mentors are key to helping novice teachers develop these relationships that will induct the novice teacher into the school's official and unofficial norms and organizational structures that are necessary to gain acceptance. Geeraerts et al. (2015) suggest that in order to facilitate the induction of the novice teacher, schools need to develop a network of mentors, each with their own area of expertise.

\section{Conclusion}

Mentoring programs have an effect on all areas of an organization. By having a mentoring program, novice teachers gain the expertise of veteran teachers. Through their mentor's expertise, novice teachers are able to improve their communication and 
classroom management skills, develop interpersonal relationships, and grow as leaders (Drew, 2014).

Novice teachers will also form networks of support with other teachers. Through that collaboration, they will learn about the organization's culture and develop positive working relationships. The mentor will gain from the mentoring program as well. By taking on a novice teacher, the mentor gets an opportunity to share their ideas and experiences with another person. The satisfaction the mentor gains from this will help energize the mentor's career through the learning of new techniques and fresh ideas from the novice teacher (Drew, 2014). Finally, the mentoring program has benefits for the school district as well. By having a mentoring program, schools can cut the cost of teacher attrition, which can cost the district as much as $\$ 17,900$ per teacher (Harris et al., 2019). Another benefit to school districts is the opportunity to change negative school culture (Drew, 2014; Muhammad, 2018). 
SECTION FOUR:

CONTRIBUTION TO PRACTICE 


\section{Contribution to Practice}

The researcher will present the findings of this study to the Missouri Association of Secondary School Principals. This organization focuses on providing secondary school principals the resources they need to meet current leadership needs in the state. Attendees will include administrators from across the state. This presentation will assist school leaders as they evaluate their mentoring programs and implement practices based on current teachers support needs.

This presentation will occur after the dissertation defense is complete and the next call for presentation submissions is published on the organization's website. 


\section{Mentoring Programs}

\section{What Mentees Need \\ What Mentors Think \\ What Administrators Need to}

Welcome everyone! My name is Derek Ward. I am a 7th grade science and 9th grade physical science teacher at Park Hills Central. I have been in the teaching profession for 13 years. Over the years I have seen many teachers enter the teaching profession. While we have many teachers who chose to stay in the teaching profession, I have seen many leave it. This presentation will describe the relationship needed between a mentor and mentee that allows for professional and personal growth, as perceived by both mentors and mentees. Now, I will explain why this is important. 


\section{Why are teachers leaving?}

The first few years of a teacher's career is defining (Kozikoğlu, 2018). Many novice teachers enter the profession full of energy, ideas, and a willingness to make a difference. They are proud to have the opportunity to teach others in a positive and meaningful way. The experiences of a first-year teacher will be a key influence on whether or not they will continue in the field of education (Kozikoğlu, 2018). However, once a teacher enters the field, the realities of the teaching profession can be a stark contrast to what they envisioned. Teacher salaries are $20 \%$ lower than those with a comparable degree. Also, according the the National Center for Educational Statistics (n.d.), a teachers salary was $1 \%$ lower in 2016 than it was in 1991 when you adjust for inflation. Teachers are also leaving the profession within the first three years because they lack support and training, which cost districts money for the recruitment and hiring of new teachers (Harris et al., 2019). 


\section{What can mentoring do?}

Mentoring programs have an effect on all areas of an organization. By having a mentoring program, novice teachers gain the expertise of veteran teachers. Through their mentor's expertise, novice teachers are able to improve their communication and classroom management skills, develop interpersonal relationships, and grow as leaders (Drew, 2014).

Novice teachers will also form networks of support with other teachers. Through that collaboration, they will learn about the organization's culture and develop positive working relationships. The mentor will gain from the mentoring program as well. By taking on a novice teacher, the mentor gets an opportunity to share their ideas and experiences with another person. The satisfaction the mentor gains from this will help energize the mentor's career through the learning of new techniques and fresh ideas from the novice teacher (Drew, 2014). Finally, the mentoring program has benefits for the school district as well. By having a mentoring program, schools can cut the cost of teacher attrition, which can cost the district as much as $\$ 17,900$ per teacher (Harris et al., 2019). Another benefit to school districts is the opportunity to change negative school culture (Drew, 2014; Muhammad, 2018). 


\section{Statement of the Problem}

* While research has been conducted on mentoring programs and their effectiveness, schools have not implemented a mentoring program that fully addresses all of the new educator's and school's needs (Nasser-Abu Alhija \& Fresko, 2014).

- Most studies of new teacher mentoring have only studied the effectiveness of teacher mentoring or the effects of mentoring versus no mentoring. These limitations have left a gap in research that links the characteristics and responsibilities of a mentoring program to professional and personal growth.

We all know people who have left a school because they felt unsupported and some who have left because they felt they were outsiders and unwelcome. By not providing novice teachers with the support they need, we push out talented educators who could have had a positive impact on student lives, the school district, and the profession as a whole.

How do we keep talented teachers in the classroom and give them the support they need? What is it that THEY say they need? 


\section{What do We Know About Mentoring}

- Reduces time to become a proficient teacher

- Allows for personal and professional growth

- Provides support

* Required in Missouri

Novice teachers are expected to be as proficient and as skilled as their veteran counterparts (Kozikoğlu, 2018). In other professions, novice workers are given time to acclimate to their surrounding and job. However, in the education world, we hit the ground running. We are expected to be masters of curriculum and classroom management. New teachers are not only juggling those responsibilities, but also being assigned extra duties on top of that. As educators, we simply do not get the time to adjust to our roles.

Geeraerts et al. (2015) listed the three supports that a novice teacher needs as professional, personal, and social supports. Often, teachers have trouble separating their personal and professional lives (Jyoti \& Sharma, 2017). Whether it is the pressure of getting grades in the grade book by the school's deadline, running copies, or developing lessons for the next unit, novice teachers often feel like time is running out. While outspoken teachers are able to create social networks that allow them to navigate this work/home balance, teachers who are more reserved struggle to cope with work and personal issues alone. For these teachers, a mentor is not only a professional coach, but a life balance ally. By providing the novice teacher with the support they need, the novice teachers' emotional needs are also met, leading to greater teacher efficacy.

Two years of mentoring is required to obtain a teacher's Career Continuous Certificate (Missouri Department of Elementary and Secondary Education, 2020). Though mentoring is required for a teacher to obtain their Career Continuous Certificate, the state leaves how it is operated up to the local school districts. However, the state does give guidance on what should be incorporated into their mentoring programs (Missouri Secretary of State, n.d.). State law suggests that a mentoring program should be teacherdriven, administrator supported, and given to all new teachers (Missouri Senate Missouri General Assembly, n.d.). 


\section{Purpose of the Study}

* The purpose of this study is to study mentor and mentee perceptions of the mentoring program in Missouri.

- This study focused on the relationship needed between a mentor and mentee that allows for professional and personal growth, as perceived by both mentors and mentees.

The purpose of this study is to study mentor and mentee perceptions of the mentoring program in Missouri. 


\title{
Design of the Study
}

\author{
- Site Selection \\ - Six Missouri Public Schools \\ - Two large schools with student population larger \\ than 3000 \\ - Two midsized schools with a population of 1000-2999 \\ * Two small schools with a population of 148-999
}

For this study, I used only public schools. Six Missouri Public Schools were chosen to participate in the study. The schools were then classified as a small, midsized, or large school district based on population. School districts with a student population larger than 3000 students were classified as a large school, schools with a population of 1000-2999 students were considered midsized schools, and schools with a population of 148-999 students were classified as small schools. Interviews took place online using zoom due to the COVID pandemic. 


\title{
Design of the Study
}

\author{
- Participant Selection \\ - Contacted Superintendents and Principals for Mentor and Mentee \\ Participants \\ * Selected Two Mentor/Mentee Pairs Per School District \\ * Interview Totals: \\ - Mentors- 12 \\ - Mentees- 12
}

To find participants for this study, I first reached out to superintendents and building principals and asked if they had any mentor and mentee pairs that I could interview for the study. They then put me in contact with the mentor and mentee pair of their choice. 


\section{Design of the Study}

\section{- Data Collection and Analysis}

- Interviews of Participants Were Held Via Zoom

- All Interviews Were Recorded and Transcribed

- All Information is Confidential and Pseudonyms Were Used

- Transcripts Were Coded and Themes Emerged

Due to the COVID pandemic, all interviews were held via Zoom. The interviews lasted between 25-30 minutes. Interviews were then transcribed and coded. Codes were then organized to discover themes. 


\title{
Design of the Study
}

\author{
- Limitations and Assumptions \\ * COVID-19 Pandemic \\ - Expanded Search Area \\ - Researchers Bias
}

Due to the COVID pandemic, all interviews had to be held via Zoom. This restricted the collection of data from the participants natural background.

Due to low response rate for the southeast region of the state, I had to expand the study to have enough participants to reach saturation.

As an educator, I had biases toward the mentoring program. In order to eliminate their effects on the study, care was taken to eliminate those biases and maintain an ethical approach to it. 


\section{Findings}

- Mentee Responsibilities

* Mentor Responsibilities

- Mentor Supports

* Program Concerns and Improvements

There were four important findings. They are: Mentee Responsibilities, Mentor Responsibilities, Mentor Supports, and Program Concerns and Improvements. 


\section{Findings}

\section{* Mentee Responsibilities}

- Take and use advice

* Be vocal and communicate

* Follow guidelines and expectations

Mentees are the second half to the mentor/mentee relationship. As such, the participants believed they play a part in the teacher induction process. This is something we all know. But what responsibilities should be placed on the new teachers shoulders? The participants agreed on three main responsibilities.

The first was that the mentee needs to take the advice of the mentor and use it in their own unique way. I know! It sounds like the old familiar, "Do as we command you to do and you will be ok!" But, spoiler alert, the mentees also said this was important! Michael, a mentee, said, “...take the advice and take the feedback and be a sponge. And don't take it personally that they're giving you feedback, giving you advice, to better you and help you, you know, develop as a teacher."

The second responsibility the mentors and mentees thought was important was for the mentee to be vocal and communicate with their mentor what they need. New teachers can be shy. Shelly said, "they should be responsible, if they're struggling, or if they're having trouble with something, they definitely need to talk to their mentor, and just say, 'I don't know what to do.'" Jim explained, "I think it's also like a two-way road. So, I need to make sure that I'm communicating with them every day. I think that should be a responsibility that it's not just them always checking in..."

Mentees also need to follow the school guidelines and be cognizant of the expectations of the school. Peggy said, "You know, just kind of following the expectations that our principal has set for us as far as being a classroom teacher." 


\section{Findings}

\section{- Mentor Responsibilities}

* Building leader

- Beginning of the year responsibilities

- Guidance and feedback responsibilities

* Mentor administrative responsibilities

Being a mentor is a huge responsibility and can test even the best of teachers. They often are over worked and underpaid, if paid at all. Mentors are asked to not only to teach their normal classes, but also teach a new teacher how to teach themselves. If that was a mouthful to to hear, it was defiantly a mouthful to say! This study asked mentors and mentees what they felt were the responsibilities of the mentor. A majority of the participants had four major responsibilities.

The first one was that the mentor does not need to be a department head, but someone who can lead a mentee to success. Eliza explained, “...it ultimately just boils down to being able to help someone through their curriculum through classroom management..."

The second responsibility that the mentor is responsible for is getting the mentee ready for day one. That entails knowing expectations, formal and informal policies, introducing the mentee to other staff, classroom setup, guiding them through the school's curriculum, answering questions, and (this is important) accept them as peers. Maria stated, "You don't want to be treated like you, you don't have anything to offer you might be fresh out of college. You may not have that experience, but surely there's something you've learned in those four years of college."

Participants also believe the mentor needs to provide guidance and feedback to the mentee. This entails working and collaborating together. Both parties gain from this. The mentees shared their new knowledge to help the mentors teaching, and vice versa.

The participants also expressed that there were some administrative duties that the mentor should be responsible for. One was knowing the procedures of the building. They need to be able to tell the mentee what the procedures are for safety drills, early outs, field days, and all of the formal procedure of the building. They also believe it was the mentor's job to take care of the paperwork. Logging PD hours, mentee program tasks, and making sure the mentee knows what they are supposed to be doing for licensure. 


\section{Findings}

\section{- Mentor Supports}

- Supportive Traits

- Supportive Actions

The mentors and mentees also listed some supports that the mentor can give to ensure the mentee is successful. These supports are divided into two categories: Supportive Traits and Supportive Actions.

A person's character can make or break a mentoring relationship. Compassionate, understanding, honest, caring, comforting, friendly, approachable, patient, and trustworthy were the top traits mentees said they needed from their mentor.

Then there are the supportive actions that the mentor can take to make the mentee feel comfortable and accepted. The first one was to welcome and introduce the mentee to other people and make them feel welcome to get them comfortable with the environment. Another action is to be available for help to the mentee. Do not find reasons they cannot help at the moment. Tasks can wait, a person in need cannot. The mentor also needs to be an emotional support for the mentee. Karen spoke about the need for a mentor to be emotionally supportive and how it was a positive impact on her. She said, "There have been moments where I've gone into her room crying. And just because I had such a long day, and I couldn't stop just because I was at that point of, like, exhausted, COVID, everything. But, I was supposed to teach a class in a moment. And so, she was like, 'Yep. Okay, you stay in here. You sit in my room and cry, and I'm gonna go teach your class."' 


\section{Findings}

* Program Concerns and Improvements

- Program implementation

- Time together

* Low empathy in program design

- Mentor Selection

Though the program seems to be successful, everything can be improved. The participants held nothing back. One of the concerns participants had was that in some cases the program had fallen to the wayside and not been implemented. Some had no clue what the mentoring program was. They thought they were just given a "go to" person for help. Another implementation issue they brought up was not knowing what their expectations were. Lisa had this to say, "We haven't really been given any structure about what a mentor should do. I'm just mentoring from the heart, I guess."

Time with each other was also a negative. They either had separate plan periods, worked in different departments, or even were in completely different buildings. Louise noted, "The bad, to me... it's just been not enough time, really, to talk."

As stated before, there is a lack of empathy. Nellie said, "It is very by the book. It's very non-emotionally nurturing. I think that's probably why there is burnout. It is very dry. We check our emotions at the door every day. I think that's the norm here, and I don't appreciate that."

Finally, schools should not pick teachers to be mentors because they are just an available person, want the status of being a mentor, are unwilling, or a combination of any of the above. 


\section{Recommendations}

- Add emotional support

- Ensure the mentor is willing

- Overhaul first year meetings

- Partner with other schools for observations

- Make mentoring accountable 


\section{Recommendations}

\section{Add emotional support}

Schools need to add a level of emotional support for mentees in their program. As participants have noted, education is a stressful time for new teachers. They are overwhelmed with expectations, extra-curricular responsibilities, and often living on their own for the first time in their life. This adds to the stress of uncertainty and making sure the curriculum is correct. New teachers need to have a safe person to vent to who will keep their conversation confidential. They also need to be encouraged to take time off for their own mental health and decompress. 


\section{Recommendations}

\section{Ensure the mentor is willing}

While the mentors who were interviewed were all willing mentors, there were several participants who told stories of mentors who did not want the job, but were assigned it. Both mentors and mentees had heard of a mismatch between the mentor and mentee that ultimately left the mentee, and themselves, feeling discouraged and not feeling like an equal in the building. This leads to the recommendation that administrators need to find willing mentors for their new teachers. Being paired with someone in their own department is not as beneficial to having a willing mentor that can work well with the mentee. If the mentoring pair is not a good fit, the school needs to allow the mentee to switch mentors. This can either be to a teacher they have developed a rapport with or to someone in the building who is helpful and personable. 


\section{Recommendations}

\section{Overhaul first year meetings}

New teachers are not only bombarded with learning the ropes of being the classroom teacher, but in some cases they are given the hardest positions, unwanted extra duties, and some will be coaching a sport. The mentees enjoyed the monthly meeting when they were thoughtful and meaningful to their needs. While learning teaching strategies is an important component to continuing professional development, many new teachers have just finished a program where those are taught. Meredith also explained, "I went to school for 4 years for this degree but every school operates differently and the program has guided me in a more independent direction." This leads me to suggest that the first year of orientation should focus on the emotional and professional wellbeing of the mentee. It is also recommended for the administrator to ask, "Is this meeting beneficial?" If the answer is yes, then every first-year teacher needs to be in attendance. If it is ok for the coach or sponsor to not be there, then why do the others need to be there? Mentoring program meetings need to take priority.

Mentors and mentees in the study have mentioned that the use of a mentor/mentee handbook was beneficial. However, the handbook needs to be utilized as a tool for the program, not a substitute for it, as the study found was the case with some schools. The handbook should include a checklist so the mentor and mentee pair fully understand what they need to get done together and individually and the timeline for completion, lay out the measurable responsibilities of each person, list procedures for switching mentors when the relationship is not working, and provide resources for professional development. Also, list any dates that are relevant for meetings and make sure the mentor and mentee understand that these are mandatory and they should plan around them. 


\section{Recommendations}

\section{Partner with other schools for observations}

Being a first-year teacher is daunting. Being a first-year teacher in a smaller district where they are the only teacher of a particular subject can be even harder. Having a mentee in the school is important, but a new teacher needs to be able to talk to another teacher of the same subject to get their perspective as well. One thing this study found was that the new teachers did not know if they could go to another school outside the district to observe other similar subjects. As Kevin stated when talking about his mentor not having all the answers, "[I am] recognizing that not all the answers are at my school, it's kind of pushed me into these other ways of learning." Schools can benefit from crossdistrict learning. This will enable a new teacher to see multiple perspectives and give them greater resource to work with which will, in turn, benefit the student. 


\section{Recommendations}

\section{Make mentoring accountable}

During interviews, some mentors mentioned they were paid and some mentioned that they were not. When the mentor is paid, the amount paid to the time needed to execute the job properly was inadequate. The most the participants were paid was $\$ 200$ for the year. Furthermore, mentoring is not a contracted position and cannot hold a teacher accountable for their responsibilities as a mentor. When taking these two things into account, there is no incentive for success. It is the researcher's recommendation that schools hold mentors accountable for the responsibilities the district places on them and compensate them as they would a minor sport coaching position. By paying mentors a reasonable salary and having set expectations, the school can ensure each mentee is getting the support they need and the district should increase teacher retention. 


\section{Future Research}

- What were the perceptions of teachers who did leave the profession?

* The study could be completed over a longer term.

The study only interviewed novice teachers who are currently in the teaching profession. Future studies should include those teachers who have left the teaching field during their first or second year.

This study was a cross sectional study, which ascertained how teachers felt about the mentoring program at one moment in time. This study could be repeated to follow first year teachers in the state through to the end of their second year to see if their perceptions change over time. 


\section{Questions?}

Mentoring is vital to the success of all of our teachers. When we invest in them and support the growth of new teachers, we are supporting and nurturing the students we serve. Thank you all very much for your time! Does anyone have any questions? 


\section{References}

Andrews, B. D., \& Quinn, R. J. (2004). First-Year Teaching Assignments a Descriptive Analysis. Clearing House, 78(2), 78.

Drew, J. (2014). How to Start and Run a Mentoring Program. Journal of Accountancy, 217(3), 34-39.

Geeraerts, K., Tynjälä, P., Heikkinen, H. L. T., Markkanen, I., Pennanen, M., \& Gijbels, D. (2015). Peer-group mentoring as a tool for teacher development. European Journal of Teacher Education, 38(3), 358-377. https://doi.org/10.1080/02619768.2014.983068

Harris, S. P., Davies, R. S., Christensen, S. S., Hanks, J., \& Bowles, B. (2019). Teacher Attrition: Differences in Stakeholder Perceptions of Teacher Work Conditions. Education Sciences, 9.

Jyoti, J., \& Sharma, P. (2017). Empirical investigation of a moderating and mediating variable in between mentoring and job performance: A structural model. Revista de Psicología Del Trabajo Y de Las Organizaciones, 33(1), 55-67.

\section{References}

Kozikoğlu, İ. (2018). A metaphorical analysis of novice teachers' perceptions concerning first year in teaching, induction process, school administrators and mentor teacher. Educational Research Quarterly, 42(1), 3-44.

Missouri Department of Elementary and Secondary Education (2020). Initial Student Services. https://dese.mo.gov/educator-quality/ certification/initial-student-services

Missouri Secretary of State. (n.d.). Retrieved June 4, 2020, from https://www.sos.mo.gov/

Missouri Senate - Missouri General Assembly. (n.d.). Retrieved June 4, 2020, from https://www.senate.mo.gov/

Muhammad, A. (2018). Transforming school culture: How to overcome staff division (Second edition). Solution Tree Press, a division of Solution Tree.

NCES Fast Facts Tool provides quick answers to many education questions (National Center for Education Statistics). (n.d.). Retrieved April 14, 2019, from https://nces.ed.gov/fastfacts/display.asp?id=28 
SECTION FIVE:

CONTRIBUTION TO SCHOLARSHIP 


\section{Mentoring in Missouri Schools: How Mentoring Fosters \\ Professional and Personal Growth}

The first five years of an educator's career are the most important time in determining if they will stay in the education profession. To help them navigate through the first few years of teaching and to increase retention, Missouri has adopted a mentoring policy. This narrative study describes mentee and mentor perceptions on the effectiveness of the mentoring program and how they feel it affects their professional and personal lives. This study opens the doors to what mentees and mentors feel is beneficial about the mentoring program and what is needed to make it better.

\section{Key Words}

Mentee, Mentor, Mentoring Program, Novice Teacher, Personal Growth, Professional Growth, Retention, Veteran Teacher.

\section{Introduction to the Background of the Study}

Historically, the role of teaching holds high esteem in American society (Muhammet \& Sarigöz, 2018). Teachers are an important factor in using the insights they have developed with students. Teachers also guide students to reach their goals. Muhammet and Sarigöz (2018) notes that teachers support students' individual and economic growth due to the influence they have on the students' life and career path. Preparing students to meet the challenges of a dynamic twenty-first century requires competent educators from the beginning to the end of their career. The mentor is a key player in developing competent educators that endure the hardships of the first five years of teaching. 
The first few years of a teacher's career is defining (Kozikoğlu, 2018). Many novice teachers enter the profession full of energy, ideas, and a willingness to make a difference. They are proud to have the opportunity to teach others in a positive and meaningful way. Further, they have high expectations of the teaching experience (Muhammet \& Sarigöz, 2018). Kozikoğlu (2018) states that the experiences of a firstyear teacher will be a key influence on whether or not they will continue in the field of education. If their first-year is seen as a success, then first-year teachers will persist and continue to grow in their profession. However, if a novice teacher fails, then they are more likely to be either a leaver or a mover. Leavers are educators who leave the profession completely, and movers are those who move from one district to another (Carver-Thomas \& Darling-Hammond, 2017).

Teachers may choose to leave the education profession for many reasons. Low salary and the deterioration of teacher status in the labor market contributes to a novice teacher's decision to stay in the teaching profession or leave it (Harris, Davies, Cristensen, Hanks, Bowles, 2019). Furthermore, teacher salaries are 20\% lower than those with a comparable degree. The National Center for Educational Statistics (n.d.) indicated the average national teacher's salary was 1\% lower in 2016 than it was in 1991, when adjusted for inflation. Educators have also seen a government policy shift which has taken the ability to have control and autonomy in the classroom out of their hands. Finally, teachers are leaving the profession because they lack support and training, which costs districts money for the recruitment and hiring of new teachers (Harris et al., 2019).

Because mentoring has shown to be a key factor in teacher retention, many districts have mentoring programs (Nasser-Abu Alhija \& Fresko, 2014). Mentoring is 
also used to acclimate novice teachers to the policies and procedures needed to be successful in their new position. Mentors work to develop novice teachers' essential skills through careful observations and effective feedback (Callahan, 2016). Mentors seek to increase a mentee's skills in classroom management, relationship development with both students and teachers, and increase the level of pedagogy by offering a high level of support. By developing the skills and competency needed for success in the classroom, mentors provide the key support that novice teachers need in their first few years of teaching. Mentoring experiences for novice teachers have shown promise for retaining competent and skilled teachers. Unfortunately, mentoring programs offer a narrow path for improving the first-year teaching experience. While mentoring has been effective in many schools, some may not be meeting the needs of their novice teachers.

\section{Statement of the Problem}

While research has been done on mentoring programs and their effectiveness, schools have not implemented a mentoring program that fully addresses all of the new educator's and school's needs (Nasser-Abu Alhija \& Fresko, 2014). This means that current mentoring programs are basic in scope, but fail to support the new teacher, nor do mentoring programs include the school's culture into their mentoring goals (Farmer, 2020). Due to this, between $20 \%$ and $50 \%$ of novice teachers leave the teaching profession within the first five years of teaching, most leaving within their first two years (Farmer, 2020).

New teachers need to feel that they are supported adequately by both administration and other teachers in the acclamation to the teaching profession and their community (Farmer, 2020). According to Dias-Lacy and Guirguis (2017), even though 
teachers receive mentoring, often the personalities between the mentor and novice teacher do not match, leading to unsuccessful growth. Farmer (2020) tells us that novice teachers are leaving due to difficult assignments, vague expectations, lack of resources, isolation, and the realities of teaching versus what they expected from the profession. Novice teachers are also expected to be proficient and as skilled as their veteran counterparts (Kozikoğlu, 2018). Not only is proficiency an issue, but the teaching assignments could be demanding. Kozikoğlu (2018) reported that novice teachers usually perform the responsibilities that other veteran teachers do not want to perform. With all of the responsibilities that novice teachers have placed on them, many new teachers are losing the initial drive that drove them to the teaching profession (Callahan, 2016). With the establishment of a mentoring program, schools can provide the professional and emotional supports novice teachers need to navigate the barriers they may face in the first five years in the field of education.

\section{Mentor}

Current mentoring programs place extra responsibility on the mentor, as they have to plan mentoring sessions outside of contracted time, often with little to no compensation (DeCesare, Workman, \& McClelland, 2016). Mentors are also lacking leadership training that is key to giving feedback that new teachers need to grow both personally and professionally (Callahan, 2016). A study by Nasser-Abu Alhija and Fresko (2014) describe a lack of structured professional development for the mentor. The lack of professional development, training in leadership, and developing interpersonal and networking skills leave mentors ill-prepared to perform the job (Callahan 2016; Israel, Kamman, McCray, \& Sindelar, 2014). 


\section{School}

Though research has shown the effectiveness of mentoring, schools may not have the resources necessary to have an effective mentoring program (Hall, Hughes, \& Thelk, 2017). Schools often ask the principal to assign a mentor, forgetting about the issues of mentor/mentee compatibility and lack of mentor training (Hall et al., 2017). In some school districts, mentors are assigned based on their willingness to do the job (Marker, Mitchall, \& Lassiter, 2013). With few people willing to be a mentor, novice teachers may not be paired with a mentor that teaches the same subject or grade level. The average cost of replacing a teacher in 2007 was $\$ 8,000$ (Callahan, 2016). Without mentors that can provide the supports that novice teachers need, school districts will continue to spend thousands of dollars to recruit and train replacement educators.

\section{Gap in Research}

Most studies of new teacher mentoring have only studied the effectiveness of teacher mentoring or the effects of mentoring versus no mentoring. These limitations have left a gap in research that links the characteristics and responsibilities of a mentoring program to professional and personal growth.

\section{Purpose of the Study}

The purpose of this study is to study mentor and mentee perceptions of the mentoring program in Missouri. Mentors are often not prepared with the right skills and tools to give a novice teacher the support they need (Russell \& Russell, 2011). If the mentor does not receive the training they need to guide a novice teacher, the amount of guidance the novice teacher receives is inconsistent and will have to rely on the school to provide additional support. Mentors are also not given the professional development they 
need in leading conversations about performance, developing intrapersonal skills, and how to network with other mentors in the district/area (Israel et al., 2014). While some states require schools to have a teacher induction program, others have pulled funding from their mentorship programs and reduced the number of mentored years from three to two years (Marker, Mitchall, \& Lassiter, 2013). Due to decreased funding, schools are not able to invest in proper mentorship for novice teachers, which leaves novice teachers feeling lost and ill-prepared. Therefore, this study will focus on the relationship needed between a mentor and mentee that allows for professional and personal growth, as perceived by both mentors and mentees.

\section{Research Questions}

The research questions guiding this study are:

4. What characteristics of a mentor are prevalent in a mentoring program, as perceived by the:
(a) Mentor
(b) Mentee

5. What are the responsibilities to each other in a mentor/mentee relationship, as perceived by the:
(a) Mentor
(b) Mentee

6. How does the current mentoring model assist in a mentor and mentee's professional and personal growth according to the:
(a) Mentor
(b) Mentee 


\section{Theoretical Framework}

The theoretical framework of this study borrowed from Day and Allen (2004) and Kram's (1983) mentoring theory. This theory states that through psychosocial support, a mentor can increase a mentee's sense of competence, confidence, and self-esteem (Kram, 1983). By increasing a mentee's self-worth, confidence, and job knowledge, a mentee will have a greater sense of career self-efficacy. Using Day and Allen's (2004) mentoring theory, a connection can be made from mentoring to teacher retention. The effects that a mentor has on a novice teacher is substantial. Mentors can increase career commitment, which then leads to goal setting and an increase in the novice teacher's pedagogical knowledge. Due to this support, the novice teacher develops a positive outlook and will continue in the education profession.

However, teaching is more than knowing what to teach. A novice teacher must develop supportive relationships with the administrators and teachers with whom they work. Mentoring should also encompass relationship development and how to balance professional and work balance. By developing relationships within the school, a teacher gets introduced to the school climate and culture. Day and Allen (2004) say that new employees also have a hard time separating work and home life, which can lead to burnout. By having a mentor who can help navigate these two aspects of relationship development, a teacher will hopefully develop a positive support system and feel comfortable staying in the teaching profession. The researcher developed Figure 1 to show the path from mentoring to teacher retention.

Figure 1. Path of mentor responsibilities. 


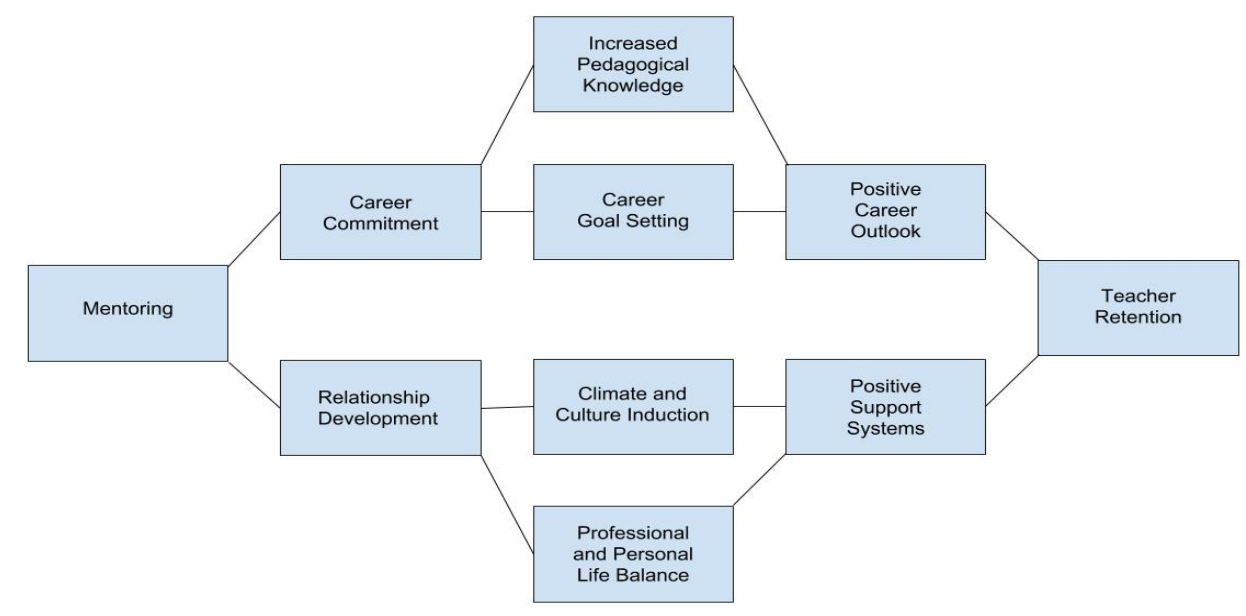

Mentoring is an important part of the networking process for a mentee. Jyoti and Sharma (2017) state that employees who are properly mentored will speak freely and openly about their problems. Mentored employees will have the confidence needed to seek help from others in the organization. By being open and honest, mentees will grow confidence, be able to learn new skills, and build a diverse system of networks within the organization. Experienced mentors have a knowledge base that young, inexperienced educators can tap into and learn from (Dias-Lacy \& Guirguis, 2017). To do this, mentors must be willing to take on the task and time commitment necessary for proper mentoring to occur (Nasser-Abu Alhija \& Fresko, 2014).

\section{Design of the Study}

This qualitative narrative study sought to understand how the participants experience the mentoring program. Abkhezr, McMahon, Campbell, and Glasheen (2020) describe narrative research as a way to give people a voice who otherwise would never be heard. Creswell (2014) says that narrative research seeks to study the lives of individuals through the stories they tell about their life. Therefore, this qualitative study sought to answer the research questions by letting the participants tell their "story" of the mentoring program. Since the narrative study sought to understand the experiences of the 
participants, this study was viewed through the interpretive epistemological perspective (Merriam \& Tisdell, 2016).

\section{Setting}

Public K-12 schools in Missouri represented the setting for this study. The study consisted of six schools in the state: two large schools, two midsized schools, and two small schools. The schools were classified as a small, midsized, or large school district based on population. Schools with a student population larger than 3000 students were classified as a large school, schools with a population of 1000-2999 students were considered midsized schools, and schools with a population of 148-999 students were classified as a small school. Interviews took place online using zoom due to the COVID pandemic. Figure 2 gives an overview of the schools selected for the study.

Figure 2. Schools participating in the study.

\begin{tabular}{|l|c|c|}
\hline \multicolumn{3}{|c|}{ Schools Interviewed } \\
\hline \multicolumn{1}{|c|}{ School } & Approximat Enrollment & Average Teacher Experience \\
\hline Adams School District & 400 & 10 \\
\hline Anderson School District & 4000 & 10 \\
\hline Chilton School District & 2800 & 12 \\
\hline Everest School District & 1300 & 13 \\
\hline Sundale School District & 400 & 8 \\
\hline Welton School District & 4000 & 12 \\
\hline
\end{tabular}

\section{Participants}

The participants of this study consisted of mentors and their second-year mentees. School superintendents and principals were contacted by email to obtain the names of the mentors and mentees (Appendix A) and to ascertain their willingness to provide the names and contact information for the mentors and mentees in their school who might be willing to participate in the study (See Appendix B). Two mentors and two of their mentees were then selected from each of the six school districts selected, for a total of 
four participants per school and 24 participants total. Mentors and mentees were then

personally contacted and invited to participate. Once both the school and the teachers had consented to be part of the study, Zoom invitations were sent to each of the participants to be interviewed. Figure 3 shows the participants interviewed.

Figure 3. Participants interviewed.

\begin{tabular}{|l|c|c|c|}
\hline \multicolumn{4}{|c|}{ Participants } \\
\hline Name & Role & Years of Experience & School \\
\hline Angelica & Mentee & 1 & Welton School District \\
\hline Eliza & Mentor & 23 & Welton School District \\
\hline Holly & Mentor & 23 & Chilton School District \\
\hline Jan & Mentor & 6 & Raymore School District \\
\hline Jessica & Mentee & 2 & Chilton School District \\
\hline Jim & Mentee & 1 & Sundale School District \\
\hline Karen & Mentee & 2 & Raymore School District \\
\hline Kelly & Mentee & 1 & Raymore School District \\
\hline Kevin & Mentee & 2 & Chilton School District \\
\hline Linda & Mentee & 1 & Sundale School District \\
\hline Lisa & Mentor & 9 & Adams School District \\
\hline Louise & Mentor & 13 & Adams School District \\
\hline Maria & Mentee & 3 & Adams School District \\
\hline Meredith & Mentee & 2 & Anderson School District \\
\hline Michael & Mentee & 2 & Anderson School District \\
\hline Nellie & Mentor & 14 & Welton School District \\
\hline Pam & Mentor & 30 & Chilton School District \\
\hline Peggy & Mentor & 11 & Anderson School District \\
\hline Phyllis & Mentor & 10 & Welton School District \\
\hline Shelly & Mentor & 5 & Anderson School District \\
\hline Tammy & Mentee & 1 & Sundale School District \\
\hline Tina & Mentor & 26 & Adams School District \\
\hline Tori & Mentor & 12 & Raymore School District \\
\hline
\end{tabular}

\section{Data Collection}

Data collection began by identifying the schools and the participants to be studied. Semistructured interviews consisting of 10-12 questions (Appendix B) allowed 
for follow-up questions to be asked during the interview to explore additional views of the interviewee. The interviews took approximately 40-50 minutes to complete.

Interviews with mentors and mentees were completed to collect data on how they perceived the mentoring process and how it has allowed them to grow professionally and personally. Interviews were also held with mentors and their mentees to determine their perceived responsibilities to each other in a mentor/mentee relationship. In other words, what do they believe their responsibilities are to each other? During all stages of data collection, artifacts were used to assist in obtaining a clearer picture of how schools prepare teacher mentors and determine the success of the program. Examples of such artifacts were state mandated policies and school board policies, if available. These artifacts were used to determine if the school's policy aligns with the mentor and mentee's expectations of the mentoring program.

\section{Data Analysis}

Interviews were transcribed verbatim and themes were developed. These themes remained fluid as data were collected and compared to each other (Merriam \& Tisdell, 2016). The phenomenon used were repeated words or phrases and contrasting data (Techniques to Identify Themes in Qualitative Data, n.d.). Creswell (2014) recommends sorting data into five to seven themes that can be interconnected. After sorting data into four themes, a word wall was created with each set of key words placed into a theme. Five outside review colleagues then checked the boards and moved words into the categories they thought the data belonged with. Once the outside review members finished, the themes were finalized. 


\section{Results}

After the analysis of the interview transcripts, the researcher gained a better understanding of mentors and mentee perceptions of the effectiveness of Missouri's mentoring program and how it allows for them to grow professionally and personally. Each participant gave the researcher a unique perspective to what they felt was important for a new teacher to succeed and the supports that should be present to allow for growth.

\section{Research Question One: Characteristics}

The first research question asked the participants what characteristics of a mentor they thought were prevalent in the mentoring program. There were five traits that both the mentors and mentees believed were the most important. Eighteen of the 24 participants noted good mentors should be supportive. Support also encompassed being helpful and providing emotional support. Participants believe that the first few years are hard on a mentee both mentally and physically. Having someone they trust and will be supported by was important for their success. Participants also said that a mentor needed to be knowledgeable. They noted that the mentor needed to know the inner and outer workings of the school. This involves showing them how to navigate curriculum, introduce them to other teachers and help them build relationships with others. This also involved letting them know the key people in the building. They also believed that mentors needed to be willing to share their knowledge with the mentee. This goes along with their belief that the mentor needs to be experienced. This experience took the shape of a teacher having seen changes in the school over time, having worked through what worked and did not work in the classroom, and their perspective on ideas based on their lived experience. 
Several traits were deemed to be negative in a mentor and mentee relationship. Not being open to the new teachers' suggestions and input was one of the less desirable traits. Participants explained that by not being open to others ideas that it shut down the new teacher and caused them to not feel like part of the team. Mentors not being willing to help the mentee is also detrimental for the mentee. Participants noted that mentors should be willing to share their knowledge and help the mentor when they need it. Lastly, participants explained that a mentor that is too set in their ways can have a negative impact. This is because they are either not wanting to be a mentor, or unwilling to try new things.

One characteristic that participants had differing viewpoints on was if a mentor should be a leader within the school. One mentor said that a mentor did not need to be a leader in the building, but helpful and knowledgeable about the curriculum and classroom management. Others had a differing view. Two participants thought that the mentor needed to be a leader. One explained they thought the mentor needs to be a naturally good leader to lead them through the initial first few years of being a teacher.

\section{Research Question Two: Responsibilities}

The second research question asked what participants believed their responsibilities were to each other. Mentees should listen and take advice that the mentors give them. One mentor noted that it is concerning when they give advice to the mentee that they should follow and they do not listen to it. Another responsibility the mentee should be responsible for is following the guidelines and school expectations. Keeping an open line of communication was the main responsibility that most of the participants said was important for the mentor and mentee relationship. They said the 
mentee needs to take the initiative to speak out when they need help or something is not working.

Participants thought mentors should help the mentee get ready to start the school year. This entailed getting acquainted with the building, setting their classroom up, getting familiar with the gradebook system, and anything that helps them get the year stated. They should also be available to answer questions and collaborate with the mentee. Mentees said they want to be viewed as peers and want to be able to collaborate with their mentor. As new teachers, they expressed the need to be able to freely ask questions and receive feedback on what they are doing. Both the mentors and mentees believed that it was the mentor's responsibility to take care of the administrative aspects of the mentor and mentee program. Those administrative duties include making sure the mentor/mentee checklist is being completed and the supporting documents are being collected. Other administrative duties also entailed scheduling observations and keeping up with professional development logs.

\section{Research Question Three: Professional and Personal Growth}

The third research question asked the participants how the current mentoring model assists in their professional and personal growth. The participants said the mentoring program has helped them professionally by giving them someone to collaborate with and share ideas and strategies. Mentees in the program noted that it has given them support and helped to boost their confidence. One mentee said it inspired him to find his own professional development. Some did say it was not the school's program that helped them, but having a person that they could talk to and get ideas from. Mentors 
expressed it makes them want to be a better teacher, keeps them motivated to do new things, and learn new tricks from the younger teachers.

The mentors and mentees expressed growth in their personal life from the process. Mentees expressed it has made them grow from just being a student into a working adult. It also forced some of the mentors to come out of their shell and build relationships they otherwise would not have formed. Mentees also expressed that having a mentor has helped their confidence grow as a person. One of the ways that both the mentee and mentor believe they have been personally impacted is becoming more patient.

Mentors said they feel they are seen as a leader in the building. They also reported they feel more supportive since they became a mentor. Mentors also said that being a mentor has taught them to be more compassionate and realize they do not have all of the answers. Some of the mentors also stated they have developed personal friendships with their mentees.

\section{Recommendations}

Based on interviews with both the mentees and their mentors, the mentoring program is not being implemented in a unified manner that benefits novice teachers the same throughout Missouri. While some schools received praise for their program from all of its participants, some had no indication of what the mentoring program was. However, all programs did express that there were some key components they felt were missing. This informed the researcher to suggest the following design changes to the mentoring program. 


\section{Add Emotional Support}

Schools need to add a level of emotional support for mentees in their program. As participants have noted, education is a stressful time for new teachers. They are overwhelmed with expectations, extra-curricular responsibilities, and often living on their own for the first time in their life. This adds to the stress of uncertainty and making sure the curriculum is correct. New teachers need to have a safe person to vent to who will keep their conversation confidential. They also need to be encouraged to take time off for their own mental health and decompress.

\section{Ensure the Mentor is Willing}

While the mentors who were interviewed were all willing mentors, there were several participants who told stories of mentors who did not want the job, but were assigned it. Both mentors and mentees had heard of a mismatch between the mentor and mentee that ultimately left the mentee feeling discouraged and not feeling like an equal in the building. This leads to the recommendation that administrators need to find willing mentors for their new teachers. Being paired with someone in their own department is not as beneficial to having a willing mentor who can work well with the mentee. If the mentoring pair is not a good fit, the school needs to allow the mentee to switch mentors. This can either be to a teacher they have developed a rapport with or to someone in the building who is helpful and personable.

\section{Overhaul First-Year Meetings}

New teachers are not only bombarded with learning the ropes of being the classroom teacher, but in some cases they are given the hardest positions, unwanted extra duties, and some will be coaching a sport. The mentees enjoyed the monthly meeting 
when they were thoughtful and meaningful to their needs. While learning teaching strategies is an important component to continuing professional development, many new teachers have just finished a program where those are taught. Tina noted, “...we do have meetings. So, they do talk about some stuff. But I mean, honestly, it's, to me, I think it's more of a waste of time than anything." Meredith also explained, "I went to school for 4 years for this degree but every school operates differently and the program has guided me in a more independent direction." It is reccommended the first year of orientation should focus on the emotional and professional wellbeing of the mentee. It is also recommended for the administrator to ask, "Is this meeting beneficial?" If the answer is yes, then every first-year teacher needs to be in attendance. If it is ok for the coach or sponsor to not be there, then why do the others need to be there as well? Mentoring program meetings need to take priority.

Mentors and mentees in the study have mentioned the use of a mentor/mentee handbook was beneficial. However, the handbook needs to be utilized as a tool for the program, not a substitute for it, as the study found was the case with some schools. The handbook should include a checklist so the mentor and mentee pair fully understand what they need to get done together and individually and the timeline for completion, lay out the measurable responsibilities of each person, list procedures for switching mentors when the relationship is not working, and provide resources for professional development. Handbooks should also list any dates for meetings and make sure the mentor and mentee understand that these are mandatory and they should plan around them. 


\section{Partner with Other Schools for Observation}

Being a first-year teacher is daunting. Being a first-year teacher in a small district where they are the only teacher of a particular subject can be even harder. Having a mentor in the school is important, but a new teacher needs to be able to talk to another teacher of the same subject to get their perspective as well. Mentees in this study did not know if they could go to another school outside the district to observe other similar subjects. As Kevin stated when talking about his mentor not having all the answers, "[I am] recognizing that not all the answers are at my school. It's kind of pushed me into these other ways of learning." Schools can benefit from cross-district learning. This will enable a new teacher to see multiple perspectives and give new techers greater resource to work with, which will in turn benefit the student.

\section{Make Mentors Accountable}

During interviews, some mentors mentioned they were paid, and some mentioned that they were not. When the mentor is paid, the amount paid to the time needed to execute the job properly seemed inadequate. The most the participants were paid was $\$ 200$ for the year. Furthermore, mentoring is not a contracted position and a teacher cannot be held accountable for their responsibilities as a mentor. It is the researcher's recommendation that schools hold mentors accountable for the responsibilities the district places on them and compensate them as they would a minor sport coaching position. By paying mentors a reasonable salary and having set expectations, the school can more easily ensure each mentee is getting the support they need and the district will hopefully increase teacher retention. 


\section{Limitations, Assumptions, and Future Research}

As the researcher is the primary instrument for data collection and analysis, it is important that the researcher recognizes the biases and assumptions that are brought into the study so they can be monitored (Merriam \& Tisdell, 2016). This study had several limitations that were taken into consideration during the course of the study. First was that as a teacher, the researcher has experience with Missouri's mentoring program. Care was taken to eliminate any bias from the research questions by having a member of the dissertation committee review and check the questions for errors. Also, schools where the researcher had had been employed were removed from the pool of possible schools to study.

One serious limitation to this study was that it was conducted during the COVID19 pandemic. Due to this, all interviews were conducted via Zoom. This meant that faceto-face interviews could not be conducted to observe the participant in their natural setting. Initially, the study was only to be conducted in the southeast region of the state. However, due to a low response rate, the study was expanded to encompasses the entire state. Once this change was made, there were enough participants to reach saturation.

The researcher is teacher who had a negative experience with a mentoring program and believes there are flaws in it. Assumptions about the program hinged on the belief that schools do not take mentoring seriously and fail teachers as a result. Understanding these assumptions about Missouri’s mentoring program were present, steps were taken to ensure an ethical approach to the study by having a research participant review and check the findings reported for accuracy. 
This study focused on teachers that are either in their first year or second year of teaching, which excludes data from those that left the profession altogether. Future research on this topic should include teachers that left the profession within their first two years of teaching. Future research could also include how teacher's mental health impacts student mental health.

\section{Conclusion}

While there have been many studies on effects of mentoring versus no mentoring, there have been limited studies on the perceptions and professional/personal growth of mentors and mentees. The study concluded that the overall program was perceived to be successful for the participants studied. However, results indicated that each school had a different approach to mentoring. Some had a structured and immersive program, while others were basic is scope. None of the programs made a focus on the mentees emotional and mental wellbeing.

The mentoring program is crucial to keeping new teachers in the profession. Providing new teachers with the support they need is key to keeping them invested in the teaching profession.

\section{Declaration of Interest Statement}

The authors declare that they have no known competing financial interests or personal relationships that could have appeared to influence the work reported in this paper. 


\section{References}

Abkhezr, P., McMahon, M., Campbell, M., \& Glasheen, K. (2020). Exploring the boundary between narrative research and narrative intervention: Implications of participating in narrative inquiry for young people with refugee backgrounds. Narrative Inquiry, 30(2), 316-342.

Callahan, J. (2016). Encouraging retention of new teachers through mentoring strategies. Delta Kappa Gamma Bulletin, 83(1), 6-11.

Carver-Thomas, D., \& Darling-Hammond, L. (2017). teacher turnover: Why it matters and what we can do about it. Learning Policy Institute.

Creswell, J. W. (2014). Research design: qualitative, quantitative, and mixed methods approaches (4th ed). Thousand Oaks: SAGE Publications.

Day, R., \& Allen, T. D. (2004). The relationship between career motivation and selfefficacy with protégé career success. Journal of Vocational Behavior, 64(1), 7291.

DeCesare, D., Workman, S., \& McClelland, A. (2016). How do school districts mentor new teachers? REL 2016-125. Regional Educational Laboratory Central. Retrieved from https://eric.ed.gov/?id=ED565612

Dias-Lacy, S. L., \& Guirguis, R. V. (2017). Challenges for new teachers and ways of coping with them. Journal of Education and Learning, 6(3), 265-272.

Farmer, D. (2020). Teacher attrition: the impacts of stress. Delta Kappa Gamma Bulletin, $87(1), 41-50$.

Freeman, G. G., \& Randolph, I. (2013). Leadership strategies for maintaining success in a rural school district. International Journal for Leadership in Learning, 1(1). 
Hall, D. M., Hughes, M. A., \& Thelk, A. D. (2017). Developing mentorship skills in clinical faculty: A best practices approach to supporting beginning teachers. Teacher Educators' Journal, 10, 77-98.

Harris, S. P., Davies, R. S., Christensen, S. S., Hanks, J., \& Bowles, B. (2019). Teacher attrition: Differences in stakeholder perceptions of teacher work conditions. Education Sciences, 9.

Israel, M., Kamman, M. L., McCray, E. D., \& Sindelar, P. T. (2014). Mentoring in action: the interplay among professional assistance, emotional support, and evaluation. Exceptional Children, 81(1), 45-63.

Jyoti, J., \& Sharma, P. (2017). Empirical investigation of a moderating and mediating variable in between mentoring and job performance: A structural model. Revista de Psicología Del Trabajo Y de Las Organizaciones, 33(1), 55-67.

Kozikoğlu, İ. (2018). A metaphorical analysis of novice teachers' perceptions concerning first year in teaching, induction process, school administrators and mentor teacher. Educational Research Quarterly, 42(1), 3-44.

Kram, K. E. (1983). Phases of the mentor relationship. Academy of Management Journal, $26(4), 608-625$.

Marker, K., Mitchall, A., \& Lassiter, S. M., Jr. (2013). Doing more with less: How to maintain the integrity of beginning teacher support programs. Journal of Cases in Educational Leadership, 16(1), 73-81.

Merriam, S. B., \& Tisdell, E. J. (2016). Qualitative research: A guide to design and implementation (Fourth edition). San Francisco, CA: Jossey-Bass. 
Muhammet, B., \& Sarigöz, O. (2018). An examination of teacher candidates’ attitudes towards teaching profession. International Journal of Educational Administration and Policy Studies, 10(4), 25-32.

Nasser-Abu Alhija, F., \& Fresko, B. (2014). An exploration of the relationships between mentor recruitment, the implementation of mentoring, and mentors' attitudes. Mentoring \& Tutoring: Partnership in Learning, 22(2), 162-180.

NCES Fast Facts Tool provides quick answers to many education questions (National Center for Education Statistics). (n.d.). Retrieved April 14, 2019, from https://nces.ed.gov/fastfacts/display.asp?id=28

Russell, M. L., \& Russell, J. A. (2011). Mentoring relationships: Cooperating teachers' perspectives on mentoring student interns. Professional Educator, 35(1), 16-35. Techniques to Identify Themes in Qualitative Data. (n.d.). Retrieved April 14, 2019, from http://www.analytictech.com/mb870/readings/ryanbernard_techniques_to_identif y_themes_in.html 
SECTION SIX:

\section{SCHOLARLY PRACTITIONER REFLECTION}




\section{Scholarly Practitioner Reflection}

Throughout the course of this program, I have been forced to look within myself as a leader, a person, and a scholar. Merriam and Bierema (2014) describe learning as a lifelong endeavor. To that I have fully committed myself. Whether through this program, job related professional development, or learning new personal skills, I have always sought to better my understanding of the world around me to enact meaningful change. Even as I write this, I am learning and adapting to change.

Entering into this program, we were placed into positions in which we were forced to provide leadership to others. As we did this, I grew as not only a leader, but an individual, too. In the past, I would place extra stress on getting something exactly right. I felt as though leaders have to be $100 \%$ right all of the time. As I spoke with other leaders, I learned there is always room for improvement and that failure is just another opportunity for improvement. After this revelation, I brought it back to my professional career and started trying new things without the fear of failure and a drive to try new things.

By focusing to better myself, I feel like I have grown into a leader that is truly a servant leader. In analyzing my strengths from the Northouse (2016) questionnaires, I initially learned that I was a very technical leader who was highly directive. Over the course of the program, I feel that is no longer true. I feel my supportive and putting others first nature has taken the front seat. I have found that if I take care of those around me, then they can focus on their best performance and enter collaborative meetings with less stress. I also feel as though I am more flexible than I was when I started the program. As stated earlier, I used to believe leaders always had to be right. I also felt that my way was 
always the best way, and others just need to see that. Now I have learned to accept the ideas of others and incorporate that into my plans.

I have also learned that good leaders empower others. By giving those around me the resources and information they need to succeed, I provide them with a sense of empowerment. Merriam and Bierema (2014) said that by empowering others, I can help them have a more positive outlook on not only their work, but their body and mind as well. This support helps others want to be the best version of themselves they can be.

Northouse (2016) gives sociability and self-confidence as two of the five most important traits for being a good leader. When I entered the program, I was lacking in both. Though I may put on the extrovert face, the true me is very much an introvert. I am the "everyone does not like me" type. This hindered me in seeking out leadership opportunities, as I did not want to bother anyone. This program forced me to come out of that shell by placing me in positions where I had to ask for help and work in a more sociable atmosphere. Recently, my principal stated, "I feel like this year you have really opened up and blossomed as a teacher." I feel that this is because I have opened up to others and felt freer to "put myself out there". I engage with my superiors and others now, whereas before I would shy away. I have learned that I should not be afraid to talk with others, and this is due to my increased self-confidence level.

As an individual, this program has given me a second family. During my first year of the program, my brother passed away from cancer. Even though he was 20 years older than I was, we had a close bond. The semester after our comprehensive exams dealt me another blow. My mom passed away with heart failure. As my father had passed five years prior to this, my remaining two siblings and I spent the next six months navigating 
courts and estate settlement. I almost felt like giving up and, had it not been for this amazing cohort, I very much would have. Part of the reason why I wanted to do this was to make my family proud. I am the product of a father that was an 8th grade dropout who worked his whole life making sure we did not do the same thing. My mother was always the money saver, making sure we had enough to pay the bills and that we had enough put back to take care of emergencies. As a first-generation college graduate, I had exceeded the odds. The work ethic they instilled in me and the love they shared will never be forgotten. My father, mother, and brother will always be a part of me and I am devastated that they did not live long enough to see me grow to be the leader this program molded me into. But in their absence, the ELPA Cohort 11 class and instructors have given me support when I needed it. I will eternally be grateful to everyone in this program as they have become some of the best mentors, friends, and family I could have ever hoped for. 


\section{References}

Abkhezr, P., McMahon, M., Campbell, M., \& Glasheen, K. (2020). Exploring the boundary between narrative research and narrative intervention: Implications of participating in narrative inquiry for young people with refugee backgrounds. Narrative Inquiry, 30(2), 316-342.

Bolman, L. G., \& Deal, T. E. (2013). Reframing organizations: Artistry, choice, and leadership (5th edition). San Francisco, CA: Jossey-Bass, a Wiley brand.

Bruno, A. L., Taylor-Dunlop, K. (2013). The effects of mentoring on the professional school culture in an effort to develop a collaborative, reflective culture and educational environment (Doctoral dissertation). Oakdale, NY; St. John's University at Oakdale.

Callahan, J. (2016). Encouraging retention of new teachers through mentoring strategies. Delta Kappa Gamma Bulletin, 83(1), 6-11.

Carver-Thomas, D., \& Darling-Hammond, L. (2017). Teacher turnover: Why it matters and what we can do about it. Learning Policy Institute.

Clark, S. K. (2012). The plight of the novice teacher. Clearing House, 85(5), 197-200.

Cooper, H., \& Mackenzie Davey, K. (2011). Teaching for life? Midlife narratives from female classroom teachers who considered leaving the profession. British Journal of Guidance \& Counselling, 39(1), 83-102.

Creswell, J. W. (2014). Research design: qualitative, quantitative, and mixed methods approaches (4th ed). Thousand Oaks: SAGE Publications. 
Curcio, R., \& Adams, A. (2019). The development of mentoring partnerships: How a shared learning experience enhanced the final internship. SRATE Journal, 28(1), $1-8$.

Day, R., \& Allen, T. D. (2004). The relationship between career motivation and selfefficacy with protégé career success. Journal of Vocational Behavior, 64(1), 72 91.

DeCesare, D., Workman, S., \& McClelland, A. (2016). How do school districts mentor new teachers? Regional Educational Laboratory Central. Retrieved from https://eric.ed.gov/?id=ED565612

Dias-Lacy, S. L., \& Guirguis, R. V. (2017). Challenges for new teachers and ways of coping with them. Journal of Education and Learning, 6(3), 265-272.

Doering, S. A. (2018). The induction mentor voice: A phenomenological study of effective practices for high quality $k-12$ teacher induction mentoring (Ed.D., Pepperdine University). Retrieved from http://search.proquest.com/

Drew, J. (2014). How to start and run a mentoring program. Journal of Accountancy, $217(3), 34-39$.

Eck, C. J., \& Ramsey, J. W. (2019). An analysis of cooperating teacher feedback: A qualitative inquiry. Journal of Research in Technical Careers, 3(2), 97-113.

Farmer, D. (2020). Teacher attrition: The impacts of stress. Delta Kappa Gamma Bulletin, 87(1), 41-50.

Freeman, G. G., \& Randolph, I. (2013). Leadership strategies for maintaining success in a rural school district. International Journal for Leadership in Learning, 1(1). 
García-Arroyo, J. A., Osca Segovia, A., \& Peiró, J. M. (2019). Meta-analytical review of teacher burnout across 36 societies: The role of national learning assessments and gender egalitarianism. Psychology \& Health, 34(6), 733-753.

Geeraerts, K., Tynjälä, P., Heikkinen, H. L. T., Markkanen, I., Pennanen, M., \& Gijbels, D. (2015). Peer-group mentoring as a tool for teacher development. European Journal of Teacher Education, 38(3), 358-377.

Hall, D. M., Hughes, M. A., \& Thelk, A. D. (2017). Developing mentorship skills in clinical faculty: A best practices approach to supporting beginning teachers. Teacher Educators' Journal, 10,77-98.

Harris, S. P., Davies, R. S., Christensen, S. S., Hanks, J., \& Bowles, B. (2019). Teacher attrition: Differences in stakeholder perceptions of teacher work conditions. Education Sciences, 9.

Hersman, B. (2018). Mentoring: A convenience or convergence? Quest (00336297), $70(2), 139-152$.

Ingersoll, R. M. (2012). Beginning teacher induction: What the data tell us. Phi Delta Kappan, 93(8), 47.

Israel, M., Kamman, M. L., McCray, E. D., \& Sindelar, P. T. (2014). Mentoring in action: The interplay among professional assistance, emotional support, and evaluation. Exceptional Children, 81(1), 45-63.

Jyoti, J., \& Sharma, P. (2017). Empirical investigation of a moderating and mediating variable in between mentoring and job performance: A structural model. Revista de Psicología Del Trabajo Y de Las Organizaciones, 33(1), 55-67. 
Kimball, S. (2018). Collegial peer mentoring programs and their effect on new teacher attrition a quantitative descriptive study (Doctoral dissertation). Phoenix, AZ: University of Phoenix.

Kozikoğlu, İ. (2018). A metaphorical analysis of novice teachers' perceptions concerning first year in teaching, induction process, school administrators and mentor teacher. Educational Research Quarterly, 42(1), 3-44.

Kram, K. E. (1983). Phases of the mentor relationship. Academy of Management Journal, $26(4), 608-625$.

Lozinak, K. (2016). Mentor matching does matter. Delta Kappa Gamma Bulletin, 83(1), $12-24$.

Marker, K., Mitchall, A., \& Lassiter, S. M., Jr. (2013). Doing more with less: How to maintain the integrity of beginning teacher support programs. Journal of Cases in Educational Leadership, 16(1), 73-81.

McCarthy, C., Lambert, R., Lineback, S., Fitchett, P., \& Baddouh, P. (2016). Assessing teacher appraisals and stress in the classroom: Review of the classroom appraisal of resources and demands. Educational Psychology Review, 28(3), 577-603.

Merriam, S. B., \& Bierema, L. L. (2014). Adult learning: Linking theory and practice (First edition). Jossey-Bass, a Wiley brand.

Merriam, S. B., \& Tisdell, E. J. (2016). Qualitative research: a guide to design and implementation (Fourth edition). San Francisco, CA: Jossey-Bass.

Missouri Department of Elementary and Secondary Education (2020). Initial Student Services. https://dese.mo.gov/educator-quality/certification/initial-studentservices 
Missouri Department of Elementary and Secondary Education (2020). Title 2.

https://title2.ed.gov/Public/Report/StateHome.aspx

Missouri Secretary of State. (n.d.). Retrieved June 4, 2020, from

https://www.sos.mo.gov/

Missouri Senate - Missouri General Assembly. (n.d.). Retrieved June 4, 2020, from https://www.senate.mo.gov/

Muhammad, A. (2018). Transforming school culture: How to overcome staff division (Second edition). Solution Tree Press, a division of Solution Tree.

Muhammet, B., \& Sarigöz, O. (2018). An examination of teacher candidates' attitudes towards teaching profession. International Journal of Educational Administration and Policy Studies, 10(4), 25-32.

Nasser-Abu Alhija, F., \& Fresko, B. (2014). An exploration of the relationships between mentor recruitment, the implementation of mentoring, and mentors' attitudes. Mentoring \& Tutoring: Partnership in Learning, 22(2), 162-180.

NCES Fast Facts Tool provides quick answers to many education questions (National Center for Education Statistics). (n.d.). Retrieved April 14, 2019, from https://nces.ed.gov/fastfacts/display.asp?id=28

Northouse, P. G. (2016). Leadership: Theory and practice (Seventh Edition). Los Angeles: SAGE Publications, Inc.

Phillips, C. (1911). The essential facts concerning the history and organization of Missouri's schools. Jefferson City, MO: Hugh Stephens Printing Company. 
Reitman, G. C., \& Karge, B. D. (2019). Investing in teacher support leads to teacher retention: six supports administrators should consider for new teachers. Multicultural Education, 27(1), 7-18.

Richardson, B. C., \& Dinkins, E. G. (2014). Life on the reservation: Cross-cultural field experiences and student learning. AILACTE Journal, 11(1), 57-72.

Roff, K. A. (2012). The story of mentoring novice teachers in new york. Journal of Educational Research and Practice, 2(1), 31-41.

Russell, M. L., \& Russell, J. A. (2011). Mentoring relationships: Cooperating teachers' perspectives on mentoring student interns. Professional Educator, 35(1), 16-35.

School Culture and Climate. (n.d.). Retrieved July 20, 2019, from http://www.ascd.org/research-a-topic/school-culture-and-climate-resources.aspx

Sciuchetti, M. B., \& Yssel, N. (2019). The development of preservice teachers'selfefficacy for classroom and behavior management across multiple field experiences. Australian Journal of Teacher Education, 44(6), 19-34.

Teacher Development. (n.d.). Retrieved September 30, 2019, from https://www.tandfonline.com/action/authorSubmission?show=instructions\&journ alCode $=$ rtde 20

Teacher Turnover In DCPS. (2014, January 15). Shanker Institute. https://www.shankerinstitute.org/blog/teacher-turnover-dcps

Techniques to Identify Themes in Qualitative Data. (n.d.). Retrieved April 14, 2019, from http://www.analytictech.com/mb870/readings/ryanbernard_techniques_to_identif y_themes_in.html 
Torpey, E. (n.d.). Projections for teachers: How many are leaving the occupation? :

Career Outlook: U.S. Bureau of Labor Statistics. Retrieved July 8, 2021, from https://www.bls.gov/careeroutlook/2018/data-on-display/how-many-teachers-areleaving.htm

Whalen, C., Majocha, E., \& Van Nuland, S. (2019). Novice teacher challenges and promoting novice teacher retention in Canada. European Journal of Teacher Education, 42(5), 591-607.

Wronowski, M., \& Urick, A. (2019). Examining the relationship of teacher perception of accountability and assessment policies on teacher turnover during nclb. $N C L B$., 27(86/87), 1-33. 


\section{Appendix A}

Introduction Letter to Superintendents

Good evening! My name is Derek Ward, and I am a doctoral student at the University of Missouri-Columbia. In fulfillment of my program, I am conducting a study on how mentoring fosters professional and personal growth. I will need to conduct interviews with a mentor and their mentee at both the elementary and secondary level. I would conduct the interview via Zoom at a time after school that would be the most convenient for them.

Your help is much appreciated, and I look forward to hearing back from you! If you have any questions, you may contact me, or my dissertation supervisor, Dr. Sandy Hutchinson.

Thank you,

Derek Ward

(573) 838-4231

djwfd4@umsystem.edu

Dr. Sandy Hutchinson

hutchinson@ucmo.edu

IRB\# 2033844 


\section{Appendix B}

Mentoring Program Interview Protocol

\section{Personal Questions}

1. Tell me a little about yourself (age, years in education, subject taught, etc.)

2. Why did you want to become an educator?

\section{RQ 1 - What characteristics of a mentor are prevalent in a mentoring program?}

1. What characteristics should a mentor have? Why are these characteristics necessary?

2. What characteristics are not necessary to be a mentor? Why are these characteristics not necessary?

3. Describe the characteristics of your mentor and the effects of them on your relationship.

RQ 2 - What are the responsibilities to each other in a mentor/mentee relationship?

1. Describe what you feel the mentor should be responsible for in the mentor/mentee relationship.

2. Describe what you feel the mentee should be responsible for in the mentor/mentee relationship.

3. How do you feel your school incorporates these into their mentoring program?

RQ 3 - How does the current mentoring model assist in a mentor and mentee's professional and personal growth?

1. In what ways has the mentoring program affected your professional growth?

2. In what ways has the mentoring program affected your personal growth?

\section{Closing Questions}

1. Tell me about your overall experience with the mentoring program.

2. Is there anything else you would like to say about the mentoring program? 


\section{Appendix C}

Schools participating in the study.

\begin{tabular}{|l|c|c|}
\hline \multicolumn{3}{|c|}{ Schools Interviewed } \\
\hline \multicolumn{1}{|c|}{ School } & Approximat Enrollment & Average Teacher Experience \\
\hline Adams School District & 400 & 10 \\
\hline Anderson School District & 4000 & 10 \\
\hline Chilton School District & 2800 & 12 \\
\hline Everest School District & 1300 & 13 \\
\hline Sundale School District & 400 & 8 \\
\hline Welton School District & 4000 & 12 \\
\hline
\end{tabular}




\section{Appendix D}

Participants interviewed.

\begin{tabular}{|l|c|c|c|}
\hline \multicolumn{4}{|c|}{ Participants } \\
\hline Name & Role & Years of Experience & School \\
\hline Angelica & Mentee & 1 & Welton School District \\
\hline Eliza & Mentor & 23 & Welton School District \\
\hline Erin & Mentor & 23 & Chilton School District \\
\hline Holly & Mentor & 6 & Raymore School District \\
\hline Jan & Mentee & 2 & Chilton School District \\
\hline Jessica & Mentee & 1 & Sundale School District \\
\hline Jim & Mentee & 2 & Raymore School District \\
\hline Karen & Mentee & 1 & Raymore School District \\
\hline Kelly & Mentee & 2 & Chilton School District \\
\hline Kevin & Mentee & 1 & Sundale School District \\
\hline Linda & Mentee & 1 & Adams School District \\
\hline Lisa & Mentor & 9 & Adams School District \\
\hline Louise & Mentor & 13 & Adams School District \\
\hline Maria & Mentee & 3 & Anderson School District \\
\hline Meredith & Mentee & 2 & Anderson School District \\
\hline Michael & Mentee & 2 & Welton School District \\
\hline Nellie & Mentor & 14 & Chilton School District \\
\hline Pam & Mentor & 30 & Anderson School District \\
\hline Peggy & Mentor & 11 & Welton School District \\
\hline Phyllis & Mentor & 10 & Anderson School District \\
\hline Shelly & Mentor & 5 & Sundale School District \\
\hline Tammy & Mentee & 1 & Adams School District \\
\hline Tina & Mentor & 26 & Sundale School District \\
\hline Tori & Mentor & 12 & \\
\hline
\end{tabular}




\section{Appendix E}

In an effort to give voice to all participants, a variety of interview responses are presented by research questions.

\section{Interview Responses}

\section{RQ 1-What characteristics should a mentor have? Why are these characteristics}

\section{necessary?}

Michael: Um, I think one experience and then being in education for a while kind of knowing the ins and outs of things, just being able to as a mentor to have your mentee kind of pick your brain. I know I've benefited from that a lot. Just hearing their experiences and what's worked well for them, what hasn't worked well for them, and just what's changed over their career. I think the biggest thing is experience and just being approachable. For some people, it's kind of hard to approach them. So, just being approachable and being willing to help I think is the biggest thing. Being able to spread your knowledge. I'd probably say, five to 10 years. I know that's kind of, I've always been told that's once you kind of hit your time, that's when you kind of understand or when you finally you don't have to maybe sit there and plan out every single thing, you kind of just go with the flow, and you're more comfortable with everything. So, probably, I'd say once you get to your 10, you probably have a good amount of experience going through a decade of it. But I think all that's being approachable, having the experience wanting to share that knowledge. I think that's important because it helps grow those teachers that are coming after you. I think we kind of all get into the profession of wanting to help students out. But we also need to help out our colleagues, because, at some point, we're 
all going to retire. So, to help the younger ones come through and hopefully make the same impact that you aim to make.

Eliza: I think there's a handful of characteristics that are important, and I don't think there's probably any that are more important than the other. I do think that mentors need to be empathetic to first-year second-year teachers and their needs. And their experiences going through the first and second year, you know, the hardest times of your life as a teacher. I think that's really important, but at the same time, I think that you really have to be honest, as a mentor with mentees if you're not honest, you're not doing them any favors and Like I said, compassion, understanding, empathy, all that's important. But if your mentor is not willing to be honest with the mentee and with the administration about the job that the mentee is doing, then that person's in for a really, you know, rough evaluation. And I just don't think you're helping them out by sugarcoating the situation for them. And it's funny that you asked me that we just had a mentor meeting for the district and she laid out some characteristics as well. And I was the only person that said honesty. Everybody else was like, oh, you know, give them hugs pat them on the back, you know, do all this and I was like, No, I was like, people, these people are teachers. It's one of the hardest jobs in the world. And you have to be honest with them because that is someone's baby in that classroom. It could be your child. It could be something I mean it's someone's child sitting in there. And if that teacher is not engaging and, you know, following the standards and, you know, planned out the next day and you know prepared if that teacher is not doing that, then those children in that room are not getting what they're supposed to be getting. And that's, to me, you know, it's all about the students. If 
it's not, then you need to find something else, because it's about them. So, I would say, you know, honesty is probably as important as empathy. But I think that when you deal with a new teacher if you're not being. I mean, you need to tell them what they're doing. But what they're doing wrong. And then help them you know help find solutions for them.

Angelica: I think the first characteristic probably needs to be that they're organized. Just because my mentor being organized. She's a very organized person. Has helped me so, much whenever I'm unorganized because I don't know what I should be doing quite yet and all that stuff. So, having her be organized has helped me become organized so, it's been super helpful that she has all this stuff like Here's module one, here's how we break it down. Here's module two. Here's how we break it down and I've been having extra activities and stuff that they've used in the years past. To kind of help me, and especially with this whole quarantining situation. Having her be there to kind of ask questions to even though she hasn't been there either yet has been really helpful. So, I think that being organized is probably the number one thing I'm trying to think, number two would probably be just experienced. Because as a first-year teacher, I don't know, half the stuff that's probably going to happen to me in my career probably less than half of the stuff that I know it's going to happen. So, having experiences and being able to help me has been awesome coming from my mentor teacher with her experiences. I don't think they have to be in a leadership position. Um, I think that a lot of times they are just because there are some of those people that go and take the lead on things. But I think that there are great teachers who aren't leaders in our school just because they stick to their set of 
what they know. So, my leaders are my mentor is she's on assessment writing on our assessment writing team, but I have a teacher right next door to me, who is also a great teacher and she's not on those teams. So, I think she would be a great mentor, she just isn't on all of the different teams that my mentor is on.

Peggy: So, I do think that the classroom experience helps out, just so, that you, you know, have that experience to be able to you know to give your mentee. You know that solid advice that's based on your own experience, not just something that's, you know, by the book. We need to be very, you know, empathetic because it's super hard to be a firstyear teacher or, you know, first year and a new district. And so, especially this year like my mentee is a first-year ever teacher. And so, I mean Welton. I don't know if you've heard, but like we're hybrid right now and we had a ton of kids in quarantine and so, I mean this is just like not at all what a normal school year would look like. You know, be being supportive, you know, and then we kind of talk about kind of showing that tough love. You know, of having those characteristics that I just mentioned, but you know to also be able, to be honest, you know, with your mentee about, you know, certain expectations and areas you know for improvement.

Maria: Okay, so, I would definitely say somebody I can trust, I guess. Tell my ideas to, you know. Like I've worked in situations where I didn't feel comfortable telling my colleagues. Hey, I got an idea. Can I share that idea with you? Have something as a strategy or something? I want to teach in the classroom. So, I would say mentors definitely have to be somebody who's open-minded or makes me feel like they're willing 
to hear me out or to hear my ideas. So, somebody I can trust somebody I guess who, what's the word I'm looking for. I guess open-minded and, you know, to the newbie's thoughts and ideas that they can offer something to the team. Well, from being the newbie, you know, you don't want to be treated like the newbie. You don't want to be treated like you, you don't have anything to offer you might be fresh out of college. You may not have that experience, but surely there's something you've learned in those four years of college. And throughout your block some surely there's something you learned from another teacher throughout your blocks that you could offer to your current job situation. So, I've been in both situations. I've been where I could not. I did not feel like I could offer my expertise. I felt like I was got shut down or quiet and, you know, whereas the mentor, you know, I currently have, she was always open and ready to hear any ideas I had. So, for me, that made me feel more confident in my abilities. Maybe more brave I guess to go out and find even more ideas and more strategies and more things that I can bring to the table to offer to my team. So, it just, made our collaboration, our team, much better.

Pam: I think there are so, many characteristics, um, you know, a mentor is an advisor counselor, you are sometimes you advocate for the person you're an advocate. A rolemodel. An opener of doors and but I think one of the most important things is that the mentor needs to be a really good listener. You know, because it's not our job to create little clones and try to tell people, new teachers. This is how you do it. You need to be just like me. It's not. We need to listen and then help. It's like a problem-solving skill. Helps problem solve. So, I think listening is really important. But I also think that role 
changes because in the beginning they really need help, you know, and but then as time goes on, that the new teacher is more independent. So, I feel like the role kind of evolves.

Meredith: A mentor needs to be very friendly and honest when it comes to being a mentor for a first-year teacher. Someone who is easy to work with and get along with. Trust me when I say that last year I probably asked some of the most obvious questions so, a mentor who is easygoing and not judgmental. Those are all very necessary because being a first-year teacher is hard enough and having someone with all of those characteristics made me feel like I wasn't failing.

Phyllis: I see a lot of different mentors, because we take turns in our department, and being mentors we try to like spread it out. So, it's not just one viewpoint. And, and I really think that knowledge would be key for me, instead of just being kind and Easy, easy to get along with, and easygoing, but also knowledgeable, especially in regards to special-ed, because there are a lot of legalities associated with it with paperwork. So, I think probably the most important is knowledgeable. And if you're really knowledgeable about curriculum standards, and how we align our standardized test to curriculum and create our own formative assessment. So, I think knowledge would be my biggest one. But I think there needs to be an importance in the program of letting both of them know that you guys don't really have to like each other or necessarily, like want to go out for a happy hour after work. You're primarily focused on how do we both develop as educators, and how are we here for this purpose. Instead of like, how do we form a working relationship? 
Kelly: I think a large one would definitely be patience um I feel like sometimes I tell my mentor, like, I'm sorry if I'm driving you crazy, I have a lot of questions. You know, she's always so, patient with me, so, I think that is a big one. I think they're just willing to help is a big one, which goes along a little bit with patients as well, but I think they need to be very knowledgeable in their field and their content, and I also I don't know if this is everywhere, but I think sometimes mentees get placed with mentors that aren't in their content area. And I've had people that I've known throughout the years and friends that I met in college that went through the journey with me and that just wasn't always the case that their mentor was someone in their content. So, I think that's a big thing. I work right next door to mine so, she's there and available anytime I need her. So, someone that's just close by willing to help and just there for you, because I do have a lot of questions. And I know I think it helps that I am close to my mentor and that we do work in the same area because it makes me more comfortable and she's very caring and considerate of my needs and she's willing to share materials with me or resources. And we kind of feed off each other in that sense. So, just that willingness to work together and be there for each other

Erin: Openness/sharing... I think some teachers want to keep all the information and lessons to themselves in fear of the mentee surpassing the mentor. I felt that way with my mentor when I first started teaching. I think if a mentor has these two characteristics that everything else will fall in place. Caring--obviously, they should care for what is best for the students. If what is best for the students is helping your mentee to be the best, then by default, you should care about every aspect of the mentee. Sense of humor--many things 
in education could make a person cry, I feel laughter/sense of humor makes it more bearable/fun.

Jan: Well, I feel like for the mentor program, and having a mentor in a school system, you have to be caring, compassionate, and understanding. I think those are my three top three. Because especially if you have a new person coming in and they're already scared because it's a new environment. Not necessarily scared but they're uneasy because there they anxious. So, that, caring, compassion, and understanding. Having somebody who has good communication skills, then, can work with that person and say, "Okay, I hear what you're saying. Let me give you some help. Let's work through this." As opposed to somebody who comes in says, "Okay, this is what you need to do. This is what you need. This is what you need to do and you're just gonna have to get over it because it's something you have to do." That's not the attitude you need to have when you have a new mentor new person coming into your building your district, whatever it is.

Nellie: I'd like to think that a decent mentor is what colleagues would refer to as the veteran teacher the teacher who has experienced numerous changes and growth within the school district and numerous policy changes. A person who knows the ropes knows how to do the paperwork, as well as knows how the paperwork came into being in the first place, and who has a decent bag of tricks, so, to speak, to help that new teacher along the way. Because, unfortunately, school districts are typically so, large that it is difficult, I believe, for the administration to keep an eye on everybody. You have to really trust the adults that you supervise because you're outnumbered 60 to one in some cases, so, you 
really have to trust them. And I think, unfortunately, with the new teacher there's a bit of a gap between college life, where your schedule is set up for you, where your assignments are set up for you, and then you get the great little mortarboard and you go walk out the door and then they're like, "Okay, guess what?! Now you have to teach these 22 students you've got six on IEP's and you have to teach two a second language. Okay, now figure it out. Good luck! Oh, and here's a basic curriculum. You're gonna have to figure the rest out on your own." So, it's good to have that mentor/mentee relationship. And it's good that the mentor actually knows what's going on in the buildings.

Karen: I feel like the top one is open. If you're not, like, open and willing from the bat to be like, “Okay, what do you need?" I guess, I don't know, the word that comes to mind is open. Like open doors, like, you can always turn to them with anything. Because there are so, many like moments where you just feel so, annoying, kind of and you're just like, I need to turn to someone and I need them to like, be there and not like, be like, not now. Or like, You're annoying. You know what I mean? You need to have that support system. So, open and supportive. Um, I'm so, bad on the spot. I'm such a writer, but I'm not like a talking person. I'm very much better at writing. I'm so, supportive, open. I'm looking for a word right now. It has to do with like... Okay, I'm going to combine to these. I feel like people underestimate how important it is for a mentor to be emotionally supportive. Because I feel like people think that it's like all like school stuff. Like how can I like mentor you in like teaching and stuff. But like, for me, the best thing that I've had so, far is like, my mentor, sit there and be like, it's gonna get easier. Like I've like cried to her. 
There have been moments where I've gone into her room, like crying. And just because I had such a long day, and I couldn't stop just because I was at that point of like, exhausted COVID everything. But I was supposed to teach a class in a moment. And so, she was like, yep, okay, you stay in here. You sit in my room and cry, and I'm gonna go teach your class. And she speaks ASL, not Spanish. And she was, like, emotionally supportive and there. At the end of the day, she came gave me a hug. Um, so, yeah, I feel like having a mentor that's emotionally supportive, is so, important. People underestimate the power of emotionally supporting someone and not just like being there on paper, if that makes sense.

Holly: I think patience is a big one more because you're taking on extra duty there. And also, it's kind of you know what you're doing, but the person you're helping out does that know. And you just got to have patience to know that there are two separate things you get to teach your class and you've got to help with the other person and everything. So, patience is a big one. Was there a number like I think that one thing I felt like is when I had my mentor if the person was extremely busy and really didn't have the time to do it very well and having enough time in want that to be a focus of helping them and being organized to be able to help them and not forget, "Oh yeah, I should have told him this!" Or, you know, something like that. But to be a little more organized, organized, patient, and caring. I guess, to put your shoes and you know, put yourself back in those shoes and stuff. 
Jim: I think a good mentor is naturally a good leader. I think it's necessary because they are leading someone who really doesn't know what's going on. Like, you know what you're going like what's going on. I think they have to just naturally be a good leader because they're trying to lead us through something that they teach you about in school, but it's totally different going to the real workforce. My mentor is really good about being very upfront about things. I think you need to make sure that you're upfront. Because if I'm trying something and they're like, "Oh yeah, I tried that it didn't work. Maybe you should try to treat it like this." It's just good. Being able to have that communication and being upfront about things in a positive way. Not negative, but, yeah, just being able to work with someone is helpful.

Tina: Okay, well, I just think I'm helpful. Somebody who's willing to be helpful. And give guidance, I mean, even their name. You know, like, last year, I'm helping somebody who is language arts, even though I that's our math, I can still give ideas. I wasn't her mentor. But her mentor wasn't really helping her. So, I was trying to help her out as well. So, I just think just being willing to share your knowledge and being willing to bounce ideas off, I don't know everything. And I can learn from my mentee, just like he can learn from me. So, it's kind of a win-win. They bring something to the table that I can steal, and he can take something or she for me, so, I kind of look at it as I can learn from them, and they can learn from me.

Linda: Okay, um, I think a mentor should be definitely well seasoned. It's easier to have somebody who's been in the game for a while. I think they should be open to really 
outrageous questions because I sort of had a lot of them. I'm just knowing, being approachable, essentially. It's hard to talk to somebody as a new teacher when they're not approachable and you don't know how they're going to take things. You're taking somebody that's easy to talk to and is understanding as well. And is also up for giving you advice or ideas that you might not think of, or letting you bounce ideas off of them. So, just someone who can listen. Try to understand what you're saying to them and genuinely care to see you succeed.

Louise: I can tell you the characteristics that they need to have is definitely communication skills. They need to have time to be available. The mentor that I had coming in when I started teaching fourth grade was a very quiet lady and she was a great teacher, but she was so, quiet. I really didn't get the feedback that I needed to start that first-year teaching. So, I think communication and availability are probably at the very top of the list, I think you should be solid in what you're teaching. And the only way you're going to be able to help somebody is to have some years of experience behind you to do it. Definitely, if there's too much on your plate, you're not going to be a good mentor. I've mentored probably six girls here, I've only been here 13 years. But my heart's in it. I know what it's like to be that first-year teacher and just be you know, floored. And so, I offer that freely. Just simply because I know that a mentor is key to feeling like you have the ability to be a teacher, it is such an overwhelming first year, if that support is not in place, it can really make a difference on whether you think that you can continue in this field or not. 
Tammy: The first thing that comes to my head is empathy. Like, I think, I think they have to be able to recognize whether the person they're mentoring is feeling and like, help guide them. Like, I think just because like, going into education is really overwhelming. And sometimes, like, at times, like, I didn't know what I was even feeling or like, how to fix something. And my mentor was very frequently able to like, Okay, well, this is what we need to do, you know, and it was just nice to have that guiding voice when I couldn't like figure it out on my own. And I'm a talker, like, I love to ask questions. And so, like, that worked to my advantage, because I'm like, okay, I don't understand this. What is going on? You know, but there were some times you know, that she was just picking up on things without me having to ask, which is really nice.

Lisa: Well, this is my first time being well, No, I guess not my first time being a mentor. But I think I need to be able to listen. And then I need to be able to share truths with them that I've learned along the way. Even when they're... it's this has been a difficult balance for me when they when they're not really ready to receive them, I sometimes still need to give those truths out. And since we're there at the SAP, some discernment to sense where they're at and what they can accept and what they aren't ready to accept yet, I guess.

Kevin: I'd probably say the first one that comes to my mind is being open-minded. Because both at my school where I student taught, my co-teacher and then the school where I currently am, which was my first position, my mentor, they're both pretty openminded. And I feel like that's important, at least to me, because in my first two years, my ideas are constantly changing. I'm on Twitter, reading things, and reading books, and I 
just have all these different opinions that I'm trying to form. And being able to go to them and discuss those ideas, they're able to look at it, find some value in what I'm actually finding elsewhere, but then also helping being able to find a house, some people might have a problem with that, and how to prepare for those problems, implementing those ideas. And then also, just so, that they're not like pushing their way on a new teacher. But I remember last year, on the door to the faculty room, there was a poster that said something, something along the lines of new teachers shouldn't try to fit into the school or change their ways to fit in with the school, but the school should try to change to be more like the new teacher who is like coming up with all these new ideas and isn't set in their ways. Ultimately, just that they're flexible, and what's best for the students.

Tori: I feel like you need to be a leader. Someone that I feel like organization helps, like, that's one of my strengths, I feel like is organization. And be compassionate, so, that you're, you know, things aren't always perfect. And even when you happen to go in, and maybe they less than flop that you're observing, show compassion with them and be ready to listen and give advice and be honest.

Jessica: I think being obviously, like, approachable. My mentor, like, I can go ask her anything, you know, and I feel like, I mean, she's not gonna make me feel stupid. Like, even if it's something you know, that I feel like, is a stupid question. She's gonna go, or she's gonna answer my question. And like, I'm not scared to ask her anything. Because if you're scared to go ask someone for help, you're never going to ask them anything. And you're going to wonder or you're just going to guess. And then I don't know, you're not 
going to do things or there might be an easier way to do things that you didn't know about, that they could help you with. Or you might need resources that you didn't know were available, or you know, just even like in conversation, we say things and she'll tell me different resources that are available to help with that, or like different laws and stuff that I didn't learn in school. Like I had one student that, like, she has trouble seeing the board and like, so, I was gonna say something to her mom, at parent-teacher conferences, you know, like, she needs to go to the eye doctor. And she said that we can't really tell them that we can tell them that she's having trouble seeing her, you know, she's squinting at the board, but so, I didn't really realize that you couldn't just tell them that. So, it was something about making the school liable, like the school would have to pay for it or something like that.

Shelly: I think a mentor should have some teaching experience, so, they know what to do. I also think that they should have good classroom management, I know sometimes you have those classes that are really difficult. But it's kind of the way that you show the different things you do if you don't have good classroom management that I don't think that you're passing that on to them. And in order to teach, you have to be in charge of your class. I would say patience, and maybe just interpersonal skills because you do work really closely with them. But the hardest part for me would be, just because when I did my student teaching, I already knew the person I student taught with. My last student teacher, who has done wonderful, I didn't know but my first student teacher, I already knew her as well. So, you can give them if you have that those interpersonal skills, then you can kind of give them here's the bad news. But this is, you know, this is the way you 
need to go. Or you need to work on this and you don't feel like you're constantly just telling them all the bad stuff. You're just trying to help them to be better, I guess. So, um, I can't think of anything else. I mean, hopefully, you're a good teacher showing them good practices and doing what you're supposed to be doing.

\section{RQ 2-What characteristics are not necessary to be a mentor? Why are these characteristics not necessary?}

Michael: I said approachable for being good characteristics are probably not being approachable, somebody that's kind of standoffish doesn't want to really may be put in the time. It might be out of their control, where they're busy with their family or coaching or dinner obligations. But yeah, actually not giving your mentee any time to kind of pick your brain or just kind of sit down and see how things are going. That's probably a big thing is not giving the mentee any time to kind of build a relationship with you where you can talk about what's going on, I guess would be one that I'm it's kind of a tough one, I guess just yeah. Not being approachable, not be willing to share kind of just the opposite of what I said earlier. I think that low empathy would probably be a poor quality of a bad mentor.

Eliza: I don't know that your best teacher has to be like, I don't know that a mentor has to be the best teacher in the building. You don't have to be the one that is even a leader in the building. You don't. I mean, you don't have to be a leader within your department, anything like that. I think those things aren't necessary because it ultimately just boils down to being able to help someone through their curriculum, through classroom 
management and all that and that those aren't necessarily the leaders of the building, they're necessarily the best teachers in the building all the time, if that makes sense. The star. Yeah, you don't necessarily need that for a mentor you need just someone, like I said, that can be understanding and honest. You don't have to be, I mean they were handing out like things that they would be looking for, for many teachers, the other day and I thought, oh gosh, I don't even do all these. You know, I thought, man, all these requirements that you're looking for when you observe them. I was like, when I come in, my classroom, they're not going to see those all the time, they might see bits and pieces of it, but I think we get to kind of hung up on that you have to have a bell ringer. And then you have to have 10 minutes of, you know, code review and then you have to have 10 minutes of direct and, you know, I think we kind of get caught up in that structure, all the time that it's not necessarily, you don't need that every day. I mean, it doesn't work every day.

Angelica: So, I think being a little positive and having more of a positive outlook on things has been really helpful for me because things can be so, negative in a school environment. So, I think if you're a negative person, you probably wouldn't be the best mentor, just because you want this new teacher to have years and years to just go and do the other thing, and I think starting off on a negative foot would not probably leave a good taste in their mouth.

Peggy: There are teachers in this building that have 30 years you know of experience, but maybe too much because they're kind of set in their own ways. You know what I mean. 
Not super willing, you know, to help out. And then, you know, kind of those people that are just really narrow-minded and you know my way or the highway. I mean not being super personable would probably be in a shoe. Or someone that you know is just stressed out all the time and makes the mentee feel like, oh gosh, this is just one more thing that I have to do you know type of thing. Yeah, I mean I could go on and on about the things that they shouldn't be.

Maria: I don't guess it's necessary that you have to be a mother hen and mentor too. I mean, it's nice to have this that somebody right there next to you, to help you but you don't have to dictate everything for your mentee. So, maybe not a dictatorship, sort of, am I going anywhere where you think All-knowing, that's a great word to use, as far as a characteristic that's not necessarily needed as a mentor. And then the dictatorship, you know, it goes, I think there's one end of the spectrum to the other.

Pam: You don't have to have all the answers. None of us do. But the ability to help to find answers or problem-solve is what I think is important. And another thing that is important is the confidentiality. So, if the new teacher has some problems, you know, or, you know, issues with classroom management or with a parent or whatever it might be, with another colleague that mentor has got to be confident, you know, hold to confidentiality, so, that the person feels free to talk to them so, that together, you can kind of figure out how best to resolve it. So, I don't think we need to be an expert in everything. None of us have all the answers. I think people, you know, we need to be able 
to admit we don't and help them find the answers. You just have to be willing to listen and work with somebody you don't you don't have to be one of the top people.

Meredith: I guess some characteristics that aren't necessary are being super involved in the school as a whole. Just being a mentor who is there to help you out and have your back when problems arise is the most necessary.

Phyllis: I would be at being unorganized as a whole, you wouldn't be a very good mentor. So, what characteristics are not helpful? Maybe being completely one-sided, like one set mindset, like not being flexible? And if you're an extreme type A, I don't think that that would make a very good mentor. And if you always have to be hands-on, and so, you wouldn't allow your mentee, the privilege of failure, I guess, in a way of like, if you're constantly doing things for them, instead of allowing them to explore and figure it out. So, if you're too, hands-on, I don't know if I answered that.

Kelly: I feel like if you had somebody that just really wasn't very helpful or willing to help, that would be a horrible situation and I have heard of individuals in that position. I, fortunately, don't have that situation. But, if a mentor is just not willing to help, be there for their mentee, or doesn't provide what they need, that that's a huge problem. Because they are to be there for you and answer questions and be helpful and kind of go and guide you through those first couple years. I feel like my main mentor be my mentor longer than that because I know I'll still go to her with questions, just because we've built that relationship, so, I think I don't relationships have always been a big thing for me whether 
it's my students or friends or family, whatever it is, so, I think if they weren't willing to, overall, just build that relationship with you, I think there's a lot of stuff that would fall underneath that just really wouldn't work well.

Erin: I have no idea and obviously must not have any of these characteristics as I can't think of anything.

Jan: I think it goes back to also like that mightier than thou attitude. It was like "I've been in here and I know what I'm doing" kind of thing. Any person who is coming into the job eager to learn and eager to be a part of it, you don't need that attitude of "I'm better than you". I know what I'm doing. It goes back to what we said, the first question, is that understanding that you're both on the same level, you're both on the same team. Yeah, you might have more experience, so, let me show you about my experiences and let's work together. Because everybody brings stuff to the table.

Nellie: There's a fine line between veteran teacher and burned-out teacher. Once the veteran teacher no longer seems to care. Once the veteran teacher's just there when she absolutely has or he has absolutely had to be, that's when she probably shouldn't be mentoring any longer. Whenever the dedication seems kind of dusty.

Karen: Judgmental, because teachers are always already like, prone to being like selfcritical, I think, or at least young new teachers. So, we don't need anyone else out there feeding into that like insecurity. So, someone that gives off a very non-judgmental 
personality or like that if someone would be judgmental, I just feel like I would shut down and not really want to seek help from them. Like you need someone who's also, or like another quality that would be detrimental would be probably, like impatient, I think it requires an amount of patience because you already have so, much going on in your life that imagine any sort of mentor. I know she's mentored a lot of people. And she's kind of like that amazing at putting them first, which I don't always agree with. I think sometimes she needs to put herself first but like, she's been very patient. So, if she was impatient, I feel like it wouldn't, we just wouldn't get anything out of it. Because, once again, there'd be no connection, I wouldn't be able to turn to her for anything.

Holly: Impatience, too busy, they got a lot on their plate. It's probably not a good fit. Because it does, it is time-consuming to you know, help them out, and sometimes you have to sit down with them and work through something to show and stuff. So, meeting, organization. Now without the positive, it's been a long day, forgive me. Yeah, they need to have, they definitely need to have time. So, if somebody is too busy, or get too many other things that they're doing, I don't think that that is something they should not do. It would be nice if it was in the same. Like I do sign language, but there's no other teacher here that does sign language. And so, our I haven't Spanish with my mentee, and you know, it's different. So, some things, I can't quite understand what she needs to know as the language because I don't know Spanish and stuff. So, maybe being in the same department or teaching the same subject would, you know, it would be hard for a different teacher not teaching the same thing. So, at least be doing that can turn that to the negative instead of the positive? I think those are the two biggest things is, and I don't, 
also somebody that's been teaching for a very, very long time, I think they need to be a little, you know, maybe six years, seven years, something like that. So, they can still remember what it was like not to know, rowdy things instead of you just assume sometimes that people know these things.

Jim: I think if your mentor was too reserved kind of on themselves or not very, more like introverted, but almost to the point where they don't like to share or work with other people, that would be detrimental. Because my mentor and I, we work together through everything. Like we share our Google drives with each other, we talk between every single passing hour, we just communicate that way. And I think that if I didn't have that, then I would not enjoy the work experience as much, and I wouldn't be as successful at what I'm doing.

Tina: Someone who's not willing to share. So, we had that somebody with that last year. That was I was trying to help the other mentee because her mentor wasn't really helping, and somebody who thinks they know more than everybody else is not a good mentor. Because they feel like they're everybody's been below them beneath them. It can't be just because they're younger or they're brand new at the game doesn't mean that they're not as good or they're not worthy of your time and effort. So, so, I don't know I hope I answered your question.

Linda: Somebody who's kind of rigid and more narcissistic or individualistic, just doesn't want to be a team player. Someone who isn't willing to feed into the eye, somebody is not 
willing to feed into someone because I think that's just awful trying to get someone to talk to you and to be helping you but just doesn't want to. Doesn't care.

Louise: Okay, so, detrimental definitely would be if you don't have time, and you're not available if you're not a person that wants to give feedback. If you know, being a mentor, it has to be a desire that you're having, it can't just be assigned to you. So, it's detrimental to assign somebody to be a mentor. You can ask them, but if they're not interested it's not going to benefit you or your school district to go ahead and assign them to that. You need to, I think, personally, same-sex mentors are probably beneficial in some ways, because of the differences. And that might just be an opinion. But I just think that we're going to be more in line with the way we work emotionally. And logically in some ways. The mentorships that I've seen have always been that way. But it doesn't mean they always are. So, I just think that there's so, much a first-year teacher is overwhelmed and has to be able to completely express herself, and not be like they can't. And so, I think as women, we're more emotional. And so, I think that that mentorship partnership has to be there has to be some like mindlessness in many areas of the way. We are not just an academic. But there's other areas that we bring to the table while we're trying to figure out how to teach.

Tammy: I think, uh, being really closed off and being like, big-headed. Kind of, you know, like your way is the best way and you're not open to any ideas. Because I was in a cohort when I was doing my master's degree. And, you know, we had weekly meetings and everything, and I heard of some student teaching, open-minded co-teacher, who their host teacher wasn't open to any of their ideas, wasn't treating them like an equal, you 
know, looking down on them. And that was really discouraging for them because it didn't like it didn't give them the opportunity that they needed to grow and it didn't make them feel respected. You know, and, and I think like, part of being a teacher is just being open to other ideas, you know, like, just because, you know, I've finally made it as a teacher, like, I think we're always learning, you know, and we have to remember that even if you've been teaching for 20 years, you're still learning, you're still human, you know, and you can always do better and, and I think, yeah, and if that makes sense.

Lisa: Maybe being overbearing and bossy? They have, I feel like a teacher has to find their own way a little bit. And I'm more there as a guide or a facilitator than to just say, this is how I do it in my classroom, and you need to model me exactly. Because everybody has a different personality, everybody has a different style. I just need to try to help them be successful with the style that they have with the person that they are.

Kevin: I'm also the assistant cross-country coach. And there was a little bit of drama between the cross-country team, the soccer team, and administration, and the head coach for the cross-country team was feeling like there was favoritism towards the soccer team. And so, there's like a, like, I was clearing things up between me the principal and the athletic director. Because the soccer team was kind of worried that I was, as the volunteer assistant coach, I was doing the full job of the head coach. So, that caused some problems. And it kind of caused tension between the athletic director and the head coach. Because the head coach is the athletic director's mentee because the athletic director is also a PE teacher. Well, um, and so, I was talking to the head coach, and he wasn't too 
happy about it. And he was telling me how he was going to let the A.D. hear about it because he was his mentor, teacher. And that's one person you really don't irritate is your mentor, teacher. And so, kind of just holding that grudge and carrying it beyond the relationship of a coach into a teacher.

Tori: Um, that one's a little more difficult. I feel I'm trying to think what I don't do. Like I said, a good card is to be a leader, I don't feel that it's my job to go in. And tell them what to do, though, necessarily, I don't feel like I feel like that's administration's job. As a mentor, I feel like you're more of a guide. And not someone that's actually telling them, hey, you've got to do this, or you've got to do that. It's more of like, hey, how do you think that went? How do you think it could go better? So, instead of taking control, you don't want to take control of their classroom because it's still their classroom.

Jessica: I mean, I don't feel like you need to have the same teaching style. Like a lot of people, I think, feel like they need to have the same teaching style or like, think about things the same way. I mean, I think there's, like, you need to get along and you need to have an agreement, but you don't need to, like be exactly the same, I guess. Because that might not I mean, that might be detrimental. Because if they're trying to make you into like that type of teacher and that's not how you want to do it. Like, that's gonna mess you up and you know, get in your head or make you think about things differently or do things the way you don't want to do them. And that makes you less excited about coming to work and all that. 
Shelly: I guess, I mean, you don't have to have a great personality to be a mentor. Um, it just sometimes, if you get along well with people, or you don't have to get along with people. Um, one of my co-teachers that I had a few years ago, she didn't necessarily get along with everybody. She's an amazing teacher. But whenever she had student teachers, she didn't always get along with him. But so, you don't necessarily have to have that. But I don't know.

\section{RQ 3-Describe the characteristics of your mentor and the effects of them on your relationship.}

Michael: Yeah, I mean, my, my, my mentor, she's a rock star. I think she went above and beyond and especially, kind of being since I am from up north not being kind of familiar to the area. It was more than just getting used to the new career as a new town and all that. And, I mean, anytime that I had any questions, she was always open, whether that's, you know, during, like before school after school, even if I would just like text her. She was always open, just giving me advice and helping me lesson plan. And, I mean, she, she had, she checked all the boxes, as far as you know, when I needed or when I had questions. She was always there to answer it. But she was also not, she didn't like baby me or anything. There was always on top of me, she kind of let my let me do my own thing and kind of find my groove. But when I needed help, she was always there to provide any kind of feedback or advice. So, I got I think I lucked out. Yeah, as far as my mentor. I mean, I think we have a pretty good relationship. It was. I mean, from the beginning, I kind of felt like I was bugging her a little bit expressing the first few weeks of school. And I mentioned it to her where I felt like I was kind of bugging her too much. 
She was like, No, no, I understand where we were all first-year teachers at one point, so, she wants to do whatever she could to help out. So, I guess we just had a good relationship where I felt comfortable enough that I could ask her any questions about what I should do and how to handle situations and things like that.

Eliza: He walked in very prepared. He went through $\mathrm{CMO}$ which I think that they have a really good education student teaching program. I think they prepare their, their teachers, the best they can. I mean, your never, obviously, you're never going to be prepared $100 \%$ but I think they do a really good job with that. And he walked in all ready. Like, he was professional, very willing to take suggestions and criticism, but constructive criticism. I mean like, you know... but there honestly there really wasn't much with him because he really did come in prepared. But I would say, you know, just willing. He was willing to listen. He was willing to work with me on stuff he would, you know, I would make things up and share with him. But he would go, you know. Well, I did it this way, and he was willing to share his information with me, which is great because I could always use a different perspective on things. I handed him the curriculum. We talked through it. We sat down, we work together through a calendar, you know, he just he instinctively knew how to do all that. And I, because I don't think some of that is when you're a teacher. I don't think that that takes years to learn for some people. But for some people, I think you just have it and he had those characteristics of already you know just knowing what he's going to do in class and knowing how to be a teacher, if that makes sense. 
Angelica: At the beginning, my mentor and myself are kind of shy people not shy but just not super vocal. Um, so, at the beginning, I think it was kind of like hard for us to communicate. But now that we've kind of gotten to know each other. And we've had different meetings together and things like that. It has really helped our relationship. I think it's helped me also grow just because I know that I have to come out of my shell and I have to stand in front of 30 kids or whatever it is per hour. And I think that has helped me so, much also talking with other coworkers, not just my kids but co-workers specifically.

Peggy: So, she actually did her student teaching at another school and in the same content that she is currently teaching in. So, you know, content-wise we don't ever, you know, have to have those discussions about, you know, misunderstandings within the content. So, you know we just try to focus like on her instructional skills and strategies. So, that's been nice. She's a really hard worker. So, anything that I asked her to do is always done ahead of time she's always prepared and I will say that one of the things I've noticed is she's pretty reserved. So, you know, I want to have that, you know, kind of personal relationship with her so, that she feels comfortable, you know, opening up to me and she'll definitely come to me with questions but I feel like she would be hesitant to tell me like anything, you know, super person or like anything that's emotionally attached. So, that's kind of been difficult, and I don't you know want to overstep any boundaries with her, you know, to make her feel uncomfortable. 
Maria: She was so, in a good sense, she was kind of a mother hen to me. She's literally right across the hall, which I know a lot of mentors and mentees don't have that option there in different buildings. But for me, I was so, lucky. She's literally across the hall. So, she would often come and pick her head in and say, "Is there anything you need help with. Do you need help, you know, organizing something and coming up the lesson or strategy, to teaching you know something we're doing in class." She was always peaking her head in. And then, so, I'm even like what parent-teacher conferences. My first part parent-teacher conference, three weeks beforehand. She's already coming in my room, saying, hey, you know, to need are you prepared for it. So, in a sense, in a good way. She was kind of that mother hen, but she wasn't overwhelming, if that makes sense. She, she had a perfect balance of making sure I was on the right page and wasn't getting overwhelmed. She, like I had mentioned before, she was open-minded, she was willing to hear my ideas which made me feel very accepted into this new role. So, that was really good. I don't know. And as far as for me, my side of it the willingness to just put myself out there.

Pam: She was student teaching here within sped and ended up, not even sure how, but in ELA with us. So, she is not trained in ELA, specifically, but what's awesome about it. And this is what I think is the best for the mentors. When you meant when you mentor someone, she's so, creative. And she has all these great ideas that I never thought of. And every time you know I have a new person in my classroom, whether it's student-teacher or whatever you just learned so, much from them. So, it's a benefit to both the mentor and the mentee. So, I think that's the best thing is, she's so, creative. She, she has great ideas, 
especially when we're not in covert situations. She has great ideas for cooperative learning activities to get the kids talking to each other and moving around and she's just phenomenal. I mean, she just made a breakout box. We're going to do "The Tell-Tail Heart" and she's made a breakout room and so, I think that's the best thing about her. She's so, creative and fun and kids love her and I do too. I'm learning more of the techie stuff she knows how to do all that stuff. And I, I do too. I mean, I know a lot, but she has just come out of college. I learned from her all the time and that's the good thing about the relationship is making sure we're open to learning from one another and the mentor needs to be open to those ideas that the new teacher has because they had great ideas. It's refreshing. Like it's good for the kids too because it's not stale it's new, you know,

Meredith: My mentor is absolutely amazing, she has helped me out more than I even expected coming into a new school as a first-year teacher. She has guided me to become more independent. She is very easygoing and non-judgmental.

Phyllis: So, she's super flexible. And she is also like, just goes with the flow. So, I don't know. Yeah, so, it makes it really easy to work with her. I guess he's never needy. So, I've worked with other mentees that like, are at my door every day. She never asked questions. So, I don't know if she doesn't know the answer, or if she's just got it, or if she's found the answer out on her own. So, that makes it a little challenging to read her someday because she always seems like she's got it and she doesn't ask much. So, yeah, I think that she is flexible. She's typically really positive. And she's kind to the students, which I've noticed her being able to develop great relationships with the kids. 
Kelly: She is very patient with me because, like I said, I do ask a ton of questions. She often will say I help her as well, so, we feed off each other. Really, I think that she's so, easygoing. You know, she's up for anything. Even if I have an idea she's like, "Well, what are your thoughts?" She asked me questions like, "What are your thoughts and ideas on this?" She doesn't just say, "Well, this is how it's done, and this is how you should do it." So, she's not pushy. She's very easygoing in that sense. She's just always they're willing to help. If I ever need anything say hey you know I need something real quick I forgot, you know I didn't have this prepared, can I borrow this and she's always willing to share whatever resources, she has. So, she's kind of sharing patient helpful she's just all of those things. I think it just fosters that relationship. It just makes it grow even more just because she is so, patient and kind and helpful that, you know, it makes it... she's very easy to get along with. So, I just think all of that together really pushes our relationship to be strong for us to work well together. It just builds that relationship.

Erin: I did not have a mentor in my building when I first started teaching. It made things much more challenging to find out the basics of the school. We also didn't meet all that often throughout the school year. I remember going to observe her once and thinking she was a great art teacher. I don't remember her giving much advice on how to be successful in the art room.

Jan: She is amazing! And the fact that when I came into this district, it's not a district that I've ever worked with before, and the people I'm working with I didn't know any of 
them. Along with that comes with different facets of "this school expects this" or "this program expects this", and sometimes that's really intimidating to ask your co-teacher. See, we're not in the same building. She's in a different building than I am in and so, sometimes it's one of those things where I don't want to ask the people around me a question because that may look bad on me that I don't know this answer, or whatever. So, having that mentor who is non-judgmental can say, "Hey you know XYZ is happening, can you give me some tips? Can you help me out?" I have these specific students who are giving me problems and I can't figure this out, so, I think the good thing with her is that I can ask her and she can help me and it doesn't look bad upon me, you know I'm saying? And so, that's just a good quality to have in the mentors. Having somebody has been a good thing for me in this district as I've been able to have somebody kind of bounce stuff off that's not going to go and be like to my principal like she has no clue what she's doing. What I love about her is she's very nonchalant. It's like, "You know you're okay here?" Openness/sharing--I think some teachers want to keep all the information and lessons to themselves in fear of the mentee surpassing the mentor. Having somebody that can relate to who gives me those experiences that she's had and what she also builds with them. That's the cool thing about, I think, of any kind of mentorship program that you have is that you have that availability to bond with another person and build a relationship, a professional relationship, with somebody that can also help you build the relationships around you in your cohort or whoever you're with. One of the biggest things with her is that she just makes me feel comfortable and she reassured me that everything's ok, you know. Even if it's not, she's like, "Yeah, this is bad, but let's fix it." And that's any mentorship program. That is one of the foundational skills I think you need. I think that 
you need to have that because that's what it is, it's a building teaching relationship to understand that this is not something that you have to go through alone, you have somebody to bounce off and to help you get through those days. And I think that that's what eliminates that burnout is that you have somebody to bounce it off of. It's not people that you're with, it's not people you work with, but it's somebody that you work with on a professional level but that's not on your level.

Nellie: I love the enthusiasm! The enthusiasm actually kind of keeps the dust, I think, off of me. In my experience, they come in bright-eyed, they're going to change the world, and I need that. Because, this is a brazen job, this is a brazen area. You're going to do hotlines, you're going to see kids come in dirty, you're going to have parents fighting. And you can't cry with the kids, you've got to be the grown-up. So, to see these wideeyed kids, you know new teachers, come in and they have a zest and they have an excitement... that is refreshing. Because you still learn from their ideas and you get to still witness their perspective. Now the problems and concerns with that are that there is they come out with little guidance and they are going to take on the world. They haven't quite realized that they're on damage control. My first year, I was going to change lives. About six weeks in, I realized that I was on damage control. But, as I got my footing and I just figured out some things I ended up, I think I do change the world for the for a better way. But, I'm not a superhero, and, unfortunately, the new guys they think they are. But they're not, and it's a rude awakening. And it's sad sometimes because a lot of the new ones break because they didn't change the world in their perspective. I love her zest, like I was talking about her. There is a bit of recklessness at times. There is a bit of, "It worked for 
this teacher several years ago, it's going to work for me." Whenever they asked me for advice and then they don't take my advice. or even better call me out and say I don't agree with you. I let them do their thing, but there are times whenever I also have to stay late and help them pick up the pieces afterwards because it didn't work out. So, the excitement is awesome. When they're not listening it's a huge concern. And not only that, but whenever they're not listening and the administration finds out they're not listening and they're doing their own thing then I'm also right there with them in the principal's office and I'm not a fan of that.

Karen: Um, okay. I also want to preface this with I was never in education. So, to me, this is my first experience ever with a mentor. Like, I don't really know what a mentor is, like supposed to be or anything. So, like, I hope I'm not, I hope you're not like looking for answers. Any questions? I'm completely like, missing them completely. I don't know, really what a mentor is supposed to be other than what I've experienced this year. Okay, so, can you repeat the question? Okay, um, I feel like my mentor is very communicative, I should have added that to the list of things, I'm going to think of all this stuff, I could add it now. She's very communicative. And that's been super important. I said, like earlier open is important when like my mentor, Annie is very open and communicative. Meaning that I can go to her, but she can come to me. So, it feels like we have this good bond where we can just help each other out anytime we're in a difficult situation. Another characteristic of any nurturing, I feel like I'm going to very emotional path because I'm a very emotional person. But she's been very nurturing throughout this experience. It's like having someone there the whole time. It's like, I got you, I got you like, not holding your 
hand a kind of like, they're to the side, metaphorically speaking, they're like good. The only thing Okay, you're good. Um, she's also just, I don't know what the word would be in, but she constantly is like checking in with me being like, Okay, do you know that this is going on? Do you know what this is? Have you seen that email, so, don't really know the word for that, what that would be. That just to me is like another way of communicating like communicative again. Um, I don't really have any negative things to say about any anywhere that she, like, doesn't know like, I feel like technology is in a strong point. So, she can't help me with technology. But in that way, because she's been so, like, honest about that. And then, like, technology's not my thing. I feel like I then can support her. And then I can be honest about stuff. It's not my thing. So, I guess honesty is another thing. Not acting like you know everything, but being there. I mean, like, I'll figure this out with you.

Holly: We were like really good friends. We hit it off right at the very beginning. And her I mean, it's just willing her willingness to learn and, and look at me and my suggestions. And because they're different subjects, to be able to say, I don't think that work for me. And this is why the openness that we could communicate, and I could tell this is why you might need to do it this way. And to be able to take that her characteristic of just, you know, being accepting and the kindness she shows and not going "what you know" kind of thing or "why are we doing that stupid", you know, kind of thing. She's okay, you know, she's willing to listen to what I have to say. And then sometimes, she goes a different way. And that's perfectly fine with me to get to decide for herself what's best for her. 
Jim: I think that my mentor, she's been there a while. She does a really good job about just making sure that we're both communicating with each other. And we talk every single day we talk we both get there. First, we're the first ones that we talked about that we plan together every single day. She's a very positive person as well, naturally. And I do well with that, because I am too. So, I think that helps a lot.

Tina: He is very positive and very eager to learn, willing to give input. So, he's willing to listen to what I have to say, but then willing to also give his two cents and we have a very comfortable relationship to where I'm not judging him. So, not being judgmental, just, you know, in sometimes, you know, yeah, you'll be like, well, you try that, and let me know how it works. Because, you know, you never know what might work for you. But, um, so, I think being willing to take risks and listen to each other and feeling comfortable in that relationship, knowing that one's not better than the other.

Linda: Yeah, so, she is, of course, a good listener. As I like, I've kind of already kind of mentioned that a couple of times. But she's been able to help me process through a lot of issues or situations that I just needed to talk to somebody about and figure out what the best path to take. Like, if a student's not behaving in my class, should I? Okay, that's fine. Should I email the parents should like she knows the people. That's okay. I'm not I'm on an interview right now. It's okay. Sorry. Okay. So, she's patient, she's helping me figure out if I need to, like email a parent or thinking about human parent, she knows who is going to support me and who might not. And so, how to handle those situations. And 
she's just willing to invest in me, and she helps me, too. Just want to make my program better. She wants to see an opportunity for kids. And so, I know that she's investing in me, and that makes me want to invest more in my students.

Louise: She goes to church where I go to church and her brothers were in school with my sons. So, I saw her at a service. And honestly, she just told me, I got hired to your district. And immediately I was like, oh, man, she's a first-year teacher, this is going to be crazy. And I know that at times this district hasn't been the best about matching people up or even providing for anyone. She was coming into a difficult position, we had not been able to keep a teacher in her position. So, that already was going to be rocky. And she was coming in in the middle of a school year. So, I told her, I would come down to the school the next day and get max to come down and get her machines hooked up and get her situated if she'd like. And she said, Well, that'd be nice. So, at that point, I just was doing that didn't really know her well, didn't really know her family. Well just kind of went to church, the same place I did. So, I came down. We did that. And then they ended up later on assigning me to be her mentor. Now, she is very articulate. She is very enthusiastic. She wants to learn, she's willing to listen and apply new ideas, new classroom management, whatever you need. She is like the perfect kid to mentee because she really desires to do it. And she wants to be successful in the classroom. She comes to my room almost every day after school. Sometimes she just needs to talk about how hard the situation was. Sometimes she has a question. Sometimes she's just checking on me to see if I'm doing okay. So, I really feel like in the circumstances her and I have, I've gotten to know her very well, and she has me. And it's worked out to be probably the best 
person I've ever had the privilege to mentor. I think a mentee needs to know how to ask questions and not be afraid to do that. They have to know You know what, this is a safe zone for you. Because this is going to be a lot on your plate. So, they have to know that they're safe, they have to know you're available. And she has done that she's coming here freely. And if she can tell if I got too much going on, she may just stay a few minutes. Other times I'll be like shut the door hang out for a while. But you got to be able to pick up on body language. You know, you just got to be able to because sometimes we just want to help so, much. But we know that other person isn't going to tell us not to be there and she can tell that I need at my even junior high kids. Sometimes I'm just wiped out at the end of the day. But she actually is reads how that goes. So, she has the characteristics great articulation, really organized, willing to try new things. Always shows up on time always does what's expected of her. This district is very fortunate to have her on board. And I've told my students that we're very fortunate to have her you guys need to make sure that you're doing what you should be doing.

Tammy: She is just a really caring woman in general, like, she's caring to all of our students and all of her colleagues. And that, that was really good for me, because I knew that it was like a safe space to fail, and a really safe place to succeed, you know, and, and even now, she's just next door to me. And so, like, we, in between every class, we go to bathroom at the same time. So, then we're like, it's like a, like a therapy session for like, three minutes. And then we go back to our class. And, you know, like, sometimes she has a really stressful class, and I listen, and sometimes I have a really stressful class, and she listens. And well, still, like, even though I'm not a student-teacher anymore, like we we've 
developed that relationship, and it's bounce ideas off of each other. And she's really the only other science teacher in our building. So, it's kind of nice.

Lisa: My mentee is a hard worker. She's very well organized. She has a bubbly personality. She's enthusiastic. It's she we really brainstorm well together as far as ideas, I get ideas from her and I hope she gets a few ideas from me as far as topic, delivery of material. Our personalities are a lot the same, which has helped us. We have the same, the same work ethic. But we're very different. You'll see when you interview her if you haven't interviewed her already. We're a lot different in age. I'm about 30 years older than her, which is good in some ways. But at some times she's she thinks I'm probably a little too old school, I consider myself somewhat not innovative, but I'm willing to try new things. And I've tried to make keep the classroom exciting, and I try to do all the new stuff that I can do. But I'm a little stricter as far as discipline than she is. And I know that that's just something you have to kind of learn. So, you know, she experiences some situations with classroom management in in the classroom that I expected that she would experience based on our personality. But I had the privilege of, of her student teaching with me this year, actually, for 11 weeks. And then she actually went into a position here at our school, which doesn't always get to happen for a student teacher to go right into that. And so, it's, I was really able to mentor her I guess, and up close and personal way, during her student teaching time, and that's, I really feel like I got to know her better than I would have if she would have just been assigned to me and said, Here, she's your, she's your mentee. And you know, but I do... she is having discipline issues right now. And she's probably not really ready for my, my strong advice on it. Right now, we just have 
to, I just have to sense where she's at. And just ask her what her ideas aren't giving my feedback. As she'll accept it, I want her to still be your own person, even though I don't necessarily I feel like is which this is hard for me, I have to just let her kind of try some stuff that she wants to try. And I can offer her my input that this really isn't gonna work. But she really feels passionately about trying something sometimes. And so, I try to support her in that scale. Let her fly. And then, you know, give her some Kleenex whenever we have to fix it as a lady. But, you know, I don't know everything either. And sometimes she does have ideas that you know, they do work, and they do reach that younger generation. So, I have to, you know, have tried to have respect for her ideas. One, I don't know if this fits in with your question or not. But one thing that I think would help us more is if we could be in each other's classrooms more, you know, pocket actually see her and be in there not so, much to judge what she does, but just to support her in and what she's trying to do. Be it's easier to build her up and point out the things that she is doing a fantastic job at, if I could spend some time in our classrooms seeing her do those awesome things. As we don't even have the same plan period. So, and we don't have the same lunch time. And so, the only time we literally talk now is before school or after school, but we're both so, busy trying to plan for the next day. But it's hard. It's really hard to you know, make that quality time to just chat.

Kevin: I really feel like I I've gained a lot from my mentor. Um, she's patient. But when I do make slip-ups, she's also firm with me saying, like, letting me know what, what I need to work on. Last year, I had a, I had a little bit of a, an attendance issue, where I was constantly showing up like two minutes before the bell, or even at the bell. Um, and so, 
she made sure not only did my principal, notify me of it, but she also let me know that it kind of shows the students that attendance isn't that important. So, she put that in my mind, but it's also very patient and understanding of being a first-year teacher taking on assistant coach for cross country and track and having these four preps and coming in on a year where the middle school wasn't necessarily the easiest group to deal with. She's very patient. And when I have problems, she does take the time to help me try to brainstorm ideas and solutions. And so, the characteristics of my mentor is she's very patient, she is open-minded, and willing to help me brainstorm alternatives to what I bring to her. And what that has done for me is kind of everyone in that hallway. Is it I know now is someone I can ask because she will send me to someone else. If she's not well equipped. in certain areas, you'll send me to another person. And so, it's, it feels pretty natural to just pop into her room, ask her a question. She'll pop in my room and see how things are going.

Tori: I feel that the good thing is that he's very passionate about science. He knows a lot about science that he's teaching. One thing that we've had to work a little bit is classroom management. We have a really tough group of eighth-graders. So, I have struggled a little bit with that. But what I tried to do is work with him to where, hey, here's what I try works pretty good in my room trying to get some gains, because he's coming to me several times and like, Hey, I don't know what to do with them. So, he's always very willing to come down, ask questions, he's willing to listen to advice. And, like I said, He's not and he's passionate about what he's teaching. So, I think that makes a big difference. And like, when I said in one day, I was like, okay, just one day, you might need to just 
like dumb it down a little bit. Because in your mind, it makes total sense, because you're teaching this subject. So, um, but I said, like sitting in or not knowing. But like I said, He's always very open and receptive to, to listening. And that I feel like, you know, it's made him very open to coming down and asking questions, because we're just like, right down the hall from each other. So, he doesn't have a problem popping down the hallway and saying, hey, what am I doing here? And like if he's going to be gone, or if he's going to be running late, I have first plan period. He'll email and be like, Hey, I'm running late. Can I Can you make sure my class is covered for a few minutes or something, which is what I want him to feel like that he has someone that he can go to. It's not my job to say, hey, you shouldn't be late all the time. It's my job to pay out help young company so, that so, that they feel like they've got somebody there, I'm covering their back a little bit.

Jessica: She's very sharing, like of resources of I mean, like manipulatives Like all of those sorts of things, even books. So, I would say sharing even of ideas, you know, all of that is very necessary. Um, I would also say she's very approachable, you know, I can go and tell her anything, or ask her anything, and she's going to answer my questions. Um, I would also say knowledgeable. I mean, she's been here for nine years, you know, she has experience. So, she knows the school, she knows everybody. So, she can, you know, make the connections or tell me who I need to get in contact with, or whatever I need to do.

Shelly: Um, she is a really good person. She's a Christian. She loves her students. And she, when she came in, she came in excited about teaching. It wasn't "I'm doing this 
and...” blah, blah, blah. It was, "I can't wait to do this!” She comes in every day, it's a new day, she comes up with more ideas to reinforce. She uses lots of strategies. When teaching, she does lots of modeling. I mean, she was meant to be a teacher. She is just that it's just one of those people that she just came in. She came in as a student teacher, but she had her own class. So, when I observed her, it's like, you're doing everything. And I can hear her through my wall. She's right next door to me. So, whenever I hear her teaching, when it's quiet in my room, she's doing all the right things. She's not. She's not being overly nice, but she isn't punishing everything, everybody for everything either. So, I don't know, she does a really good job. She made it really easy to be her minty.

\section{RQ 4-Describe what you feel the mentor should be responsible for in the mentor/mentee relationship.}

Michael: Um, I think responsibility for the mentor is just to be kind of be it just provide guidance. Be someone to give advice and give feedback to them.

Eliza: They have to at the beginning of the school year, they have to help them get acquainted and adjusted to the building. I mean, whether it's bathrooms copier, you know, I mean just the little details that being a teacher in the building, you need to know. I think that's really important. Grading systems just that basic school information is it's very important. And it's a lot of things that you don't feel like are necessary. But, to a new person walking in the building, they don't know that on Mondays, Wednesdays, and Friday, we have a bell schedule that looks like this. But then on Tuesdays and Thursdays, 
we have a bell schedule that looks like this, you know, just those kinds of details are important. Just that basic school information. And then I think it's really important for just communication on curriculum and checking in on them.

Angelica: I think that kind of getting things started is kind of the mentor's role, just because the new teacher doesn't know what is even going on yet so, like the first week of school or the first module. And like not doing it completely by themselves, but inviting that new teacher to come in and sit down and say, "Here's how we create study guides, and here's how we create summitives, here's how we create what we do on a daily basis, based off our pacing chart and things like that because coming in. I think I had a lot of great experiences in like field observations and being observed in the field, but I had never created like a simple example, like a study guide. I've never created a study guide for something so, she actually caught brought me in and showed me. Here's how you take a screen a screen capture of whatever's on your Chromebook, and you can paste it onto a different thing like things that made my life so, much easier,

Peggy: Okay, um, you know, so, just kind of like, first off, like just welcoming her into our building, you know, with those first couple of days. You know, just so, that she doesn't come into the school walking into a meeting, you know, totally overwhelmed. So, we, you know, took her on the tour of the building, you know, introduced her to as many teachers as we could, you know, just making sure she was set up in her classroom with any materials that she needed or resources or anything like that. And then once the school year started and she, you know, just kind of checking in on her. You know, kind of 
emotionally and academically, as far as you know what she needed. And then, you know, kind of like what you said some of those more formal things is, I have observed her, you know, to give her some feedback on her instruction. And we share lesson plans. You know, giving her, I gave her like my lesson plans and then I always tell her like don't feel obligated you know that you have to use these, but at least they're available to you if you need them. And then just kind of like I said be in that check-in person and she's just two classrooms down for me, you know, so, I can just kind of pop in and check on her.

Maria: She literally helped me with just getting into our school portal getting my class roster set up, my seating charts. I'm talking like just the little stuff that I mean I knew to do that. But she showed me how to do it on our, on our Infinite Campus school portal site. She showed me how to set up my grade book and she just she just made sure I had all my ducks in a row. So, her responsibility to me was just making sure I was ready. Even though yes on the inside and screaming and feeling overwhelmed, technically I had everything I needed because she made sure that I was getting everything ready that I needed to get ready. So, I would say definitely her first role to me, I guess, was to make sure I was ready for day one, with all the little practical things that need to be set up all that. Gosh, what's the word, I'm looking forward to all the things that need to be set up beforehand. An open door that I can come on my prep and watch her teach. Just watch her teach. She thinks there's things that she knew how to teach better obviously than what I did. Some lessons were coming up at one point where I had no idea like I had to sit down and teach myself. I had no idea what else speaking. So, I asked her, can I come in and just watch what you're doing. Her other responsibility, I would say, then, is just being 
available for me to come and observe and learn the strategies that she's using in the classroom. So, I truly appreciated the fact that she was always an open door for me in that respect.

Pam: So, at the very beginning, it was the basics. You know, like she knew some things about our schools because she's students hot here but it's content. She doesn't know specifically eighth grade LA content, you know, so, she's having to learn from, from our department we had. There's another person that teaches eighth grade and we just work really well together but I think at the beginning, the whole the classroom management, you know, and then there were the first year some parent issues you know that we had to talk through together. So, I would say classroom management at the beginning classroom management, let's say like lesson planning and parent communication and solving parent issues. But then as it evolves. I mean, we're just equal professionals. And so, I think we have a responsibility to accept the mentee as a professional on the same level. We're not I'm not above her. We're in the same level. And so, it's a give and take relationship. But then also I have some things as mentor that I have to make sure happen due to DESE requirements. So, it's important to make sure they're keeping track of their professional development hours, that they've done their beginning teacher Assistance Program workshop, that we're talking through the Missouri learning standards and helping her understand those, and how she is applying those in her classroom. 
Meredith: The mentor should be first off responsible for all the paperwork for the mentor/mentee program which gives us new teachers less stress for our first year. Checking in on the mentees ever so, often.

Phyllis: The mentor is ultimately responsible for like the overall wellness of like, check checking in to say, "Are you doing okay?" The dropout rate for teachers of not making it more than five years is real. We're not making those statistics up. So, overall, saying how are you doing? And the responsibility of letting them know not to sweat the small stuff, and again, the failure component of Yeah, that's okay, move forward, move on, pick it up. The next day, no one's going to remember instead of like beating yourself up about things you can't control, I think is the overall. And like, learn, of course, learning the procedures and learning the IEP process and learning the building, of course, that but the bigger picture, I think the responsibility of the mentor, is letting them know that not to be hard on themselves, and that the job is hard. And to stick with it if they still like have the passion to so, we don't lose more good teachers. So, I think it's ultimately the mentors, responsibility to introduce them to people in the department. But then I think it's a group effort, like we need to surround each other. And as long as you have like a really good team around you that you collaborate with, and that is a part of your department, that shouldn't be a hard task.

Kelly: I think that mentor really needs to make sure you know just simple things like how the building works, where things are, and the do's and don'ts. I mean, there's been things like even still today, you know, I'll have, talking to another teacher, say, "Oh yeah, well 
you're never supposed to do this, or you're never supposed to do that!" I'm like I was never told that you know, so, I think just them laying things out for you and saying you know this is how this works, and you know if you ever have any questions about it. But, providing them with kind of those basic steps to get going as far as knowing your building or your district, maybe resources other teachers or things that might be helpful to you and your content area. You know, pointing those things out. Just that guidance of maybe they should check and say, "Okay, just to keep you on track, what are your plans for next week?" Which we do talk about that a lot. We teach some of the same classes, and so, we. collaborate on what we're teaching in a certain course for the next week. I think the mentor should provide that guidance and ask you those questions, just to make sure you're on the right track and you're doing the things that you need to be doing. She's always told me she feels like oh you got this you know what you're doing. Why, you don't even need my help. But, I do think that is important. I've had friends that are like, "I don't know what I'm doing. It's my first go at this and I need some help, and who do I asked where do I go?" So, I think that's just it's just the guidance and kind of those steps and just that basic information that you need to know.

Erin: Guiding the mentee. I feel there is more than one answer to any problem. My mentee doesn't have to have the same answer that I have. I want my mentee to see many options and choose the one that best fits her. I am there if she needs to bounce off ideas or to work out problems. I am not going to give her the solution but help guide her to finding the solution that is best. In the beginning, I also think it is the mentor's job to 
show the mentee "the ropes" of the building. Where is everything, how do you order supplies, that kind of thing.

Jan: The mentor/mentee programs always have a lot of the paperwork, the deadlines, and all the observational stuff, and all the nitty gritty paperwork type stuff. And she keeps me in line with that, because as a second year in this district I have a lot going on in my personal level. And I know she does too, and so, she just keeps me on track she's like hey you know we have this let's do this day. And, and that helps me out a lot, because, as she's got a system she's got you know set she's been in the district for a while she knows what she's doing. Sometimes I get overwhelmed with deadlines and dates and things like that, because I haven't streamlined everything quite $100 \%$ yet. Where she's like okay here, this is what's do we have a week let's get it done. She has weekly check-ins with me. We check-in, "What's going on? You're needing two questions." You're having them and it's one of those things that. As far as the mentor responsibility, is huge for me, is that she takes on that responsibility and she checks on me. You know and it's one of those things that I'll reach out when I need help, but most the time it's those check-ins and the deadlines and she has held on to that. And it is tremendous for me and helped me out. Because, I've had mentors before and other districts that I worked at and it's like you're floating on your own. "If you need my help you call me." And I'm like that's great, but I don't know what I need help with. And that's just another added stress to what's going on. So, as far as the mentor's role, I think, for me in this situation, this has been great because she has taken control of that and contacted me and kept me on track with dates and things like that. I think that it is great being able to introduce you to other 
people, kind of get you comfortable with the environment that you're in. Procedures and like professional development things that they know that you would need. Those kinds of things, heading those up, and getting those introductions. I think those are phenomenal things. Because coming in, as a new person, you are on your own. Like if you, especially if you have nobody else. So, that is like your contact person is that your that's your branch. So, yeah definitely I think they should be responsible for kind of introducing you to everybody. You know she did introduce the principal and kind of talk, talk to you like facilitate all that is a great thing. Because, like again, you're in the middle of an ocean and you've got a life preserver and that's it. Like when you have a tugboat that will help take you to the mainland.

Nellie: I need to make sure that she can do her paperwork, or he can I need to make sure that data is collected correctly, I need to make sure that procedures are followed appropriately. I need to be there emotionally because yeah like I said earlier, they come in wide-eyed and gonna change the world and they're gonna hit that wall where holy cow it's a different world than it was six months ago, in a college class. So, I need to be there for them emotionally. It's almost a parent relationship at times. I need to make sure that they're turning everything in on time, I need to make sure that they show up on time. I need to make sure that they're taking care of themselves it's huge deal to be a mentor. So, I mean it's a lot it's almost like a parent thing so, it's good to have a strong relationship. Show them the ropes teach them the folks. Show them who's really in charge, which we know are the secretaries, custodians, and the cafeteria ladies. I will show them, you know the unwritten laws, the unwritten rules and then the next year you let them go and figure 
it out. If they're making very bad decisions on who they hang out with like you know the teacher that sneaks out early, or this and that, or the gossip or something... maybe drop it in conversation here and there, but for the most part, you got to make them, let them make that decision.

Karen: Well, I don't actually know any of their responsibilities from the handbook because I got that in the beginning of the year, and it's been a heck of a year. So, this will be just going purely off of my opinion. So, you said that what should be their responsibilities? Um, I feel like they're like main responsibility is just like check-in and make sure that the mentee has just a basic clue of what's going on. And that includes, like, I think people underestimate, like, letting them know about small stuff mean, like, do you know what that means? Do you know what we're supposed to do on fire drill days? You just got an email about club day. Do you know what club day is? Do you need help figuring that out? I made these flyers would you like any help making a flyer like constantly checking into me like you good. Do you understand? Do you need help with me explaining it? So, I think a little day-to-day stuff like that, just making sure that like certain things that everyone else at the school kind of takes for granted is like, Oh, yeah, it's club day. Don't know what club is didn't know what it was, I was freaking out about it before school started, I was like, code day. So, she, like, always have my back with that. I think another responsibility is just like, I'm gonna say it again. Now emotional support, just being like, hey, there's gonna be days where you're really struggling. We've all had them. If you need me to step in for you, I got you like, knowing that they just having that 
emotional support system, I think is like been something that I don't think I could have truly gotten through this year. without you.

Holly: I think a lot of times, I'm assuming I did not go to like I said, teachers' school. So, I don't know, how much you learn, or what kinds of things that you learn in that kind of things. And I've been told before, there was a lot of things that never came up what they were taught, you know, in school, or, you know, there was a lot of things they didn't learn in school. And it's just kind of knowing what we do as this school and what, what might be different from a different school. So, I would take the traditions, different policies, those policy-type things that aren't written down anywhere, you know, that are just known. I think traditions are a big deal to know and that you're not caught off guard. I remember feeling like what are we doing? You know, I don't know what we're doing and what my role is and stuff and just kind of, you know, letting them know what role they have in it and what forms need to be turned in. Spiritually if it's one that you've done for a long time, but you're realizing that no one's talking about it, and it's going to come up soon. So, they need to know about it before it hits him in the head, you know, kind of things. Just kind of The basic serve like, you know, out Fridays we get to wear jeans. And or you probably shouldn't do that because it's not looked, you know, do not shut the bathroom door because it's walked permanently. That kind of thing. But I think it's my role to make sure that she gets things done that is expected and that she might not know about. 
Jim: So, she has done a good job in our school district does a good job providing like, this is what they need to make sure they're doing. They're required to check in on us, which we naturally do anyways. Checking in is important, even if it's just like a, Hey, how are you doing today, or like that kind of like a mental check-in more than anything. I think that needs to be a thing, not necessarily like paperwork, showing that you're doing a bit, they just need to have that relationship. She's also been really helpful going through, which our school kind of requires that the same time, all of like the PD stuff that I have to do as a first and second-year teacher making sure I have all my paperwork, I have all that kind of stuff in because it's a lot to navigate. So, she like keeps an extra copy of everything to be like, "Oh, these are all the service days that we did. Here's a copy of the paper." Like all of that kind of stuff. I'm worried about making sure my lessons are good for the next day and grading and just making sure that all of the kids are good, and not all of the other stuff that just comes naturally to them at that point. So, like keeping up with all the paperwork, and just helping with that is good, because they're used to it.

Tina: The beginning of the year, making sure that, you know, they feel comfortable with all because you just get bombarded with so, much stuff, just make you feel that they're not over, making sure they don't feel overwhelmed, and telling them you know, in the scope of life, it's gonna be fine. Just do what you can do. It's okay, if this is do but do you know, prioritize, get done whatever you need to get done first. And just trying to make them feel like, yeah, you have 100 million things coming at you that, prioritize it and get it done. And, you know, if you don't get everything done at the date, we will, it'll be fine. So, just and then at the end of the year, making sure they have all the checkout. And so, 
those are main things, but then the meat of everything, you know, just getting together and planning out units and tests and all that kind of good stuff.

Linda: I think asking questions. Probably trying to get a better sense of what the culture is of the school. Whether that's asking about demographics or students, brothers and sisters, and just trying to understand the students more. So, asking lots of questions about the school itself, how to approach it, how to talk to students, those kinds of things, I think is something a mentee should be asking.

Louise: Well, this district doesn't have anything set up that. And I know some school districts do that you fill out the paperwork, and we don't want things to just look good on paper, that's not going to do anybody any good. But the responsibilities do include that you are available, and that you're willing to go down to that classroom and watch what's going on to help her or the guy that is being a first-year teacher. I think that responsibility is not clarified here. And I think it's good that it would be I don't really even know how to put them down in a list because it's never been done in the area that I'm in. But I do know that basically, if you're not going to be yourself available, if you're not going to really desire to have that teacher be able to do what they need to do as far as ask questions and try new ideas of yours and share your experience that you have as a teacher, then you have to be open to give away your secrets. And you have to be open to be willing to help them invest in what they're trying to get to. 
Tammy: Um, the first thing that comes to my mind is being intuitive about what level your mentee is at. Because, I mean, like, I think I was a really fast learner and grower, but I know that there's probably a lot of people, other people who aren't, you know, and so, maybe somebody else might need like, three more weeks doing more preliminary things, you know, or maybe they might be ready to ready more ready before me, you know, and I think just being conscious of where they're at, and being able to kind of structure their experience gradually.

Lisa: I never really thought about that too much really, or I definitely felt like for me, I want to be, I want to be a support. And I want to provide her with answers to any questions she just has about daily operations. Our district, you know, when you're new here, you don't really nobody really tells you where to where the best place to park is or where you just all those nuts and bolts questions. I feel like a mentor can do a good job helping with the nuts and bolts questions about what do you do about grades? And what do you do about parent-teacher conference? And what do you do about this? And what do you do about that? And like just someone to ask instructional questions about.

Kevin: I'd probably say the mentor's responsibility would be to ensure that the mentee is feeling comfortable in their role and that if they are having any troubles with students, whether it's creating lesson plans or classroom management, helping provide those strategies or resources to look up those strategies and checking in with them to make sure that they are making that progress so, that they are growing as a teacher. 
Tori: I feel like our job is to help make sure they know, number one, safety features, where all that's at the school, to kind of help them know procedures, extra expectations, that's all laid out, like in their beginning of your orientation when they start, but sometimes it's overwhelming when you're told a lot of stuff. So, we have like a monthly checklist of certain things to go over at certain times of the month. So, like, especially like October, you know, parent-teacher conferences, I think it's good to have a checklist of things that are relevant to your school, during that particular time period, to kind of have a checklist to check off, hey, did we cover this? Hey, did we cover that because something we do on a normal basis, may not be normal to them, because they've never done it before. So, and it's easy to take for granted that they just know what to do. So, I feel it's our job to make sure they know all those expectations to kind of guide them in their classroom and answer questions that they have. And, and it can just be a mental support for them. Because sometimes they just need someone to vent to. That has nothing to do with their curriculum. Maybe the kids are really bad that day, maybe their lesson bomb. And sometimes it helps just to let off some steam sometimes.

Jessica: I would say, just checking in to make sure that they feel comfortable and make sure they know what they're doing, or they feel like they know what they're doing. I'm just making sure that they're getting everything done that they need to make sure they're aware of things on different deadlines, things like that. And I would say just to be open with the other teacher or with the mentee, let them know different things. I mean, and being honest, you know, if they're doing something that's wrong, you know, it's nice to know, because sometimes you don't realize you're doing something wrong. 
Shelly: The mentor should be responsible for making sure that their mentee is doing okay. I'm scheduling meetings with them on a regular basis, doing the paperwork. And then, of course, we have like, which I know you said it wasn't necessarily school, but we have like a checklist of things. So, making sure that those checklists of things are gone through so, that our mentee knows what we're supposed to do and when we're supposed to do it. So, let's schedule of events, possibly our list of rules and guidelines. Several things it's like, so, this is how we do it. So, that she knows, but it's not necessarily for all schools, making sure that they're doing their grading and their grades, punctual, those kinds of things.

\section{RQ 5-Describe what you feel the mentee should be responsible for in the mentor/mentee relationship.}

Michael: On the flip side, being a mentee, I think it's crucial to take the advice and take the feedback and be a sponge. And don't take it personally that they're doing the that they're giving you feedback, giving you advice to better you, and help you, you know, develop as a teacher. So, I think that's kind of the biggest responsibility just being openminded as mentee and being a sponge and taking the feedback and being able to actually try to apply it and try to use what they're telling you.

Eliza: I think, communication, again, is very important. If you know if you're not being honest and truthful with your mentor, then they're not going to know how to help you. So, 
the mentee has to communicate has to ask questions, because the mentors not going to remember to cover everything, you know, though they will try, but there's going to be things that are going to be left out. So, the mentee has to communicate and ask questions. the mentee needs to accept all the help that they can get, you know, I mean, and if that means you know, a PowerPoint that they don't have to create. It's okay take that stuff and make it your own, but don't try and reinvent the wheel.

Angelica: I think that the mentee needs to want open lines of communication. Because I know mentors are so, busy was just school and then getting a mint tea. On top of that, that is a lot to ask of them. So, I think they need to be patient also and just offering help. So, at first I didn't really know what to do. And I wish that I would have offered more help, instead of just sitting back and being like okay. Just tell me when you need me or done what you need me to do kind of thing, because they are taking so, much of their time to help me out or the mentor, mentee.

Peggy: I think just being honest, as far as, you know, questions or concerns or needs and just so, that I can be sure you know that kind of helped me do my job. You know, just kind of following the expectations. You know that our principal is set for us as far as being, you know, a classroom teacher. And then, honestly, you know, once that is kind of in place, then it makes my job a lot easier with her. But, you know, like I said basically just being honest that open communication and then, you know, just making sure as best as she can. You know, to kind of follow what the expectations are, you know, just for being an educator in our building 
Maria: And so, there was a lot of paperwork, I'm sure you already know, that I have to keep up with for DESE, and for our local district. So, I feel like my responsibility was to make sure I stayed on top of that and not expect her to babysit me and okay, do you have this? Okay, look, we need to get that ready I I felt like it was my responsibility to have that ready and not expect her to come behind me and push me along so, I made sure that was all taken care of. And if I had a question. I just went to her about it. I guess another responsibility was making sure we schedule those observations, you know, because those first two years you're supposed to observe her and then she supposed to come and observe me and then we're supposed to talk about you know what we could do better. So, I guess my responsibility there was making sure those got scheduled and got taken care of before our deadline.

Pam: Asking questions when they need help, you know, don't, don't let it simmer asked questions. For seeking their own professional development. You know, it's not my job to professionally develop them, you know, as a mentor, but to want to improve themselves and to listen when it you know it again. It's a revolving kind of thing, because in the beginning. There's a whole lot of me of a mentor trying to really say well this, you know, this is what we've done in the past. But, but they need to be the new teacher needs to, you know, feel free to jump in and say, well, how about this idea, you know, but at the same time, recognize I think this has kind of been a little bit hard. But we do have a responsibility to our curriculum and I can't just do what I want all the time. I have to make sure I cover what I have to cover, so, a lot of times I help her see the big picture, 
and then it's her job to help make sure she's following the curriculum, you know, doing what we're expected to.

\section{Meredith: No answer}

Phyllis: Again, in letting somebody know, and they're usually so, young that they don't know people can't read minds. And I think they're responsible for ultimately letting them letting somebody else know your name. Because if the mentor is not there, they don't know. And I think so, many times they're just they just think that I don't know, I think that they don't ask or they're too ashamed to ask. I don't know. But my biggest thing sometimes with mentees is they the closed mouth aspect of it. So, they don't let you know when they have a question. Or if they're struggling, or, or anything and they and they kind of either expect you to know, or they just don't want to be an inconvenience or a bother.

Kelly: I think you should definitely ask questions if you if you have questions don't sit back and guess and do what you think you should do. I think you should be in the mentee should be encouraged to ask those questions that they need to ask, so, they are on the right track and doing the right things. I think observation is a big one. I do observe my mentor were required to do that three quarters out of the year, so, we have three observations that we do. But we also don't have to even observe our mentor. We can go observe other teachers, and so, I have actually gone to classes that are comparable to ours where there are projects or things that they're doing that are a step-by-step process and 
just seeing how that teacher provides that to their students and how they demonstrate things. And so, I think observation is a big one. We're required to do things like go to a board meeting. We're supposed to keep a log of professional development.

Erin: Being receptive to information. I see some new teachers that come in and they think they know EVERYTHING! I don't say that as some old person "back in my day..." kind of crap but as a person that believes learning is an everyday activity. As I mentioned, I have been teaching for 23 years; there are things that happen all the time that I have never experienced and that I don't have the answer for. I am not bullheaded into thinking I know what is best. I love my mentee! We bounce ideas off of each other constantly! Granted, I did that with the other mentor, too and she wasn't my mentor. I think that is a good trait for all teachers--being able to bounce ideas off one another and to listen to suggestions.

Jan: So, definitely reaching out asking questions and if, if you have anything talk to them immediately and say hey I need help with this. Because, as a as the mentee I don't know what I need to know until I don't until I need to know it, you know kind of thing. And so, if I don't reach out and ask for help, then that's totally on me. Like, I have that life preserver and I need to use it. So, I need to take initiative and be like, "Okay, well, these are the things that I need help with. These are the things that I know I struggle with. What kind of things do you have?" It's that building that relationship and that back and forth. Because that's what they're there for. They're there to help you facilitate all that. And so, my first year, last year, I have students that I just have blown my mind and I can't figure 
out how to fix this behavioral and academic and all this stuff. And so, that was my responsibility to say hey I'm drowning. She was great. She was checking in on me, but, at times, I was like it was my responsibility to reach out to her. Because I can't leave it all on her either because she's a teacher too and she's got a lot going on. I need help with this. You need to know that you need to reach out. That you need to have a list of things that you need. They don't know you, and so, you have to advocate for yourself.

Nellie: The mentee should listen and should try. Whenever there's a deadline, the mentee needs to make it whenever there's a question the mentee needs to reach out. That's my biggest problem is that, unfortunately, these kids are coming in and they're like, "Oh, okay. It's a technicality to have a mentor. I'm going to go do my own thing. Thanks!" And then their professional development plans aren't completed or their grades aren't turned in. And I after I've told them, "Hey, this is what we need to do. You need to do it in this time." They don't do it, and then both of us are in the principal's office and I'm like (sigh)

Karen: Hmm, I feel like it's not fair for me to expect all the same, like the be emotionally supportive and non-judgmental and all that stuff, if I'm not going to do it, too. I also feel like I need to be super, I think mentees need to be super honest with their mentor. I feel like we have a habit of being like, no, I got it. I understand I'm fine. And then at the last minute be like, fine. So, like, I think it's really important that like, Annie is the person that I like, I might not feel comfortable doing it with everyone. But I need to 
know that. I don't understand something. I just need to admit it. Go ask her. There's no stupid question. But just being honest and swallowing your pride sometimes when you feel a little bit like I'm the only one that doesn't know what's going on.

Holly: Trying to make sure that she does get all of those things and ask questions if you don't know. Sometimes I think not with her, but in the past, I have thought that they might know something just on general. And they didn't but didn't was curious about it, but never asked, you know? And then it was like, Well, nobody told me kind of thing. It was like, Oh, yeah, that was my job, you know, but I need you know, you, you need to take a step up for yourself to and say, you know, what about this? I heard someone say something about that. What is that? You know, that stuff that? You might not know, but until at least listen, and then make your own judgment.

Jim: I think it's also like a two-way road. So, I need to make sure that I'm communicating with them every day. I think that should be a responsibility that it's not just them always checking in, it's you also going and being like, Hey, I'm doing this. I think it's also part of our responsibility to make sure that we are listening in keeping open mind with like everything within the whole building, too.

Tina: Make sure that they are asking any questions that they have, like don't if you question anything, just ask because you know, no question is dumb. Because how blokes do something could be totally different than how somebody else does something. So, just feeling like you know, write it down if you think of it. I'm the mentee. You know, he 
comes to me a lot. I Come to him. So, I'm so, making sure that you know both lines, he's coming to me on coming to him. So, it's not always one coming to the other, because that can be kind of that could be a drag. If I made him come to me all the time, where he feels like he's bothering me, I always make an effort to, you know, stop by his room, and then sometimes he stops by my room. So, kind of having it where that person doesn't feel like me. And I keep going to her room and bugging her. So, um, so, him coming to me, me coming to him. And for him to feel comfortable with that, you know, it's just, and having anything and everything that he has a question about feeling comfortable asking. So, I think just making sure that he knows what he's doing. And if he doesn't make sure he does.

Linda: I think asking questions. Probably trying to get a better sense of what the culture is of the school, whether that's asking about demographics or students. Brothers and sisters are just trying to understand the students more so, asking lots of questions about the school itself, how to approach it, how to talk to students, those kinds of things, I think is something a mentee should be asking.

Louise: They definitely have to make the effort to come to the classroom of the mentor, they have to be willing to text us or email us if they run into a problem. And we're not $\mathrm{x}$ school. And that has happened. And she has done that. They are responsible to be able to ask for help. And to listen and try those ideas that is on them, they can listen all day. But if they don't try some of the new approaches, it's not going to make any difference. They have to really want to get the advice and the and the experience, maybe the wisdom of 
that person that's mentoring them. And that is their choice, that experience can be really positive, or it can be very detrimental. Or it can just be kind of the one I had I really respected like she was a good teacher. But I didn't gain a lot. And I wish I could have gained more from her. But she just didn't. I don't know, she just didn't feel like she had the time or she just was a quieter person.

\section{RQ 6-How do you feel your school incorporates these into their mentoring} program?

Michael: I'm, in the very beginning, like for the school year, even started, they kind of walked us through, you know, the responsibilities of me being a first-year teacher, and then them as a mentor. So, they kind of outline what our different responsibilities were. And then we had to take kind of a class every few weeks, we'd have a, we'd have a meeting, one, one night a week, and they would constantly kind of remind, you know, make sure that you're still talking to your mentor and things like that. And they did a whole lesson about, you know, there's Mary golds, and there's walnuts. And you want to be a Mary gold and spread, thread, the happiness, spread the colors, and all that kind of stuff. So, I think that was something that they implemented early on for my new teacher stuff, and they would keep coming back to it and checking up on it and stuff. It was more like every other week. And then once the snow day started hitting, and then COVID hit and it kind of tapered. We didn't. Yeah, but during the first, I would say at least twice a month, during the first semester. Last year, we had a meeting for new teachers, but the mentors didn't have to go. 
Eliza: I think that our district puts a lot on our new teachers. They have to go to a class. I'm torn I'm caught in the middle of it because I totally understand, you know, making sure that that they're ready to teach, but at the same time when your first-year teacher, you don't have time for all that. It used to be like a couple times a month they have scaled it back to where it says once a month now, which I do think you know that's not as bad. But I think that we just we asked a lot of our beginning teachers. I think that the administration, you know, they're going to pick on those people to be sponsors of clubs or coach things. And I don't think that that's appropriate all the time either. Unless that's one of the reasons why they're hired. You know, I just think the less that you can throw on them, the better. And then just less you know as much support as you can give them, but try not to bog them down with all the extra stuff. But then again, I do. I do think what we do in our (mentor/mentee) class is important. So, I don't know how to do that without having a class, I guess. But I think that there's maybe they wait till their second year or something like that to ask that of them because I think their first year they're just trying to say, you know, they're just trying to stay above water. I do like though that we're becoming organized, though, and with our mentee mentor program. Like, they have a checklist of these are the things that you need to cover, they have you know expectations for the mentee and the mentor. I really, I like that part of it that it's not just hey you know help that person get acquainted and good luck! You know that we do. I like the fact that the mentors know what is expected of them and helping those mentors. So, but I do think we require a lot of our people. 


\section{Angelica: No answer}

Peggy: They actually have a class that they take. I think I want to say it's once a month, and I do think maybe they have altered that where maybe they just meet in person, they alternate between in-person and virtual. They base it around the book teach like a champion. So, they try to use a lot of those instructional techniques from the book and then, you know, relate those to the class. So, then that kind of helps them improve and structurally, you know, based on these different strategies and then we actually all of us mentees met together so, that we could kind of talk about what the expectations are. We were given areas that we they needed support in. We were given, like, a schedule as far as like what our expectations were for each month so, different, like an observation schedule basically

Um, and then we also have feedback forms that we fill out. So, the feedback forms are filled out whenever they come into our classrooms and whenever we go into theirs, so, that we can kind of talk about you know the different things that are happening in our classrooms. And actually, I don't know if anyone's giving you the name but Allie Hensley she's in charge of our mentor program here. So, she is kind of working on formalizing a lot of this and putting it on our district website. You know, so, then teachers have access to it or maybe even teachers that are interested in coming into our district can see the types of supports you know that we have in place. For teachers, you know, hopefully, to make our district a little bit more appealing. So, that's awesome. So, with that she's kind of asked us to give her some feedback on just like what the expectations are there. She really hasn't broken down to where you can see exactly what the supports are in place so, 
she did say, and I agree with her, that one of the things that we probably need to work on is maybe like with our special education responsibilities. Sometimes that tends to be an issue. So, kind of formalizing what that looks like would maybe be an area for improvement.

Maria: From the district level, they have a team of people that put together this huge mentor, mentee book. That literally just step by step. Everything that you should be aware of throughout the year during your mentor, mentee program and there's really no way that you can fail as a mentor or mentee. If you follow the book that they hand over to you. It really is like your Bible to your first two years of teaching is great. So, as far as the district. I feel like they were very responsible or in that respect in making sure that they set us up for success from the very beginning. The only thing I feel like, and it's not. I don't think it's their fault. I think it's just what it is like I said at the beginning. Is some teachers and mentors and mentees don't have the same opportunity that I had in that my mentor just right across the hall. Some have their mentors in a different building so, they can't just pop their head in, you know, at the spur of a moment or get on the phone and say, "Hey, I'm having trouble in my classroom. Can you come help me real quick?" That they don't have those options. So, maybe that's if I had anything negative to say, but I don't think it's to any of their fault. It's just what it is sometimes is that sometimes not every mentee has $100 \%$ time, you know, the support the hundred percent support that they should get from their mentor. 
Pam: Of course, since I'm in charge of it. I don't think that that's probably not the right person to ask. So, normally we have a checklist of things that we need to make sure we're taking care of we have released stays the first year we have released days where we can go and observe other teachers or other schools, which is awesome and the district provides workshops for we usually do one on cooperative learning we usually do classroom management. We've done the Ruby pain a Ruby pain workshop most years for teachers to try to understand because we have high poverty here in our school system. So, how do we help those students who live in that situation. I think we have a great mentoring program here and we stay with the same person for two years. And then the third years, you know, just a little less. So, a little the third year's more informal. The first two are pretty formal and paperwork has to be turned in.

Meredith: I believe our entire district is doing pretty well when it comes to the program. The first year we have a couple of meetings at the Board Office to sit and chat and build on that relationship with each other.

Phyllis: Again, in letting somebody know, and they're usually so, young that they don't know people can't read minds. And I think they're responsible for ultimately letting them letting somebody else know your name. Because if the mentor is not there, they don't know. And I think so, many times they're just they just think that I don't know, I think that they don't ask or they're too ashamed to ask. I don't know. But my biggest thing sometimes with mentees is they the closed mouth aspect of it. So, they don't let you know 
when they have a question. Or if they're struggling, or anything, and they and they kind of either expect you to know, or they just don't want to be an inconvenience or a bother.

Kelly: I feel like it's a little vague. At times, the way they incorporate it in. I don't feel like our mentor-mentee program is very thorough. I mean, we have our list of things that we're supposed to do. They implement it through a Google classroom where you can keep track of what you need to do and when it's due by. We have beginning of the year meetings. Like first-year second-year mentor meetings... mentee meetings. So, it's there, but I feel like maybe it could be implemented a little bit better. I almost feel like it's kind of pushed to the wayside, a little bit. It's just a list of things it's just a checklist you know it's just not very thorough. I feel like there's a lot more, they could do. For me, like I said I didn't really feel like as new teacher there was things they had us do. It was like this is silly like why do I have to do this because I already know all these different things they were telling us. And I just thought, for somebody new, it was probably helpful. For me, I'd already been in the district a lot subbing, and so, there was a lot of things they told us they already knew but I do feel like it's really like a checklist. I don't think they make a great big deal about it.

Erin: I think our school gives the mentors/mentees the basics and allows for each set of teachers to cover things how they see fit (which in some ways is not good). I was the mentor for the Alternative Education teacher (like 8 years ago). He fell into the "I know everything" category. I tried to go over the information that we had to check off but he 
wasn't paying attention--too busy planning football plays. I was able to check off that we "discussed" each item but it wasn't beneficial.

Jan: The first year they give us the introduction. We went through the seminars and it was great, and it was good. There's not much interaction between the mentor program and the mentor/mentee I guess. We have like deadlines of things we have to do, but as far as like them reaching out and saying how is this going what's going on, like touching base with us between, I mean, I should say they might do it with her, but they haven't reached out to me. My mentor is the only one that's ever reached out to me through the program, except for the very beginning, of course, when they introduce everything. But they do a good job, outlining it. But I could see if you didn't have a good mentor where you could kind of fall through the cracks. You're doing the bare minimum of the observations and the checklists and if you have a mentor that's really not into it or not involved. Like, my mentor checks in with me all the time she's like said we get together at least once a week. I think the bare minimum is once a month, I think, in our program. But I'm not sure. But if you have a mentor that's not as actively involved, I could see how you can fall through the cracks or not get as much out of it as you should. If you don't have a good mentee who is an advocate and you don't have a good mentor, who is a very good.

Nellie: We have gone online. They give you a list you check off the list. The list is handy. But there are times that I miss the face-to-face interactions that mentees and mentors were required to do for trainings and collaborative meeting and stuff like that. Because, I feel there's a disconnect now. I've done it long enough to know check the 
boxes go through do this but there's still an emotional. I don't want to say neglect, but break. Especially now that we can't really get together and kind of compare notes, so, to speak. Like I said that structure that face-to-face interaction is not there now. I don't think the question the questions are being answered per se. I also think that the head of the mentorship programs need more time to prepare it I think they need more training, not because they're doing a bad job it's just that now we're like I said we're online. Okay, so, now, they have to learn how to do the Google classroom if they're not familiar with it, and they have to do you know, make sure that all the other all the ducks are in a row, and that everybody's accounted for, and so, I think that maybe there should be more training a little higher up. I do think that we are going a little backwards. But, I I don't know if it's the pandemic, or if it's the lack of luster because it's no longer new this mentorship program. It's "been there, done that."

Karen: Like I don't even know what the mentor is, like, technically supposed to be there for. I'm gonna be honest. And I do have a book. So, that's, like, partly on me. But we did go over it one time, during the most hectic time of the entire year, which was that first day when they're like, here's this and this and this and this. And as a new time teacher, I was like, I'm gonna die. I'm so, like, I don't even know technically what their responsibilities are.

Holly: There's like a checklist, they say you ought to do this, this and this. The first, you know, talk about this when you first meet and go are there, but they're not everything that's on the list that would be you know, just between her and I as the foreign language 
department. It's too general, you know, but there is a checklist of all the different things to do, we're supposed to get together certain times, you know, at least so, many times a month or whatever, her I were right across the hall, we speak daily, you know, write stuff and we're supposed to work on a, it just gives you a thing like to do professional development or goal, a professional goal for the year and stuff. It's all in a book. Well, you spare book mounts all online, just kind of have a checklist on stuff. And we do that. And we probably don't look at it as often. I wish we had set times where they would give us time to work together. Instead of on our own, you know, our own time. I'm here an hour before school and here two hours after. But I use that time. I need time, maybe during the day, if we could get head time once a month or something. I wish we had more. I don't know there's a lot in the books and stuff. But I wish the time would be right where we could just focus on that.

Jim: I think so, we at the beginning of the year have meetings that we have to go to that just kind of talk about it and get us in. She got my phone number before even started with, like texting me and being like, during the summer, like, hey, let's check-in, let's just kind of see what's going on. So, you're not thrown to the wolves the first three days or whatever. So, that was helpful, too. So, school does a good job.

Tina: Um, we do have somebody in charge of the mentor-mentee. And we do have meetings. So, they do talk about some stuff. But I mean, honestly, it's, to me, I think it's more of a waste of time than anything. Because, I mean, if I feel like if it's not working, then there needs to be something set up for that. Because I know what our paperwork it 
says, if it's not working, you just said submit something in writing to the principal. Well, that's kind of awkward to like, you know, just if it's not working, I would think the principal would be able to tell that and try and switch things up or talk with both of them and figure it out. So, I'm kind of disappointed. Last year, that didn't really happen, because it was obvious that the other person wasn't getting the help. But I think that would be an improvement, trying to figure out when it's not working, what do you do?

Linda: I'm not sure. We didn't really have like a guide thing. It just kind of was like, “Oh, you're my mentor? Okay!” So, it was just, it wasn't like a set program, I guess. At least that I know. But it was just kind of, I have someone there that if anything goes wrong, or whatever I can go to.

Louise: Our district definitely has room for improvement there. I think one year there was something brought to the table about that. But they didn't... I think a school district would be greatly benefited if they just had a packet to start that with and if they would make sure that they make a good match. And if it doesn't work, they're aware of, that they can get a different mentor for that person. The district really should be in charge of making sure that new people have access to their room to the technology to the tour all of that, which is kind of what I did with her when she first came. So, yeah, I think the district would benefit themselves to do that. But if not teachers that really care about this profession, they're gonna step in and do it. You know, and I've been at this district all this time. And with that said, I really care about these kids here. I've watched him grow up. And so, I want it to be good for them. 
Tammy: I don't think this school really has a mentoring program. Like it was just by chance that me and her became mentors. Like there's nothing structured. I think they all assume is she will be my mentor. But there's nothing like, "Hey, you're a new teacher. "This person's gonna show you the ropes and they're gonna show you this on this day." You know? And it was just like, I'm just like, sitting in here trying to be teachers. I'm like, so, how do I post my grades? Like, I have no idea, you know, and I think I think it naturally happens with her, but I don't I don't think it happens. Many other places. No, and then there should be and what I obviously this is my first year and they've told me we just had like a diminished a lot of administration change, as I'm sure you probably heard from others. And I've been told that there used to be a program that it used to be like, orientation for new teachers, you know, make sure they knew what was going on. And my situation was unique because I came in in the middle of the year but still like there's nothing in place and I think that needs to be I mean, how can I tell the kids what to do if I don't even know what's going on? You know, and, and I think that's one of our weaknesses of this school.

Lisa: Well, if it's out there, we haven't really been given any structure about what you know, this is what a mentor should do. And this is what, you know, I haven't really had any guidance. I'm just mentoring from the heart, I guess. I don't know if that answers your question or not. 
Kevin: So, the first year we were supposed to observe. I think we're supposed to observe our mentor and they were supposed to observe us Twice a semester, and then observe one other teacher, once a semester, this second year, I don't know if it's because of COVID. Or if it's the usual policy for a second year, mentorship participation is once in your mentors class and once in another class each semester. And so, we do get in and visit other classes. I don't know how they choose mentors, or if people volunteer to be mentors, but of the mentors that I do know about. I would say, for the most part, they're, they're finding good mentors, they're finding the ones who do want to help the kids and help teach you to help new teachers be able to help the kids. I should have brought my mentor folder home for this. I'm trying to think we do have, we do have a checklist, where each month we should be meeting at least once a month, in going through this checklist to discuss the different aspects, keeping up on grades for quarter reports, keeping up on end of school activities, and monitoring student mental health and all that. So, I think that helps with the mentors, role of responsibility. And then at least the patients part that I listed, I don't think that's built directly into the mentorship program. I think that's just a characteristic that they possibly look at in their teachers that want to be mentors or that they ask to be mentored so, that they're not running a new teacher off. And then, as far as the mentee, being able to reflect on their teaching and be able to ask their mentor or another teacher about areas of growth on the classroom observation sheet that we have, there is a section that says that or asked like, what is the teacher doing to engage the students? What type of lesson is it? And at the end, it asks, "What is something that you can take away from this lesson to use in your classroom?" I feel like that kind of has that part built-in. Because then you're actually reflecting on what are you 
doing and how can you be doing something better. And then they want us to meet with that teacher that we observed to be able to discuss those.

Tori: I'm like our school we have like, it's like a two-year program. So, we are required to observe our mentee a certain number of times a year, and then our mentors are supposed to observe us as well. Then we get together and we talk about those observations. We try to meet at least once a month so, like on our PD days, we try to set aside time where we can talk, go through our checklist. I know that like Chris and I will have a lot of quick like before school, he'll pop in or after school, or he'll pop in or between classes in our four minutes. He'll come down and be like, Hey, I'm gonna try this. Do you think this is gonna work and then I'll try to follow up with him and make sure, "Hey, how'd that go? I know you said you're gonna try that." So, but we do ours, it's like I said, a two-year program, we have those setups or vacations. And then I also try to we're supposed to facilitate and try to find, like if they're struggling with classroom management, and you know, a teacher is really good to school with your classroom management, trying to set up a time for them to go watch them, or help cover his class so, that he can go and that they can go watch those or get someone to cover. So, they have those observation opportunities.

Jessica: I think they did a really nice job. So, at the very beginning of the year, they had a spill out or that much, I think we're still supposed to be doing it. But like a log of when, like, we meet with our mentors, and like at PD days, they were good about having, you know, some time to get with your mentor, which mine also teaches third grade. So, it's 
nice that we, you know, we do the same things. And then they also gave us a list of like, they gave us a list of like different times that we need to check in with each other and make sure that we're getting things done. And then like a list of conversation stuff like talking about it was just like before, the first before the first teacher workday, even like introduce yourself and give them a tour of the building, you know, talk about the dress code, and all those sorts of things. And then it like goes through in August, you should talk about these things in September, you should talk about these things. And so, I thought that was nice, because some of that stuff you just don't think about, you know, but with that list, it kind of helped us go through and get that.

Shelly: I feel that our school does a really good job of it on the elementary and high school is a little bit more difficult, because you don't have everybody in the same places. Because you have because we have like our specials like our ag teacher, we have our business teacher, we have them. So, it's kind of hard to mentor them, because you don't know about all of the FFA stuff you have to do, or the FBLA stuff you have to, which is in addition to what they already do. So, I think they do a good job with just general teaching stuff. But then, like in high school, they have all those extracurriculars that they are responsible for as well. And so, sometimes that's difficult too because you don't know the scheduling or the timing of different events or contest. That's what I was trying to think of, or conventions, those kinds of things. So, you know, if I were to mentor, our business teacher, I had no, I would have no idea when the business conference would be and how to schedule a bus and all that kind of stuff, because I've never had to do that. Um, so, sometimes when you get those mentors that haven't had to do that then and then 
on the other side, because I do have a friend, that's the ag teacher, she's been mentoring our business teacher, but she gets so, busy, sometimes those times a year that she has little or no time to actually be the mentor. So, it's kind of a double edge thing. But Elementary, I think we do a really good job. They have checklists, they have, they send out emails saying you know, this is due, when this is due and you need to do this. And we have a folder for each of our mentees, so that we can go through them. We can go through everything with them and talk with them about what we need to. It helps you keep you on task a little bit.

\section{RQ 7-In what ways has the mentoring program affected your professional growth?}

Michael: Um, it's just, it's given me somebody to talk to, and kind of bounce ideas off of, and get feedback from. And just somebody that, you know, from class to class, I have somebody that their rooms right next to me where I can just talk to them and say, you know, I was teaching this today, and I just didn't feel that it went right. What else do you think I could do here? And just things like that. It's not like a super, like, I wouldn't explain it as a just like a rapid thing. It's just kind of a day by day. And just having those conversations where was slowly I'm just kind of picking their brain and just having those conversations that over time that really like changes my teaching, and kind of my outlook on lessons and things like that. Oh, ah, I mean, my mentor did a really good job, which I'm, she's somebody from the Farmington area and has taught here for a while. So, she knew a lot of the people and introduced me to all the different people, people that definitely needed to know and just kind of get me involved in the culture and what, what 
Farmington is all about and what the high school is all about, and things like that. And not just only my mentor, teacher, but the entire department was really helpful with that too.

Eliza: I really like it when mentee share ideas and strategies and you know information that they found. I think that's really important for someone who's, you know, I haven't been 23 years in the school classroom but I mean a long time in the classroom and I love the enthusiasm that I can get off them. I love you know the newness. I think that's really exciting because I like I said, this is my fourth mentee in five years, and I'm just, I learned from them just as much as they learned from me.

Angelica: Okay, so, one of the things that we have are a lot of meetings here, especially for new teachers. And I think that has both helped a lot with my professional growth. Just because I'm learning new things. I'm going to a New School District. I don't know how to use half the stuff that they use here yet. So, I think my mentors definitely helped me with those aspects like the little nitty-gritty stuff and the overall big stuff, it's like kind of those things in the middle where I'm missing days with my kids like I'm not here at school with my kids because I'm at a meeting or I'm at a professional development day with my mentor to try and work on some things which I think are important, it just makes me sad that I'm not here with them because I know that they could be getting a better understanding of our new stuff or if it's even holds up review. If I was here. So, that was kind of a negative of it, but also it's nice because you can't hardly find time in a day to meet with your mentor before school they have things to do after school things to do, 
especially if I was a coach. So, there was hardly any time we meet, and over here on different teams. So, we don't have the same plan period so, that also makes it difficult, but I think anytime I asked for help. She's right there. She's awesome. So, she has definitely helped me professionally grow a lot. And personally, even me saying that I need to go ask for help is a big step. I'm like, admitting that so, I think she has helped a lot. It's just more so, whenever I'm not in class with my kids that it's a negative.

Peggy: Honestly, it just, it makes me want to be a better teacher. And then I was like, so, I was so, this year I have a mentee. And then I also have a brand-new sped teacher that I co-teach with and she is also a first-year here. So, I was talking to our process coordinator, and like it makes me want to be a better teacher you know for them because of the turnover for us, especially in the math department. It's quick and so, my whole thing is I mean we're doing our co-workers a disservice if we're not providing them enough support. You know what I mean, to keep them. And that's really where they want to be, um, you know. So, just to kind of, like I said, personally, just be a better person, you know, to be able to provide that support to be able to keep teachers and education that really need to be here. So, one of the things I've tried to focus on professionally is my use of technology. Not just using it, but to try to use it in a way where the kids aren't just like sitting in front of a you know a Chromebook screen. You know, to try to use it a little bit more interactively, you know, to get the kids involved. So, I definitely think, you know, the use of technology and then also, you know, for some of our kids that don't come from great homes that have been in a two-week quarantine like I've been trying to explain to my kids. Like, some of these kids that are put in this two-week quarantine that 
don't come from great homes like that's not a good environment for them, you know. So, when we talk to our kids about like wearing masks and stuff, you know, it's like it's not about whether you want to wear it, it's about protecting the other people you know the other students. And so, I think professionally it's made me kind of open my eyes to dive in a little bit deeper into that, you know, social, emotional well-being of our students because I mean some of these kids have been some of our kids have been in two rounds of quarantine, so, that's been four weeks you know that they've been out of school and you know. So, just as a teacher, taking into account, you know, that aspect of it. So, those are probably the two main ones for me is the technology piece and you know the be more aware of the social, emotional, you know, state of our students.

Maria: So, when I first started teaching preschool. You know, I was probably 23 years old right out of college. I thought I knew everything. I don't know if you were like that when you graduated college, but I thought I knew everything. But I literally went home crying. Almost every single night. My first-year teaching preschool and I couldn't understand why I'm like, I love these kids. I absolutely love them. Why am I having such a hard time with them, or having such a hard time knowing what I'm supposed to do, even though it's right there in front of me? There was teachers all around me, but not one of them, and I do mean not one of them, reached out to say, hey, do this, this and this, nobody I was literally on my own, and I feel like as far as on an academic or professional level. The only thing that really saved me in a sense was their curriculum was one of those curriculums that you read every single little thing and it dictated everything you should say in the classroom and what worksheet. And I live in that book and helped me to 
survive that first year of teaching. But I didn't have a mentor and not even the AM the admin. They didn't even really come in unless there is a problem, you know, and then they, you know, okay, we need to change this. So, fast forward to hear when I get this job and I have this wonderful mentor. I didn't go home crying every day but I sure went home stressed out because of all the work all the data. I didn't have to do dad at my last job, so, I was overwhelmed with the grading the data and I think that's pretty much it. As far as my stress levels, but it was enough to keep me up. You know, I didn't sleep a whole lot that first year. So, having her as my mentor and a professional level. She helped me to know how to grade it faster to be more proficient with the grading. I think I was trying to be like a college professor and greet every little tiny thing and obviously, that's not efficient. Another thing was simple things like making copies. Who would have thunk it? We slowly break things up as teams like one week I make all the copies for the team and next week, somebody else's making all the copies. So,, I would spend two or three hours in the copier or a copy room making copies for everyone. And she came in probably two months later, and she said, you know, there's no faster way of doing that. And she showed me. It was a simple little trick of you put the copy each put the master copy. And one way. Make the copies for one teacher you know like 60 copies. Flip it over the other side, run it through again for 60 , you know, however many numbers you need and then flip it over again so, I can run it and leave go do something else and come back and all I had to do flip through the pile to see where we're at flipped over and change and like okay well that's your coffees. These are your copies. Yeah, you know, I mean, it was simple stuff like that. But she was able to show me that saved me so, much time. So, yeah, on a professional level. I don't know. I could probably come up with a million 
things that she did to help me to be more efficient, even to the grading. As far as keeping the great book. And what days like picking days like okay, I'm going to grade on these days, and on these days. I want to go home and spend time with my family and not ignore them, because I'm overwhelmed, you know. And then as far as the data we did that together, which obviously we have to share data. Anyways, so, yeah, I honestly I don't know that I would have stuck through this job as much as I love the kids and I love the teaching. I don't know that I would have stuck it out. If I didn't have her helping me out, to be honest with you, because it's very overwhelming at times.

Pam: I said it's not it's not just the mentoring program. But when you have a new person in your room, a student-teacher or a new teacher, you just get great ideas from them and sometimes they'll even mention, like, books I haven't read. And you're like, oh, I need to read that. It keeps you a little more up-to-date with what's going on and education at the university level. And then I love all the fresh ideas that they bring to the classroom.

Meredith: The program has most definitely affected my professional growth just in the way that I've gained more confidence when it comes to my overall job. I went to school for 4 years for this degree but every school operates differently and the program has guided me in a more independent direction.

Phyllis: Oh, again, like, not only have like, should somebody come to me, especially since I've been like in the pandemic world of technology, now I can go I have another ally that I can go to that I've met through the process. So, in the professional world I 
learned things from them to like, oh my goodness, even the simplicity of teaching different ways to teach long division, she'll learn it, like they'll learn in college that I have no idea about, and they'll teach me those new strategies. And so, I think professionally, we just have to learn from each other but that's like, it's education at its finest. So, we just embrace that with a mentor.

Kelly: I do feel like I've learned a lot, I feel like I feel a lot more confident. But that, again, could have a lot to do with my mentor being so, encouraging and helpful. And if she was to observe me at times and so, she would observe me and say you know I noticed you say this, a lot, you know, try to cut that out a little bit because you're saying this over and over. Or, you know, you started with this, but maybe like I think the teaching strategies and learning activities came more so, through that aspect because my big things in teaching is keeping the students engaged and she had taught me, you know, move from, you know, keep them moving go from a learning activity, maybe they do some guided practice, and then they move on to you know to just some studio work time and just keep them moving. So, that part came more so, through her. So, I think I have grown a lot there, but it was more so,, what my mentor has taught me and done for me than what the program itself has done. But I do feel, I feel a lot more confident, I feel like I've grown in and how I conduct my classroom and my lessons and things such as that.

Erin: Having Rosie as my mentee makes me want to be a better teacher! Not to toot my own horn, but I have always received very high marks on my evaluations, but I see her new teacher enthusiasm and it is contagious! I also love how Rosie and I are so, willing 
to share ideas. We plan all of our common classes' lesson plans together and bounce ideas of each other for lessons for our other classes.

Jan: Professionally it's actually helped me grow because I get another person's input and different ways of looking at things. So, it's helped me grow tremendously because she's been able to show me different things we've been able to advocate for different things that I would have never even approached. Because, like different programs and things like that that she has spearheaded at the middle school that something that I can take a notch of and in reach out and do. I'm able to kind of get together with her, my students are going to her, so, the situation with mine is the professional growth is there situations where that come up that I don't quite understand or know how to deal with. And so, with her experience and with my kids going to her, I can talk to her and be like okay so, here's the situation, this is where we need to get them to, this is what you need, I need help lets work together. That, grants, and programs and things that are outside the educational field but also help with life skills and things like that. Things that I wouldn't have even thought to even try to do. And so, professionally that's really expanded my professional realm. With that too is she has experiences and things that she's been able to do and kind of show me, "Hey, this is how I got to here, this is how I got there, this is how I was able to get to this point. This is how I got these programs for my kids to be able to use." It's untapped stuff that I wouldn't have thought about because I've not ever experienced it. So,, professionally, like she's been able to stretch and grow that part of my professional realm in that she's given me experiences and ways to get to different things that I didn't know I could do. As well as you know, just different ideas and thoughts. Because she's 
been in the program for so, long and she's been in that this facet of that so, long that her experiences help grow me as well.

Nellie: Like I said, it does keep me motivated to come up with the new lessons, the new activities. So, they give me a kind of a technological edge. Having a mentee, they're younger, they have the most current information that's definitely a growth. Keeping track on with their work helps me to maintain my track and making sure that my works done so, that's helpful. Watching them whenever they succeed, of course, that's intrinsic. When they succeed because they took your advice or something like that, or they just finished it all like when they were supposed to finish it, you know that's a big deal. Building relationships with the younger group is so, important for the building in general. It's neat that I'm beginning to watch the kids that I mentored. Now they're taking on leadership roles, six and seven years later.

Karen: I feel like I've kept... it's a tough one. It's hard because I've kept my head so, down like this whole year, because that's my defense mechanism. So, like, I've really leaned on her for emotional support. And like support with like, things like what do all these meetings mean? Like, what does that email mean? That kind of stuff. But like, I don't really know if it has other than it has helped me with interpersonal relationships, which is a professional aspect I guess. So, in that way, it has interpersonal relationships and working with people. But I don't know if it's been like the most, like, helpful and professionally developing, maybe I just have a different definition of professional development. I feel like the thing that it's probably I think the area that Annie has helped 
me with the most of the program's helped me with the most is behavior modification in the classroom, that's probably the area for me. Because I am so, much younger than Annie. I feel like a lot of my like, lessons and stuff. I'm like, finding out from other young teachers. So, it kind of goes where I like, teach her about that kind of stuff. However, I struggle with conflict. And so, having teenagers for the first time when I'm used to little kids, also very different. So, I feel like in that way, and he has helped me a lot with behavior modification in the classroom, like appropriate and appropriate things to do. Um, stuff that's worked for her over the years. So, I feel like, in that way, I'm developing as a teacher because I had none of those skills with teenagers. Teenagers are terrifying. So, I've learned from her different techniques, different tools that I can whip out now I'm like, Oh, that's good. I should do that instead of just sit there and stare at them in horror.

Holly: It makes me look at all of the details that I should I be doing, that I may have forgotten, you know, with all the listeners that, "Oh, yeah, I need to be better at that." As I'm telling her, this is what she should be doing, or you know, what she could be doing and stuff, it helps me stay connected to all of the things and not forget, some of the main ideas or the things I should be doing. It shouldn't be teaching or should be remembering to do and stuff.

Jim: I think without my mentor in the program, without the program and my mentor, I wouldn't be nearly as confident or really know what I'm doing quite as well. I think I'd 
have been way more lost. So, I think without it, I think I would have been way more behind.

Tina: Um, well, I think I kind of touched on it some, a little earlier that, you know, he can gain insight for me, and I can gain insight from him. So, he's a lot more techie. And I've learned some stuff from him. And so, when we kind of divide and conquer, we're able to get a lot more done. So, that's helped us be able to incorporate more into our classroom as well. So, finding good resources for you know, when the kids finished the work, it reinforcement activities that they can do so. So, you know, I think just being able to get more accomplished as well.

Linda: I think it's made me want to be more organized. And I'm trying to play an out stuff I seeing a seasoned teacher of like, 20 plus years, it's, it has me, I don't know, it's more of a goal of where I want to be. And so, I have a clear vision of how to get there than I did. And seeing somebody in the classroom emulating all of these things that I want to be, I can even ask her, like, "How did you do this? What those kinds of things?" I have a clear goal of where I want to be as a teacher in a couple of years.

Louise: Definitely the questions that are asked of me, sometimes I have never asked, and I needed to find out that information. So, I think that to say that their questions always keep us aware of the changes and the current technology and all of that fresh kids fresh out of school come in here and they show me things that I haven't been, I haven't seen, and it is definitely beneficial to my students and to myself. So, and then you also develop 
relationships, work relationships. So, when you get put on committees together, you know, it's just it just branches out. It's a ripple effect. There's everything positive to be gained by that mentor-mentee relationship.

Tammy: Um, well, since we don't have a mentoring program, are you just saying like, my having her as a mentor? How's that helped me? Um, well, honestly, a lot. The majority of what I do in class has been what she taught me over there, like the way I've structured kind of the way we do things with our science notebooks and everything. And a lot of it is the teacher who taught us before he left a lot of resources for me, but I've kind of been molding that with my own style and things that she taught me. But I think the biggest thing is just having a support and having someone to bounce ideas off of and like, I can tell her certain situation and like, how do you think I, this is how I handle that? Do you think that was right? Like, just knowing that she's always there to like, guide me in the right direction. It's just really nice.

Lisa: Well, with this particular candidate, it's been a great help to me, because she's fresh graduating from college, she was earning her master's while she was finishing up her all our teaching. And so, she had just a lot of fresh ideas, and just that spark of the beginning teacher and so, it's just really, it's really sharpened me, it's helped me want to be better, even just in the classroom professionally. It's just helped me want to be better and try other things, you know, try, try some different I got to you know, see her try some things that she learned in college, and I saw the success of those. And so, once she left my classroom, I tried those same practices once she was gone. 
Kevin: I can't think of any specific examples, but just being able to go and ask my mentor certain questions and things suck a lot of the time, she doesn't. I can't say a lot of times, but on certain things, when she doesn't know the answer, it has caused me to dive more into professional development books and her stations and see what's going on. Um, and so, just recognizing that not all the answers are at my school, it's kind of pushed me into these other ways of learning. And so, I have, like a podcast that I listened to, I have a book that I'm reading through right now, and then several Twitter communities that I check in on every now and then just to get other ideas from them. And then specifically, what, what it has helped me with is just being able to find those resources in the school for the certain things that I do need help with.

Tori: I feel like it's made me kind of step up as a leader more in the school. Like I said, I'm I was older when I started teaching. So, I came in with a lot of the life experience that I think he's actually probably younger than my daughter. But just being able to share what I've done, what I've been successful with, has made me feel more confident in my teaching, I feel like I'm being able to share that. I do have pretty strong classroom management skills. So, I feel like that's made it even started. Because he's like, hey, how do you get him to be so, good? And then you're like, okay, it makes you kind of reflect on yourself to as you're talking and discussing with them, trying to be a good leader for them. So, it really makes you focus on your own teaching. So, you're setting a good example. 
Jessica: I think I mean, it's helped me grow a lot because I do have someone to go to personally, you know, and it's the same person every time. So, it's not like I'm trying to find whoever I need. So, I think it's helped me just to become more comfortable with the school and to be able to just think about things in a different way even when I don't know what Like when I have a problem, you know, I tell her about it, and then we talk through it. And so, I think that helps me think about it more.

Shelly: If you haven't really good mentee, it kind of shows you where you have shortcomings. So, there's been several things that she has done this year that I'm like, "Oh, I probably should do that." Or. "I used to do that." But it's been several years. So, yeah, that's something that we really shouldn't be doing again. So, it kind of shows me my own shortcomings and things because they're newer, they're younger, they're coming in excited. And it kind of reminds you how it was at the beginning, when you started and how you were excited and you wanted to do everything great.

\section{RQ 8-In what ways has the mentoring program affected your personal growth?}

Michael: besides going off to college, this is the first time that I've been really like, far away from my family, but on my own. And so, just kind of just kind of just growing up, and just kind of grown into myself as an adult, kind of, and it's just part of that is the mentoring program and having somebody to talk to because I'm sure if I didn't have questions about, you know, just random stuff, you know, where to take my car or something, if I my car's broken down, down here, like where to go and stuff. So, that's 
probably one way that I guess my mentor could help me out is just now that I'm kind of on my own way for my family and stuff is kind of just having somebody to talk to you about that. I guess. That is tough.

Eliza: I do think when your mentor, you're seen as a leader. Like I said earlier, it doesn't necessarily have to be the best teacher or the star, you know, leader of the building. But I do think that people, you know, tend to look at you as maybe just knowing what's going on. And, you know, having an understanding, like here again for district expectations. Personally, I don't know that it's affected me that much other than just, you know, maybe being looked at is just someone that is a leader within the building.

Angelica: So, coming out of my shell, I would say, is a big one. Just because I don't know. I am one of those people. I'll just sit there and let other people talk. And I'll just listen. Not that I won't say anything, if I need to, but I don't know. So, I think that has helped me a lot, but also building relationships with coworkers and like learning little tricks and things to build a relationship with my kids has been really big before school started. That was one of our meetings was about relationships like specifically with our mentors and that was huge. So, and even whenever I went to ask her that question about the seating chart. She gave me some really good ideas as far as like discipline and how to set up a seating chart kind of thing. So, just being able to bounce ideas off for has been really good. 
Peggy: I mean, I don't know, kind of just, you know, being just that supportive person. Um, I don't know.

Maria: Um, I would say in leadership, maybe leadership skills in general. Of course, I mean, there's other things that take place in my life that also helps me build my leadership skills, but there are some things that I think I'm learning from her because I watch how she interacts with other people. And times that I think I probably would have responded to people in a negative way. And I'm not a negative person any sorts, but I would watch her deal with certain situations gracefully and be able to talk things out with people that I think I probably did face those situations, I might have walked away and say, okay, we need to address this another day because I'm too upset to talk to you right now. Dealing with students and parents and will, you're telling personal thing you said I need to talk. I know she's always, I will tell you this. She's always telling me to go home because I will. I'll say here to six, seven o'clock at night, working, and she'll leave a four and she'll knock on my door, and she'll say stop working. Go home, be with your family and she did that a lot that first year. So, I'm thankful. She did that because it was a constant reminder that you know I love my job, but my family's still number one. So, on a personal level. She definitely helped me keep that balance.

Pam: I think that it helps me to realize personally that I don't have all the answers that I need to. I really like to read. And I think it's important that we as teachers continue to improve ourselves in the professional realm as well as the personal and if I have a friend, you know, it's not just like someone I work with, we're friends. And I think that's 
important and helps me as well as I hope you know we both were friends outside the building, not just here so, I feel like it helps. I'm not saying it very well, but it helps us to be able to laugh and lighten our day, you know. We kind of talked in the hallway, because we're right across from each other and that helps lighten the load and ease the tension and sometimes when sometimes, you know, you can look at each other and be like, I need to step out for a second. But I just think it's been a blessing to me to have someone like my mentee who is so, upbeat and creative and fun and the kids love her and I just get great ideas that my students love because I get them from Betty and it's fantastic. And I'll say to her, sometime you know it's time to go home. That's not, don't, don't. I've already told her for Thanksgiving and like don't do this work over Thanksgiving. Go home. Enjoy your family, but she struggles with that. With trying to constantly, you know, get it all done and it's difficult. And, you know, what one of my neighbor teachers once told me when I was a young teacher that a good teacher is only caught up on the first-day school and the last day of school, it's okay because I was like that too. You know, I want to be caught up. I want to, but you never caught up, so, it's okay.

Meredith: Definitely has affected my personal growth in the way I present myself and my own personal confidence.

Phyllis: And then as far as personal growth, it's teaching me to be more compassionate. Yeah, and more understanding of coming from different educational backgrounds. 
Kelly: I think it's helped me become a stronger person as far as like teaching and just stronger. And what I can deal with and knowing that I can do it. Even, like I said, with the meetings that we'd have monthly just the feedback and everything that the individuals in the meeting would provide like I'm not alone in this. I think it's made me want to reach out more when I do have questions. Not that I wouldn't before, but I feel like it's okay to ask things. I feel like I've grown in that sense, because I would shut down before. I've learned that all the other teachers here, you know, they're there for me if I have questions or I need that guidance. So, I'm more apt to come out of my shell and ask things. I just feel like overall my experience, or last couple years, and then and being in the program and having someone there mentoring me and helping me has just personally made me feel stronger and more vocal.

Erin: Learning something new every day! Not being stagnant.

Jan: It's helped me be able to relate to other people, and not so, much on my own. I've been so, independent for so, long. So, personally it's helped me out because it's getting me in and getting comfortable with a large group of people. Even though I've worked in several different schools and I've done that in my field it's a very separated process. And so, professionally, and in this personally, she's given me confidence to go out and talk to people in my building and build those relationships with people. And she's given me those people skills to help me be professional yet still personable with people in my building because that's another thing is I'm a very personable person. I will meet with you and be with you and be friends with you in a heartbeat. And one of those things is 
learning those professional and personal boundaries and realizing that not everybody you work with it has to be your best friend. She's showed me how to be in that environment without being overly involved in that environment, if that makes sense.

Nellie: I've got to say there are sometimes whenever it helps keep me be organized personally. It keeps me on the ball. Also, it has played a little bit on my patients. Sometimes, depending on the mentee, I've had amazing mentees that were dream mentees. They showed up, did the work, that was great! I have wonderful relationships. And I got to bridge over once the mentorship program ended and actually be their friend and do stuff with them. Then there were some that it was like head butting constantly. "I'm right you're wrong", "I'm doing it my way", and it took a toll on my patients.

Karen: I think that I think any just like, my mentors just made me like a better human being probably I think that through like, showing me support and like constantly like, hey, do you need help with this, you know, but this it's like made me realize the importance of like community in the school. And how I should also be doing that a little bit more, maybe not this year, but next year, like she's inspired me to, like, want to be a mentor to someone else. And like, I know how rough it is. So, I think in that way, she's helped me personally grow.

Holly: Oh, really, I mean, it can be overwhelming. But I... I like it... I feel like, even if I wasn't, you know, named mentor, I'd still be doing it, you know, I'd be helping out as much as I could to help him, because I remember not having a lot of help. But the first, 
you know, I wish somebody would have done that, you know, for me, too, but I, I like doing it. As you know, I've gotten much closer to her. And I think, you know, it just gives me that person that you just kind of connect to with more that you don't always get to connect with everybody. And it gives you more reason to talk to that person and make that connection too.

Jim: I think it just kind of goes back in towards confidence and stuff like that, and not being afraid to be like, Hey, this is what I think we should do. And just being able to stand up even not just with my mentor, but like the whole building.

Tina: I mean, I consider him a friend. It's always good to add friends, you know, into your, to your social circle. And, I mean, I definitely care about him. I think he's a great person. And so, I think, you know, it's always good to have good quality positive people in your life.

Linda: I think it's made me feel more confident in the school. Um, I'm kind of a naturally shy person. And I don't like talking to a lot. So, having someone there who's willing to back me up for like, anything is super helpful. I remember the first couple of weeks she'd like, I had to go talk to principals. And it made me really nervous sometimes because it was difficult situations going on, and she would go with me and just be with me and make sure I'm not freaking out, which I frequently would anyways. Um, so, just having her there to help me make sure I'm expressing what I need to, especially during those first couple of months when I didn't know what I was doing. 
Louise: I think basically, you know, I just am very compassionate about people trying to do this job, this job is a hard job. It's a very rewarding job. But we have got to have that support. And we've got to have that empathy. And sometimes that bleeds over into a personal life. And that person just happens to show up whenever you need them unexpectedly. And because of the relationship you've had, you know each other pretty well, you've seen each other vulnerable. And that leaves a person in a much better place of feeling supported. So, in my personal life, I think that there's probably been three girls that we've remained good friends after they're no longer at our district. And we have a reason to know that academically. We did everything we could for the kids here, but we also developed a friendship that was meaningful that helped us get through some of them tougher days at school.

Tammy: I think the biggest thing that I've learned so, far as I'm not a patient person, which I knew all along, but I feel like every day, I'm presented with more and more opportunities to practice patience. And it's really hard for me to like, I'm really sensitive to not taking things really personally. And I think my biggest growth has, you know... I don't... that's really a hard question.

Lisa: Um, well, for me personally, she's become a good friend, I would say in this just a friendship. That has always been the case with other people I've mentored not that I'm there. I think probably my patients has increased a little bit just with that whole with the whole really have opinion will give type thing you know, I've been doing this a long time 
and just but just that discernment of when to just some growth and discernment. Maybe patience of waiting for the right time to give advice or help.

Kevin: I feel like I have definitely become more patient. Um, I remember, I remember when I was student teaching, I had one class, it was my first hour of the day, and it frustrated me so, so, much. Because I, I just kept thinking to myself, how can they not understand this, it's like this simple thing. If I throw a phone, it's gonna keep on moving until something makes the phone stop moving, or whatever the example was. And it was constantly frustrating me. But between discussing with her and hearing about some of the student's family lives that I never had to deal with, I definitely feel like I'm more patient, both professionally and at home, my fiancé, she, she has some things that she's working on. She has some insecurities about how she thinks my family feels about her. And so, being able to stay patient with her and talk through those, I think has all been aided in being able to discuss certain family things at school.

Tori: I would say, it's made me be a little more patient. Because it is, it's kind of like you have to remember, everybody's not going to be just like you. So, I'm making me realize that just because maybe they're not as organized or they're not as punctual. I mean, it doesn't mean that they can't be an effective teacher. That's just an area of growth, possibly for them to work on. So, makes me just like I said, just a little more aware of other people's needs. 
Jessica: I honestly feel like it's made me more outgoing. Because like before, like, I'm not very like, I'm not a very talkative person. I'm not a very outgoing person. But like, since having this and like, I mean, she's just right next door. So, like, anytime I have a question, I just go over there. And so, I think that's made me more outgoing. And just to learn, you know, just ask the questions, you know. So, I think it's helped me in that way.

Shelly: Well, I'm with this one, it just she's like the same age as my oldest daughter. So, personally, we've been talking about the different things that she's been doing. And she has just met somebody that she's been going out with for a while. So, personally, we're kind of forging a friendship just because she's kind of like one of my kids. And so, you know, and like I said, she's a really good person, and somebody else here, set her up with someone, I'm like, you can't go out with him, because he's terrible. You don't need to go out with him, you know? And she's like, well, I've only texted him. I said, Well, don't text them anymore. Because it's done. You don't need to do this. So, anyway, so, just kind of more mothering, since she's so, much younger than me. 


\section{VITA}

Derek Ward holds a Bachelor of Science in Secondary Education, Science and Social Studies Education, as well as a Master of Science in School Administration. A doctor of Education in Educational Leadership and Policy Analysis is expected from the University of Missouri in July of 2021. He has been in education for 12 years as a Secondary Science teacher. Derek's love of social studies and science leads him to be inquisitive of both data and people's lived experiences. He continues to see each moment as a learning opportunity and loves to share his experience with others. 